\title{
Guía sobre tiempos escolares ${ }^{1}$
}

\section{School time guide}

Daniel Gabaldón Estevan y Sandra Obiol Francés²

\footnotetext{
1 PROYECTO OTR2016-16943SERVI. Febrero de 2017. Realizado con el apoyo de: Confederació d'Associacions de Mares i Pares d'Alumnes del País Valencià "Gonzalo Anaya" Conselleria d’Educació, Investigació, Cultura i Esport.

2 Profesores del Departamento de Sociología y Antropología Social de la Universitat de València.

Daniel.Gabaldon@uv.es ; Sandra.Obiol@uv.es

Artículo recibido: 5 de febrero de 2017; aceptado: 1 de marzo de 2017.
} 


\section{Índice}

Resumen

1. Introducción

2. Clarificación terminológica

3. El uso del tiempo escolar en perspectiva comparada

Tiempos totales de escolarización

El tiempo obligatorio de enseñanza por etapa

El tiempo obligatorio de enseñanza anual

El calendario escolar

Flexibilidad vertical y horizontal del tiempo de enseñanza

Distribución por edad del tiempo obligatorio de enseñanza

4. Estudios existentes sobre tiempo escolar y rendimiento

Efecto de la edad de inicio de la escolarización obligatoria en el rendimiento

El efecto de la falta de alimentación y descanso adecuados

Evidencias acerca de los ciclos de alerta y fatiga

Efecto de los cambios en los tiempos de enseñanza

Uso eficaz del tiempo de enseñanza

5. Modelos actuales de jornada escolar:

5.1. Comparativa a nivel de CCAA

5.2. Comparativa a nivel europeo

6. Las otras jornadas

7. Una propuesta para el debate

8. Conclusiones del estudio

Referencias bibliográficas 


\section{Resumen}

Este trabajo trata sobre el tiempo escolar, tema complejo y poliédrico. Como mostramos en las secciones que siguen, el tratamiento que se hace del tiempo en la escuela es muy variable entre sistemas educativos, entre niveles educativos y entre actividades que ocupan esos tiempos. Esta guía pretende contribuir a una reflexión informada, a partir de la recopilación y estudio de aquella información oficial que nos permite conocer cómo se organizan los tiempos escolares y qué ha aportado la investigación científica reciente a ese respecto.

Del análisis comparativo podemos subrayar que el del Estado español es uno de los sistemas educativos de Europa que mayor carga lectiva presenta y donde la intensidad de las jornadas lectivas tiende a ser más elevada. Se caracteriza también por tener un sistema educativo rígido, con muy poca flexibilidad a la hora de decidir cómo se distribuyen las cargas lectivas. Del mismo modo, el sistema educativo español se agrupa en el conjunto de sistemas que hace un planteamiento de cargas lectivas más elevadas y más rígidas en tanto que no se ajusta a una progresividad que acompañe a la también progresiva evolución de la capacidad del alumnado. Produciéndose además el salto más notable de carga lectiva en el tránsito de la enseñanza primaria a la secundaria. El sistema educativo español se sitúa además entre los países en los que más a menudo se recurre a la repetición y a las clases particulares, y en los que en consecuencia se produce un elevado abandono escolar. El amplio recurso a los deberes, las tutorizaciones y las clases de repaso significa que se requiere una mayor carga de trabajo por parte del alumnado de la establecida como tiempo de enseñanza teórico.

Por otro lado, los estudios sobre el rendimiento subrayan la relevancia de la buena alimentación y un descanso suficiente para un rendimiento escolar óptimo y la necesidad de adaptar las clases a los ciclos circadianos del alumnado. El tiempo de enseñanza que no se sincroniza adecuadamente a las necesidades y características del alumnado es, en buena medida, tiempo perdido además de una pérdida de tiempo. Indicios razonables apuntan por tanto a una posible relación entre tipo de jornada escolar continua y empeoramiento del rendimiento académico. En la comparativa de países europeos que se presenta podemos observar que, independientemente de que a diferentes niveles de edad se asigne una carga lectiva diferente, en 14 de los países señalados la jornada es de tipo partida, con una pausa para comer de duración variable. En tres casos la jornada es de tipo continua, y en otros cinco países coexisten modelos mixtos, no obstante, en varios de estos países la tendencia es hacia la consolidación de la jornada partida.

\section{Introducción}

Este trabajo, encargado por la Confederació d'Associacions de Mares i Pares d'alumnes del País Valencià "Gonzalo Anaya" trata sobre el tiempo escolar, tema ciertamente complejo y poliédrico. Como mostramos en las secciones que siguen, el tratamiento que se hace del tiempo en la escuela es muy variable entre sistemas educativos, entre niveles educativos y entre actividades que ocupan esos tiempos. Esta guía pretende contribuir a generar una reflexión informada, a partir de la recopilación y estudio de aquella información oficial que nos permite conocer cómo se organizan los tiempos escolares y qué ha aportado la investigación científica reciente a ese respecto. El momento, sin lugar a dudas, no puede ser más idóneo, dado que 
los cambios normativos que recientemente se están dando a nivel autonómico, están dotando de mayor oportunidad de decisión sobre la jornada escolar a los centros escolares sostenidos con fondos públicos. Pero esta oportunidad de decisión, por otro lado muy limitada, para que se transforme efectivamente en capacidad de decisión, requiere que los diferentes miembros de la comunidad educativa dispongan la suficiente información que les permita formarse un criterio razonablemente informado. A ello se destina esta guía.

Hay que subrayar que la guía que presentamos es principalmente el resultado de una revisión de la literatura científica disponible sobre tiempos escolares y del análisis comparado de la información de otras fuentes, generalmente de organismos internacionales y de las administraciones públicas, que nos ayuda a presentar la realidad del tiempo escolar existente en nuestro entorno. Somos conscientes de que se ha generado cierta polémica en torno a la gestión de los tiempos escolares en nuestra comunidad autónoma incluso con anterioridad a los recientes desarrollos normativos. Es nuestra voluntad aportar las evidencias existentes sobre tiempos escolares que ayuden a clarificar qué se sabe sobre sus efectos, principalmente sobre el rendimiento y la enseñanza conseguida, que es a nuestro entender la principal razón de ser de la escuela en sus niveles obligatorios y post-obligatorios, no así en la educación infantil. Creemos que la guía puede ser útil también para desechar algunos de los mitos y medias verdades que rodean los debates, a menudo desinformados, sobre los tiempos escolares. Hay que denunciar también la opacidad de muchas de las administraciones educativas de este país que, por omisión de su deber de velar por los intereses de nuestras hijas e hijos, no han realizado ni facilitado que se realicen estudios rigurosos sobre los efectos que las modificaciones horarias en el ámbito educativo han tenido sobre la calidad de vida y el rendimiento del alumnado. Especialmente en un tiempo en el que la transparencia se está convirtiendo en un concepto clave en la gestión de las políticas públicas.

Por último, descargamos a la Confederació d'Associacions de Mares i Pares d'Alumnes del País Valencià "Gonzalo Anaya" de cualquier responsabilidad sobre las interpretaciones u opiniones vertidas, que son únicamente responsabilidad de los autores.

\section{Clarificación terminológica}

A efectos operativos conviene clarificar al principio de este trabajo los términos utilizados en relación al tiempo escolar, a fin de facilitar la exposición posterior. Esta clarificación es importante en tanto que, como se muestra en este estudio, los tiempos tienden a ser no coincidentes.

Edad de escolarización obligatoria: edad a la que niñas y niños deben obligatoriamente acudir a un centro educativo a recibir enseñanza reglada [salvando aquellas excepciones reguladas].

Duración de la escolarización obligatoria: Rango de edad en el que niñas y niños deben obligatoriamente acudir a un centro educativo a recibir enseñanza reglada [salvo excepciones reguladas].

Calendario laboral: Días en los que la mayor parte de la población activa desempeña su trabajo, a efectos de cómputo para este trabajo descontamos periodos de vacaciones, festivos y fines de semana [para el curso 2015-2016 en el País Valenciano contamos con 252 días laborables].

Calendario escolar: Periodo anual en el que se imparte la enseñanza reglada en los centros educativos, generalmente $3 / 4$ partes [75\%] de los días laborables son lectivos en el Estado español. Pueden existir variaciones en función del nivel educativo de que se trate (para el curso 2015-2016 en el País Valenciano contamos con 184 días lectivos en primaria]. 
Horario escolar del centro: Horario en el que el centro está abierto para actividades escolares lectivas, extraescolares, u otras.

Jornada laboral del profesorado: 37'5 horas semanales divididas en: lectivas [25h. en infantil y primaria; 20h. en secundaria] complementaria [5h. de permanencia en el centro] y de libre disposición [7'5h. dentro o fuera del centro; 12.5h. en secundaria]. Como se deduce de lo arriba explicado, aproximadamente un 25\% del de los días laborables son no lectivos en el Estado español [para el curso 2015-2016 en el País Valenciano contamos con 64 días laborables no lectivos].

Jornada escolar del alumnado: Horario en el que el alumnado están en el centro escolar ya sea recibiendo clases lectivas, clases de apoyo o refuerzo en el centro, realizando actividades complementarias, actividades extraescolares, recreo, comedor o siesta (en los centros y niveles que se permite]. Pueden existir variaciones en función del nivel educativo de que se trate o en periodos estivales [junio y septiembre].

Jornada lectiva: Horario en el que se organiza las sesiones lectivas, esto es destinadas oficialmente a la actividad docente. Pueden existir variaciones en función del nivel educativo de que se trate o en periodos estivales.

Tiempo de enseñanza teórico: Número de horas anuales que los estudiantes deben dedicar, en las aulas formales, al aprendizaje de las partes obligatorias y no obligatorias del currículo según la legislación educativa [OCDE, 2011, citado en Gromada y Shewbridge, 2016]. Puede calcularse como el resultado de multiplicar la jornada lectiva por los días lectivos [ajustando por el horario reducido en junio y septiembre en el caso español].

Tiempo de enseñanza real: Tiempo enseñanza resultante una vez descontados los posibles cierres del centro educativo (por causas extraordinarias) así como las faltas de asistencia o de puntualidad, bien del profesorado [bajas enfermedad, formación, etc.] bien del alumnado [enfermedad, absentismo], [Gromada y Shewbridge, 2016].

Tiempo de atención: Parte del tiempo real de enseñanza en el que el alumnado presta efectivamente atención [Berliner, 1990, citado en Gromada y Shewbridge, 2016]. Por tanto se habrá de descontar aquel tiempo en el que el estudiantado no presta atención y aquel tiempo destinado a resolver problemas disciplinarios y otras disrupciones.

Tiempo de aprendizaje: Es la parte del tiempo de atención en el que se produce un aprendizaje efectivo [real], requiere que el material académico suponga suficiente dificultad e interés, y esté alineado con el currículum [Cotton, 1989, citado en Gromada y Shewbridge, 2016]. La dificultad ha de estar calibrada para que permita y no impida el avance en el conocimiento por parte del alumnado.

En su estudio, Gromada y Shewbridge [2016], en el que nos apoyamos en secciones relevantes de esta guía, no incluye el tiempo de aprendizaje fuera de las aulas formales [enseñanza fuera de la escuela, deberes, tutoría individual, estudio privado antes o después de la escuela, las oportunidades de aprendizaje informal] o la calidad de la enseñanza proporcionada, los cuales tienen un impacto en rendimiento y conocimientos conseguidos de los estudiantes. 


\section{El uso del tiempo escolar en perspectiva comparada}

Como indicábamos en la introducción, el tiempo escolar es ciertamente un tema complejo y poliédrico. En esta sección mostramos como diferentes sistemas educativos europeos lo organizan en base a criterios variables y que tienen como resultado organizaciones diferentes en cuanto al tiempo que niñas y niños han de pasar en el sistema educativo. En este sentido cabe tener en mente que al hablar de la distribución de los tiempos de aprendizaje no importa solo el cuánto [años de escolarización, tiempo de enseñanza] sino el cuándo [a qué edad, en qué momento del año, de la semana o del día].

\section{Tiempos totales de escolarización}

Hoy en día en la mayoría de los países de nuestro entorno la escolarización obligatoria se inicia al principio de la enseñanza primaria (ISCED 1) por lo general a los 6 años, excepto en Estonia, Finlandia, Letonia, Lituania, Polonia y Suecia que se inicia a los 7, e Inglaterra y Escocia en las que se inicia a los 5 años de edad [OCDE, 2016]. Además, en 15 de la cuarentena de sistemas educativos analizados por Eurydice, la asistencia a los últimos cursos de educación preescolar de 5 años, es ya obligatoria (European Commission/EACEA/Eurydice, 2016a) ${ }^{3}$.

Cabe indicar que la proporción de la población que participa en educación no obligatoria, tanto previa [ISCED D, preescolar o infantil] como posterior [secundaria no obligatoria, ciclos formativos y estudios universitarios], ha ido en aumento durante las últimas décadas, de modo que la escolarización es un hecho ampliamente generalizado desde los 3-4 años de edad (ver tabla 1 y gráficos 1 y 2), tendencia que sigue incrementándose.

El Estado español se sitúa a la cabeza en términos de escolarización en la etapa de infantil de segundo ciclo (de 32 países ocupa las posiciones séptima en escolarización a los 3 años, décima a los 4 años y duodécima a los 5 años] pero en posiciones más retrasadas o intermedias en la post-obligatoria (de 32 países ocupa las posiciones vigésimo cuarta a los 15 años, décimo séptima a los 16 años, décimo octava a los 17 años y vigésimo primera a los 18 años].

Más concretamente, el gráfico 2 nos muestra la esperanza de vida educativa en los países de la Unión Europea pertenecientes a la OCDE, por sexo para el curso 2012-2013. Esto es, el número medio de años de educación formal que se espera que un individuo recibirá desde los 5 a los 39 años. En él se aprecia que el Estado español, con un valor de 17,7 años esperados en educación, se sitúa justo por encima de la media de los 21 países europeos de la OCDE [17,6 años] y de los países de la OCDE en su conjunto $[17,5$ años]. Finlandia $[19,7]$ seguido de Dinamarca $[19,6]$ y Suecia $[19,1]$ encabezan el listado, y Luxemburgo ${ }^{4}$ y Eslovaquia con 15,1 y 16,2 años respectivamente, son los países que tienen menor número esperado de años en educación.

En casi la totalidad de los países europeos contemplados, a excepción de Alemania (con una diferencia de 0,3 años favorable a los hombres) el número esperado de años en educación es superior para las mujeres. En particular, las mayores diferencias entre mujeres y hombres se dan en Suecia [ 1,9 años], seguida de Eslovenia, Polonia y Estonia (las tres con una diferencia de 1,4 años] [Sistema Estatal de Indicadores de la Educación. Edición 2016].

\footnotetext{
${ }^{3}$ EACEA es el acrónimo de Education, Audiovisual and Culture Executive Agency y Eurydice lo es de Education Information Network in Europe, ambas dependientes de la Comisión Europea.

${ }^{4}$ Los datos de Luxemburgo pueden estar afectados por el alto número de jóvenes que estudia en países vecinos, según indica Eurydice.
} 
Tabla 1: Tasas netas de escolaridad en edades significativas. Curso 2012-13. Fuente MECD Las cifras de la educación en España. Estadísticas e indicadores. Edición 2016

\begin{tabular}{|c|c|c|c|c|c|c|c|}
\hline & 3 años & 4 años & 5 años & 15 años & 16 años & 17 años & 18 años \\
\hline Unión Europea (28 países) & 85,3 & 91,8 & 97,0 & .. & .. & .. & .. \\
\hline Alemania & 91,6 & 96,3 & 97,7 & 98,2 & 97,4 & 93,3 & 85,0 \\
\hline Austria & 71,3 & 91,4 & 96,3 & 94,7 & 91,0 & 88,6 & 74,0 \\
\hline Bélgica & 97,7 & 98,0 & 98,1 & 99,6 & 99,2 & 98,4 & 83,4 \\
\hline Bulgaria & 72,7 & 79,6 & 89,7 & 91,8 & 88,5 & 85,7 & 80,1 \\
\hline Chipre & 41,4 & 72,2 & 97,2 & 93,2 & 92,4 & 87,3 & 38,7 \\
\hline Croacia & 56,7 & 57,8 & 62,4 & 100,0 & 98,6 & 91,3 & 72,0 \\
\hline Dinamarca & 96,3 & 97,5 & 98,8 & 99,1 & 95,1 & 90,9 & 86,9 \\
\hline Eslovenia & 84,3 & 89,0 & 90,7 & 97,8 & 97,5 & 96,3 & 92,1 \\
\hline España & 95,7 & 96,7 & 97,5 & 97,3 & 95,5 & 91,8 & 80,2 \\
\hline Estonia & 87,4 & 91,0 & 88,7 & 100,3 & 97,9 & 94,9 & 87,7 \\
\hline Finlandia & 68,2 & 74,7 & 79,7 & 98,1 & 94,8 & 94,8 & 94,1 \\
\hline Francia & 99,5 & 100,0 & 100,0 & 98,1 & 93,7 & 90,3 & 77,1 \\
\hline Grecia & 15,9 & 58,0 & 95,7 & 95,7 & 96,2 & 95,7 & 93,9 \\
\hline Hungría & 75,3 & 93,1 & 96,2 & 97,3 & 94,2 & 93,0 & 84,4 \\
\hline Irlanda & 45,6 & 94,5 & 100,0 & 100,0 & 100,0 & 97,7 & 100,0 \\
\hline Italia & 94,4 & 98,5 & 98,9 & 99,6 & 97,1 & 91,7 & 78,6 \\
\hline Letonia & 82,6 & 89,3 & 96,3 & 98,7 & 98,6 & 98,3 & 93,0 \\
\hline Lituania & 74,8 & 80,7 & 83,2 & 99,8 & 99,3 & 98,0 & 94,7 \\
\hline Luxemburgo & 70,9 & 99,3 & 99,5 & 97,3 & 86,5 & 81,9 & 72,0 \\
\hline Malta & 97,0 & 100,0 & 101,0 & 101,2 & 80,1 & 71,8 & 59,3 \\
\hline Países Bajos & 83,2 & 99,7 & 99,3 & 99,2 & 98,5 & 96,0 & 86,3 \\
\hline Polonia & 52,3 & 66,4 & 93,2 & 96,4 & 96,7 & 95,7 & 92,5 \\
\hline Portugal & 77,8 & 90,4 & 97,6 & 100,0 & 100,0 & 94,8 & 80,6 \\
\hline R. Checa & 58,9 & 82,7 & 88,9 & 99,8 & 97,8 & 95,6 & 89,5 \\
\hline R. Eslovaca & 62,6 & 73,8 & 81,3 & 97,8 & 93,2 & 90,0 & 84,2 \\
\hline Reino Unido & 96,8 & 96,1 & 97,1 & 99,1 & 93,8 & 90,3 & 67,2 \\
\hline Rumanía & 79,5 & 83,3 & 89,5 & 86,6 & 86,3 & 79,7 & 77,7 \\
\hline Suecia & 92,9 & 94,5 & 95,3 & 99,3 & 99,7 & 98,4 & 96,3 \\
\hline \multicolumn{8}{|l|}{ Otros Países Europeos } \\
\hline Islandia & 96,0 & 96,8 & 95,6 & 99,1 & 96,0 & 90,2 & 82,5 \\
\hline Noruega & 95,3 & 97,1 & 97,6 & 100,0 & 95,3 & 92,7 & 89,6 \\
\hline Suiza & 3,1 & 41,4 & 96,8 & 97,9 & 93,2 & 91,3 & 84,6 \\
\hline
\end{tabular}


Gráfico 1. Tasas de participación a los 3 y 4 años de edad en educación infantil y primaria (2014). Fuente: elaboración a partir de datos de OCDE, 2016.

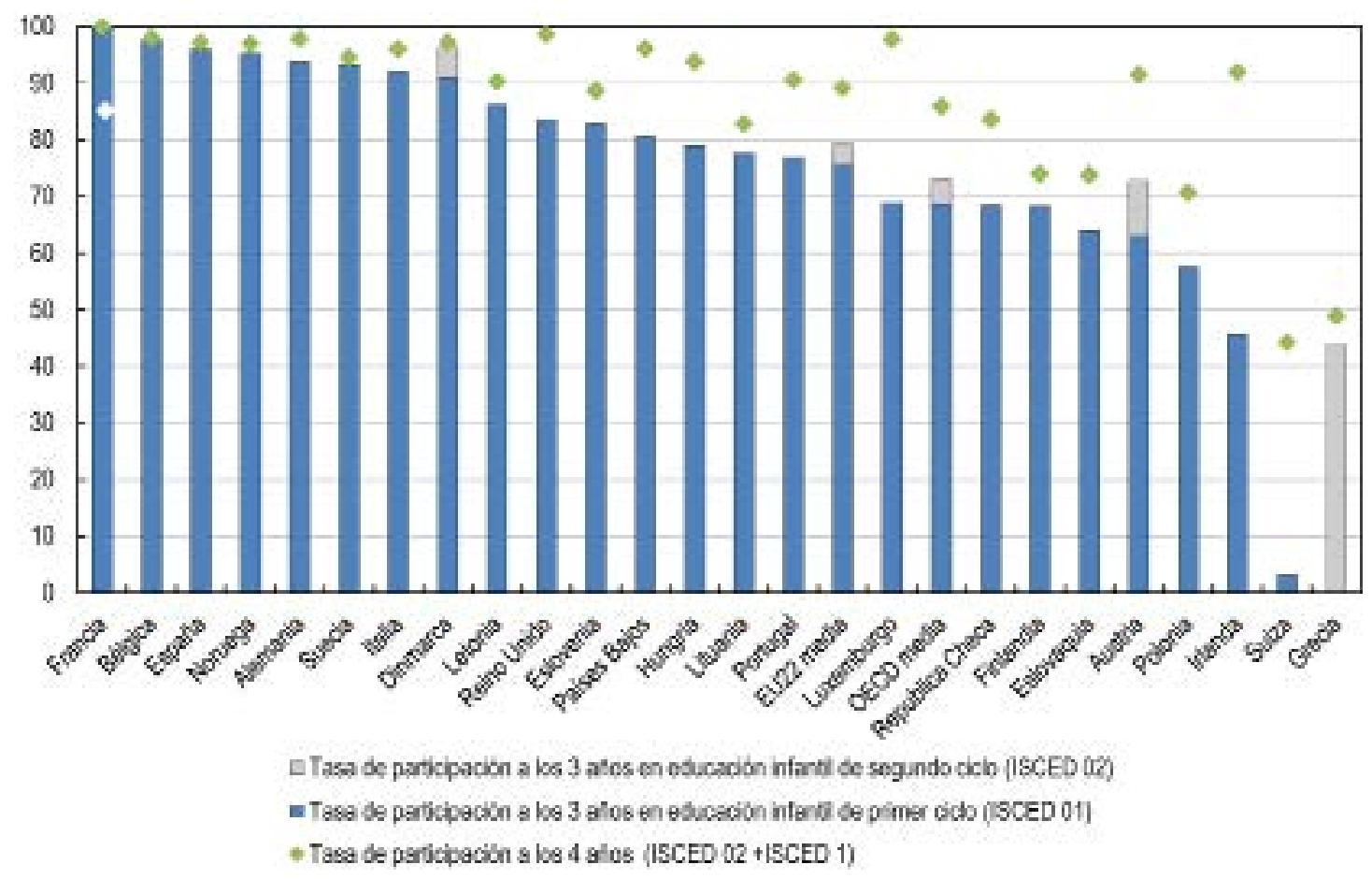

Gráfico 2. Número medio de años esperados en educación desde los 5 a los 39 años en los países de la Unión Europea pertenecientes a la OCDE, por sexo. 2013. Fuente: Sistema Estatal de Indicadores de la Educación. Edición 2016.

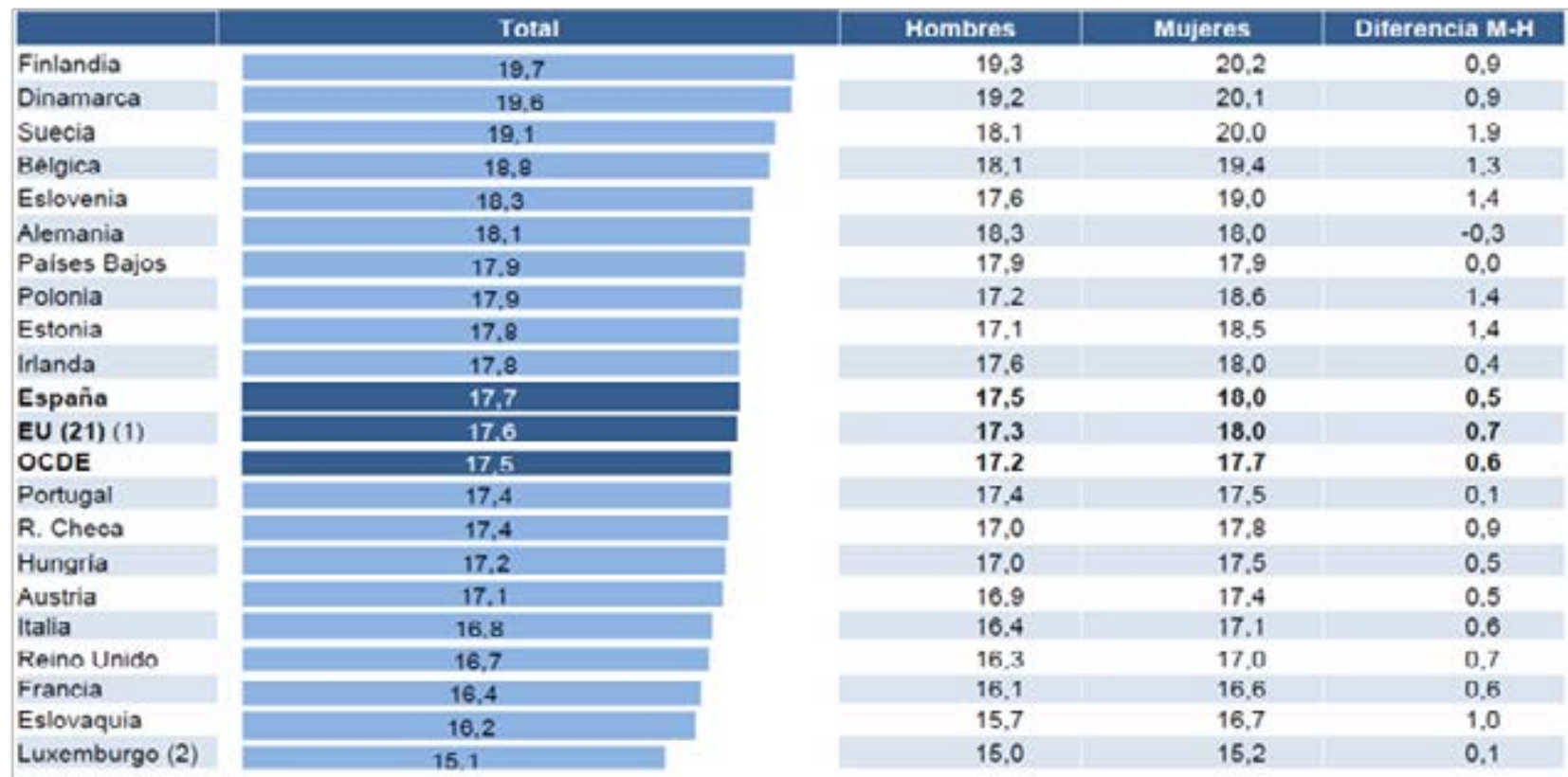

(1) No se dispone de datos de Grecia

(2) Los altos niveles de matriculacion en el extranjero y la inmigracion pueden afectar al numero de anos esperados en educacion. 


\section{El tiempo obligatorio de enseñanza por etapa}

En la mayoría de los sistemas educativos europeos, la educación obligatoria a tiempo completo dura de 9 a 10 años y termina entre los 15 y 16 años. Según datos de Eurydice, en Bélgica, Alemania [en 12 Länder], Luxemburgo, Portugal, Irlanda del Norte y Turquía, la duración de la enseñanza obligatoria es de 12 años, mientras que en Alemania [en 5 Länder], Hungría o Macedonia, la asistencia obligatoria es de 13 años.

El período obligatorio de educación suele abarcar los niveles de enseñanza primaria [ISCED 1] y secundaria inferior [ISCED 2) y corresponde al nivel de asistencia a la escuela a tiempo completo. En Bélgica, Alemania, los Países Bajos, Portugal y en Macedonia es obligatorio permanecer en el sistema educativo hasta los 18-19 años. Sin embargo, en estos países, desde los 15-16 años y 18-19 años, los estudiantes pueden asistir a programas obligatorios de formación que combinan cursos a tiempo parcial en la escuela y formación a tiempo parcial en el lugar de trabajo. Sólo los programas en los que se evalúan los estudiantes tanto para los cursos en la escuela como en el lugar de trabajo se consideran como "tiempo completo de formación obligatoria" (European Commission/EACEA/Eurydice, 2016a].

En Austria, Polonia e Inglaterra, después de la edad oficial de salida de la escuela, los estudiantes todavía tienen que permanecer en el sistema educativo o formativo hasta su 18 cumpleaños, si bien la asistencia a tiempo completo no es obligatoria y los estudiantes pueden cumplir esta obligación participando en educación o formación a tiempo completo, aprendizaje basado en el trabajo o educación a tiempo parcial o capacitación [European Commission/EACEA/Eurydice, 2016a].

Si miramos a las horas totales de enseñanza, según la OCDE [2016] el estudiantado de los países de la OCDE reciben un promedio de 7.540 horas de enseñanza obligatoria durante su educación primaria y secundaria inferior [ESO], pasando de 5.720 horas en Hungría a casi el doble que en Dinamarca [10.960 horas]. Como se muestra en el gráfico 3 en el Estado español se imparten 7.878 [ 4.746 horas en primaria y 3.134 en los tres primeros cursos de ESO) lo que la sitúa entre las de mayor carga lectiva anual tras Dinamarca, Países Bajos, Irlanda, Francia y Luxemburgo. 


\section{Gráfico 3. Tiempo de enseñanza obligatorio en la enseñanza general (2016). Fuente: elaboración a partir de datos de la OCDE, 2016.}

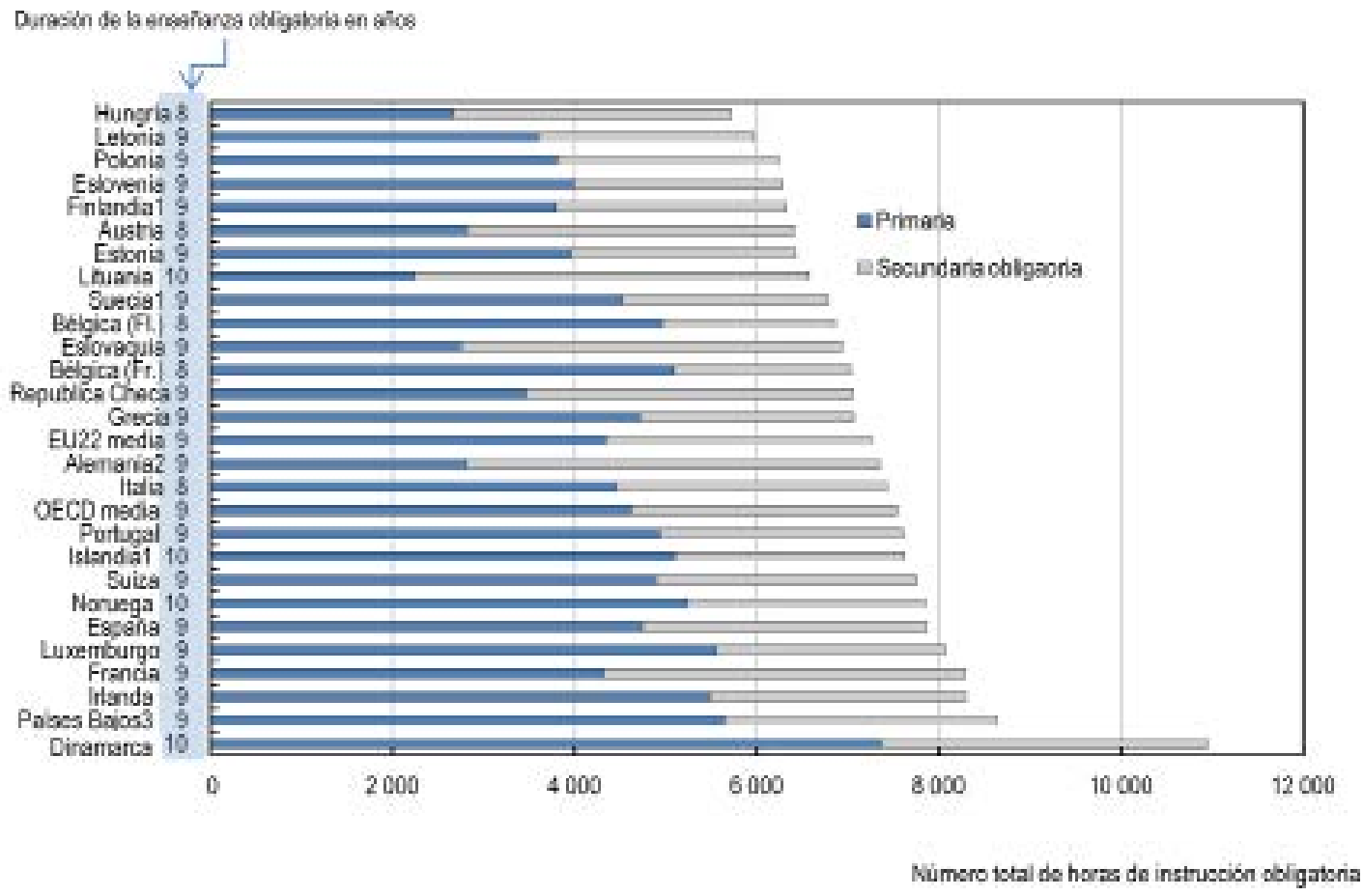

Notas: 1. Número estimado de horas por nivel de educación basado en el número promedio de horas por año, ya que la asignación del tiempo de enseñanza en múltiples cursos es flexible. 2. Año de referencia 2015. 3. El número de cursos en la educación secundaria inferior es de tres o cuatro, dependiendo de la vía. El cuarto año de educación secundaria pre-profesional [VMBO] fue excluido del cálculo.

En España la escolarización obligatoria se prolonga de los 6 a los 16 años como en la mayoría de los países de nuestro entorno. Nuestro país destaca no obstante por una mayor carga lectiva que en el promedio de países europeos y de la OCDE.

\section{El tiempo obligatorio de enseñanza anual}

Siguiendo con el estudio citado y en cuanto a los días lectivos (ver Gráfico 4), el número de días varía entre 162 días en Francia [excepto en la enseñanza secundaria superior] y 200 días en Dinamarca e Italia. En alrededor de una veintena de países los días lectivos se sitúan entre 170 y 180, en otros 15 países el número varía entre 181 y 190 días. En general, el número de días escolares es el mismo en primaria y secundaria salvo algunas excepciones [en Bélgica, Francia el número de días escolares es mayor en la enseñanza secundaria superior que en la enseñanza primaria; mientras que en Irlanda, Grecia, Chipre, los Países Bajos y Polonia hay menos días escolares en la enseñanza secundaria que en la enseñanza primaria] [European Commission/ EACEA/Eurydice, 2016b].

Según la OCDE [2016] en promedio en los países de la OCDE, los estudiantes de primaria tienen 185 días de enseñanza por año, y los estudiantes de secundaria inferior tienen 184 días. Sin embargo, el número de días de enseñanza varía entre los países en más de 50 días en los niveles primario y secundario inferior (de 160 a 219 días en el nivel primario y de 152 a 209 en el nivel secundario inferior]. 
Gráfico 4. Número de días lectivos en los sistemas educativos europeos curso 2016-2017. Fuente: European Commission/EACEA/Eurydice, 2016b.

ISCED 1

ISCFD?

ISCED 3

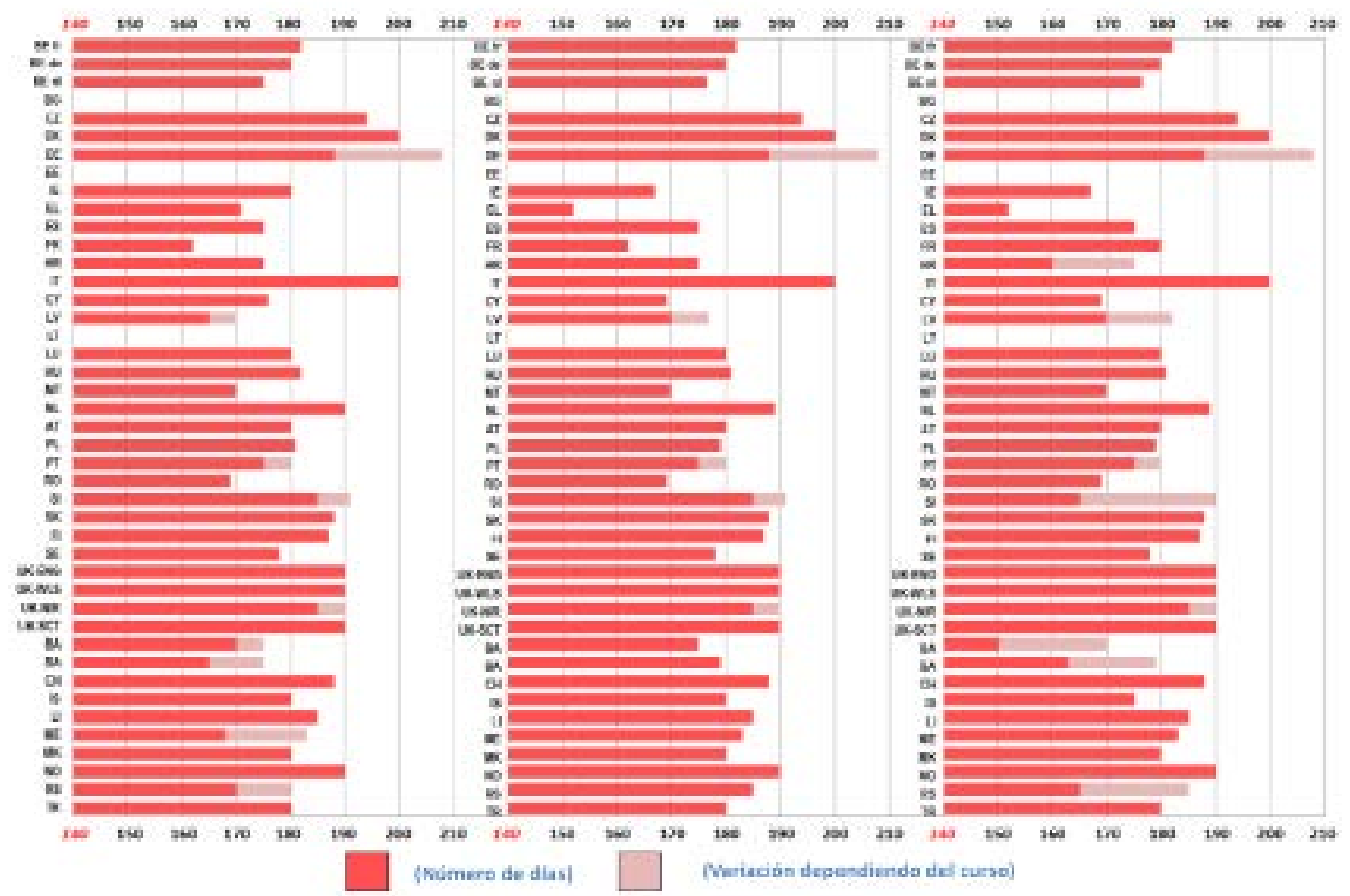

Tabla 2: Tiempo de enseñanza en la enseñanza general obligatoria (2016). Fuente Elaboración propia a partir de OECD, 2016.

\begin{tabular}{|c|c|c|c|c|c|c|}
\hline \multirow[b]{2}{*}{ País } & \multicolumn{2}{|c|}{ Primaria } & \multirow[b]{2}{*}{$\begin{array}{c}\text { Posición } \\
\text { de } 25\end{array}$} & \multicolumn{2}{|c|}{ Secundaria obligatoria } & \multirow[b]{2}{*}{$\begin{array}{c}\text { Posición } \\
\text { de } 25 \\
\end{array}$} \\
\hline & $\begin{array}{l}\text { Duración } \\
\text { años }\end{array}$ & $\begin{array}{c}\text { Horas } \\
\text { promedio }\end{array}$ & & $\begin{array}{c}\text { Duración } \\
\text { años }\end{array}$ & $\begin{array}{c}\text { Horas } \\
\text { promedio }\end{array}$ & \\
\hline Alemania & 4 & 703 & 17 & 5 & 907 & 10 \\
\hline Austria & 4 & 705 & 16 & 4 & 899 & 11 \\
\hline Bélgica (FI.) & 6 & 826 & 8 & 2 & 952 & 8 \\
\hline Bélgica (Fr.) & 6 & 849 & 7 & 2 & 971 & 6 \\
\hline Dinamarca & 7 & 1051 & 1 & 3 & 1200 & 1 \\
\hline Eslovaquia & 4 & 688 & 19 & 5 & 837 & 18 \\
\hline Eslovenia & 6 & 664 & 21 & 3 & 766 & 23 \\
\hline España & 6 & 791 & 11 & 3 & 1044 & 2 \\
\hline Estonia & 6 & 661 & 22 & 3 & 823 & 19 \\
\hline Finlandia & 6 & 632 & 24 & 3 & 844 & 16 \\
\hline Francia & 5 & 864 & 6 & 4 & 991 & 4 \\
\hline Grecia & 6 & 786 & 12 & 3 & 785 & 22 \\
\hline Hungría & 4 & 665 & 20 & 4 & 765 & 24 \\
\hline Irlanda & 6 & 915 & 4 & 3 & 935 & 9 \\
\hline Islandia & 7 & 729 & 15 & 3 & 839 & 17 \\
\hline Italia & 5 & 891 & 5 & 3 & 990 & 5 \\
\hline Letonia & 6 & 599 & 25 & 3 & 794 & 21 \\
\hline Luxemburgo & 6 & 924 & 3 & 3 & 845 & 15 \\
\hline Noruega & 7 & 748 & 14 & 3 & 874 & 14 \\
\hline Países Bajos & 6 & 940 & 2 & 3 & 1000 & 3 \\
\hline Polonia & 6 & 635 & 23 & 3 & 810 & 20 \\
\hline Portugal & 6 & 822 & 9 & 3 & 892 & 13 \\
\hline $\begin{array}{l}\text { República } \\
\text { Checa }\end{array}$ & 5 & 694 & 18 & 4 & 897 & 12 \\
\hline Suecia & 6 & 754 & 13 & 3 & 754 & 25 \\
\hline Suiza & 6 & 815 & 10 & 3 & 958 & 7 \\
\hline
\end{tabular}


En la tabla 2 se puede observar el número de años que comprende la educación obligatoria en primaria y en secundaria, así como el número de horas promedio por ciclo. En ella se observa que el Estado español por número de horas promedio por ciclo se sitúa en las partes altas de la tabla, más en secundaria obligatoria (posición 2 de 25) que en primaria (11 de 25].

En el Estado español el número de días lectivos se encuentra entorno a la media de la OCDE, pero la carga lectiva supera la media de la OCDE, en consecuencia esta mayor carga lectiva se traduce en una jornada lectiva más intensa que el promedio de países europeos y de la OCDE.

\section{El calendario escolar}

Por su parte, el calendario escolar ha ido evolucionando en función de los cambios que se producian en el contexto social en el que se insertan [Fernández Enguita, 2001; Sintes, 2012) por ejemplo haciéndolo coincidir con el calendario agrícola en sociedades poco industrializadas todavía [Gromada y Shewbridge, 2016] o acomodándolo al calendario característico en sociedades industrializadas y post-industriales o de servicios [Egido, 2011].

Como se muestra en el gráfico 5, los calendarios escolares presentan variaciones relevantes entre países, pero tienden a emular el calendario laboral en sociedades industriales y postindustriales o de servicios, esto es, extendiéndose a lo largo del año con periodos más o menos prolongados de descanso entorno al verano, las navidades y la pascua.

Entre los países europeos, hay otros cuatro períodos principales de vacaciones escolares aparte del estival, estos son en otoño, en torno a Navidad y Año nuevo, en invierno-Carnaval, y en primavera-Semana Santa. Las fiestas de fin de año son en su mayoría similares en estos países, pero las vacaciones escolares difieren tanto en cuanto a la duración como al momento en que se inician [OECD, 2016].

En cuanto al descanso estival, también según datos de Eurydice [European Commission/EACEA/ Eurydice, 2016b] se distinguen cuatro grupos de países:

1. Los que tienen un máximo de 6 semanas: Inglaterra, Gales, Dinamarca, Alemania, Países Bajos o Liechtenstein.

2. Aquellos que tienen entre 8 y 9 semanas: Irlanda del Norte, Escocia, Noruega, Francia, Bélgica, Luxemburgo, Suiza, Austria, República Checa o Eslovaquia.

3. Quienes tienen entre 10 y 11 semanas: Islandia, Suecia, Finlandia, Polonia, Hungría, Eslovenia, Croacia, Serbia, Bulgaria o Grecia.

4. Y los que tienen entre 12 y 13 semanas: Irlanda, Estonia, Letonia, Lituania, Portugal, España, Italia, Bosnia-Herzegovina, Montenegro, Macedonia, Rumanía o Turquía. 
Gráfico 5. Calendarios escolares en los sistemas educativos europeos curso 20162017. Fuente: European Commission/EACEA/Eurydice, 2016b.

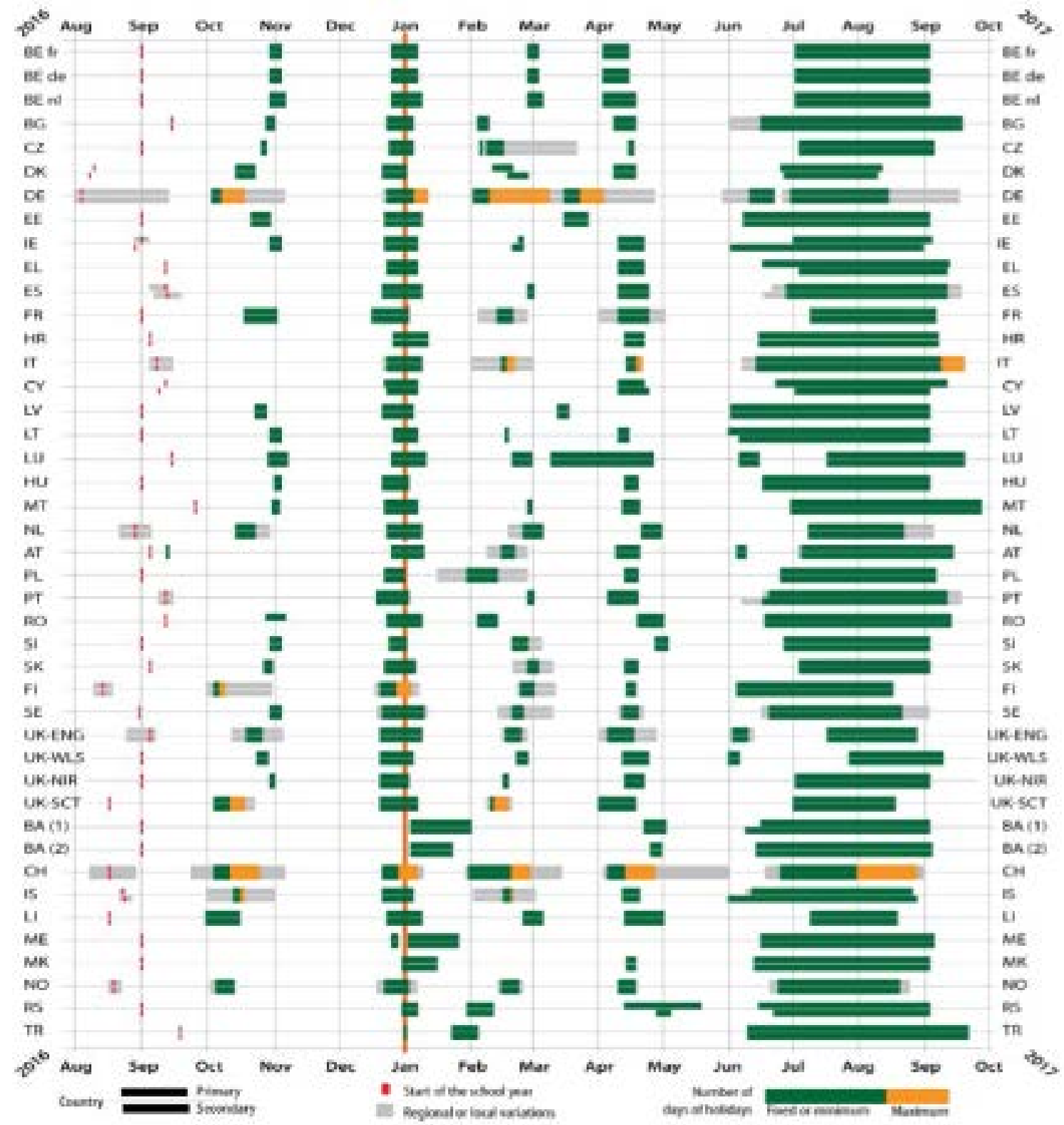

La tendencia internacional actual parece inclinarse hacia el acortamiento del descanso estival y la distribución de los periodos no lectivos de una manera más equilibrada a lo largo del curso, intercalando varias semanas lectivas [de unas 7 semanas] con un periodo de descanso [de una 0 dos semanas]. En este sentido algunos estudios muestran actitudes diferenciadas entre familias de distinto estatus socioeconómico respecto al acortamiento del descanso estival, así las familias de mayor estatus tenderían a oponerse a su acortamiento dado que interfiere con sus planes vacacionales, mientras que las familias trabajadoras verían más problemáticas las vacaciones prolongadas por falta de una alternativa atractiva [Silva, 2007; Duffett y col., 2004, citados en Gromada y Shewbridge, 2016:28]. 
También se ha observado que el alumnado del hemisferio norte muestran más fatiga y propensión a enfermar durante los meses de noviembre, febrero y marzo y, aunque hay cierta controversia sobre si esto se debe a un efecto de fatiga acumulada [Reinberg, 1998 citado en Gromada y Shewbridge, 2016:20] o si se debe al cambio de estaciones [Testu, 2008 citado en Gromada y Shewbridge, 2016:20] de cualquier modo las recomendaciones se orientan al modelo cíclico de periodos de 7 semanas lectivas seguidas de 2 de descanso.

En España es de los países con unas vacaciones estivales más largas. La

tendencia actual lleva a planteamientos dónde se huye de concentrar las semanas de descanso optando por intercalarlas entre periodos lectivos.

\section{Flexibilidad vertical y horizontal del tiempo de enseñanza}

Según Eurydice existe además variabilidad entre modelos educativos en cuanto su grado de flexibilidad. En algunos países, en los que hay menos requisitos definidos de manera centralizada, las autoridades locales y las escuelas gozan de mayor flexibilidad para decidir la cantidad de tiempo de enseñanza que deben dedicar a las diferentes materias obligatorias y, a veces, pueden tener cierta flexibilidad para elegir qué asignaturas enseñar lo que puede redundar en su capacidad para adaptarse a las necesidades de su alumnado (ver gráfico 6).

\section{En esta sección reproducimos literalmente la descripción de Eurydice:}

"Las autoridades locales o las propias escuelas pueden tener cierta flexibilidad en la asignación del tiempo que debe dedicarse a materias específicas [flexibilidad temporal]. La flexibilidad temporal puede extenderse a lo largo de los cursos [flexibilidad vertical] o entre materias [flexibilidad horizontal). En algunos países, existe también cierta libertad para elegir las materias del currículo [flexibilidad de la materia].

La flexibilidad vertical se produce cuando las autoridades educativas centrales indican el número total de horas para que una materia específica se enseñe en más de un curso, sin especificar cómo se distribuirán estas horas. Así se define el tiempo mínimo de enseñanza en Estonia, los Países Bajos, Polonia, Finlandia, Suecia y Noruega. En Estonia y Polonia, en la enseñanza primaria, se indica por separado para los cursos 1 a 3 y 4 a 6 . En Finlandia, la combinación de cursos varía según la materia y, a veces, abarca diferentes niveles de educación. En Suecia, el tiempo mínimo de enseñanza de las materias obligatorias se fija para la duración de la enseñanza obligatoria, sin distinguir entre los niveles ISCED. En otros países se da una flexibilidad vertical más restringida.

La flexibilidad horizontal se produce cuando las autoridades educativas centrales fijan un número total de horas de enseñanza para una combinación de materias obligatorias dentro del mismo curso. Las autoridades locales o las propias escuelas tienen entonces que decidir cuánto tiempo asignar a cada asignatura. En dos sistemas educativos, Reino Unido [Gales] y Países Bajos, hay plena flexibilidad horizontal. En Gales el gobierno establece el tiempo mínimo de enseñanza total para cada curso y corresponde a las escuelas decidir cuánto tiempo asignar a las asignaturas individuales. En los Países Bajos tienen plena flexibilidad con respecto a la asignación de tiempo [horizontal y vertical] ya que los requisitos mínimos para el tiempo de enseñanza se establecen por nivel de educación, y las escuelas tienen flexibilidad plena para asignar a través de las materias y cursos. En otros sistemas, como en Bélgica [Fr. y Ge.], Irlanda del Norte e en Italia en el nivel de primaria, las escuelas tienen una cantidad significativa de flexibilidad horizontal para asignar la mayor parte del número definido de horas por curso en materias obligatorias." [European Commission/EACEA/Eurydice, 2016c:18-20] 
Gráfico 6: Flexibilidad temporal (vertical y horizontal) y flexibilidad de materias, $\%$ del tiempo total de enseñanza por nivel ISCED, 2015/16. Fuente: European Commission/EACEA/Eurydice, 2016c

ISCED 1

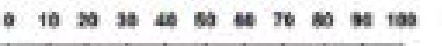

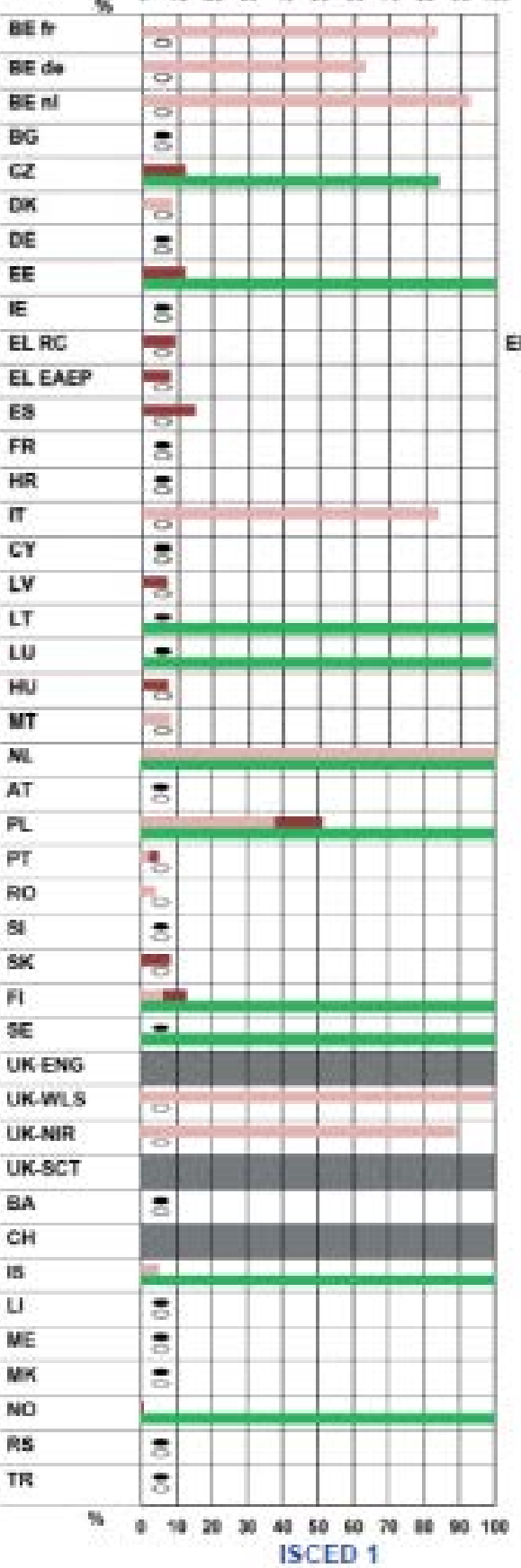

ISCED 24

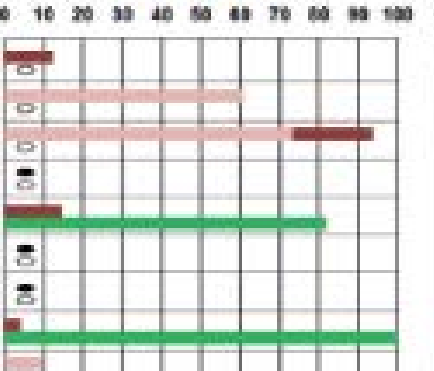

a

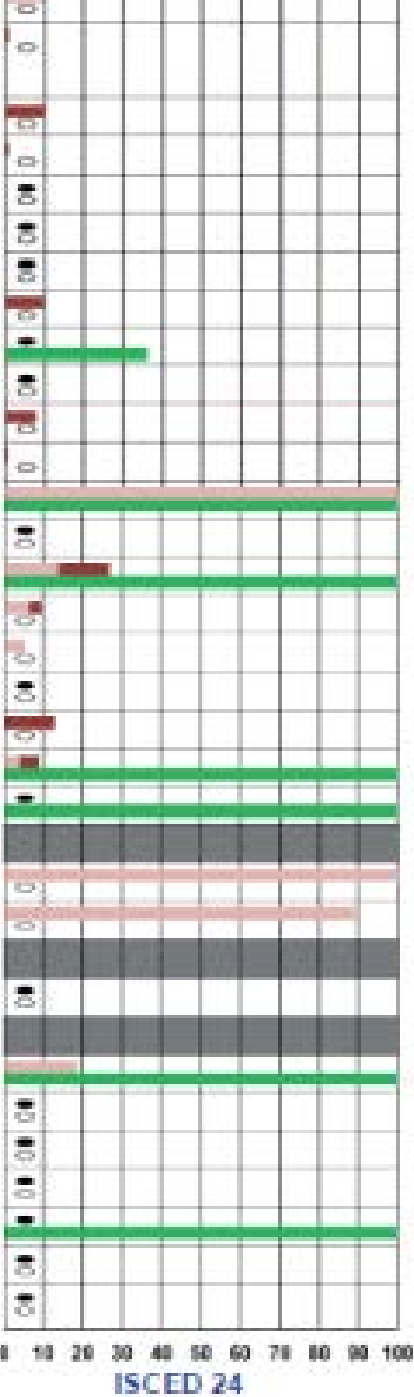

ISCED 34

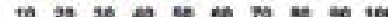

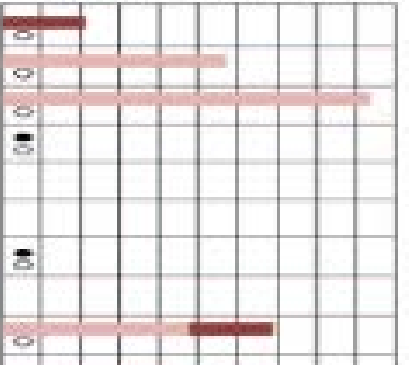

- No horizontal flexibility

- No vertical fexibility Horizonta sime fexibaly

- Subject fexibitis

- Vertical time Iextrity

- Full fexcility
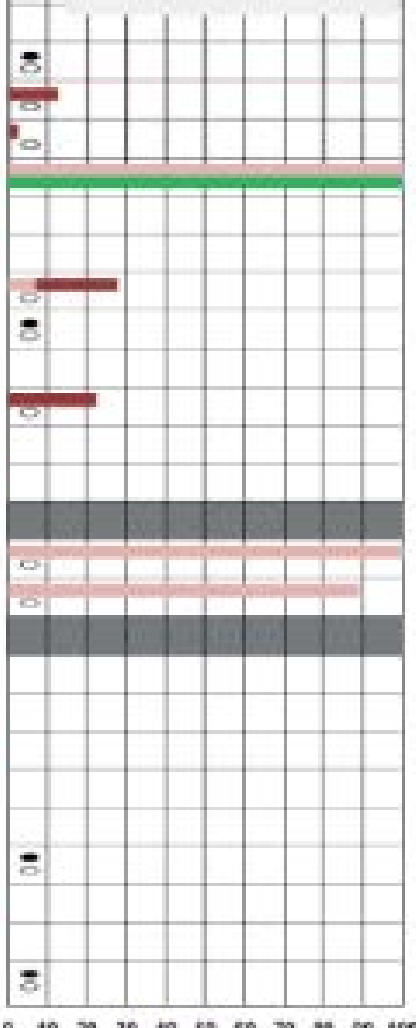

ISCED 34

En otros países [...] como en Malta y Rumanía,, existe cierta flexibilidad horizontal, pero esto afecta a una proporción menor del plan de estudios. En Dinamarca, la flexibilidad horizontal sólo se aplica a algunas materias en el primer curso de la educación primaria. Mientras que Polonia, Finlandia e Islandia tienen flexibilidad vertical completa y también un alto grado de flexibilidad horizontal. 
Además de la flexibilidad temporal, las escuelas también pueden tener cierta flexibilidad para seleccionar una serie de asignaturas obligatorias ya sea como una elección abierta o de una lista predefinida. La flexibilidad de materias se puede encontrar en un número similar de países, pero afecta a un porcentaje menor del tiempo total de enseñanza en todos los casos [entre 1\% y 23\%]. Algunos países combinan la flexibilidad del tiempo vertical con la flexibilidad de algunas materias [República Checa, Estonia, Polonia, Finlandia y, en menor medida, Noruega]. Las Comunidades Francesa y Flamenca de Bélgica, así como Irlanda y Portugal combinan en algunos niveles de educación la flexibilidad del tiempo horizontal con alguna flexibilidad de la materia. En Grecia, España, Letonia, Hungría y Eslovaquia (y en menor grado en Francia y Malta en el nivel secundario] también se puede encontrar flexibilidad en las materias.

\begin{abstract}
El grado más alto de descentralización local y autonomía de la escuela se puede encontrar en el Reino Unido y Suiza. En Inglaterra, el Departamento de Educación ya no establece el tiempo mínimo de enseñanza, pero sigue siendo necesario que las escuelas permitan el suficiente tiempo de enseñanza en cada año para impartir las áreas de currículo legal. En Escocia, el Curriculum for Excellence no establece ningún tiempo mínimo de enseñanza general para el currículo o para cualquier asignatura [con la excepción de la educación física], pero establece que la Fase General de Educación General [cursos 1-10) debe incluir todas las experiencias y resultados en ocho áreas curriculares. En Suiza, a nivel estatal, sólo se definen los estándares educativos [competencias básicas] para las materias básicas. No existe un plan de estudios estándar ni un tiempo de enseñanza predefinido [con la excepción de un número mínimo de horas de educación física] a nivel nacional. En el marco de las normas educativas, a nivel regional, los cantones son libres de determinar los planes de estudios y el tiempo de enseñanza previsto" [European Commission/EACEA/Eurydice, 2016c:18-20).
\end{abstract}

La flexibilidad es por tanto la capacidad de adaptar ritmos e intensidades de aprendizaje a las características del alumnado a través de la reorganización del currículo y de las cargas lectivas entre asignaturas, entre cursos y/o entre ciclos. La flexibilidad puede incrementar la eficacia del proceso de enseñanza-aprendizaje cuando se alinea con las características, ritmos y necesidades del alumnado. Como indica Eurydice, son Estonia, los Países Bajos, Polonia, Finlandia, Suecia y Noruega los países que cuenta con mayor flexibilidad vertical. Gales y Países Bajos cuentan con flexibilidad horizontal plena, y Polonia, Finlandia e Islandia con flexibilidad horizontal elevada. Otros países presentan una flexibilidad temporal menor (Bélgica, Irlanda del Norte, Malta, Rumanía o Dinamarca o Portugal). España por el contrario está en el grupo de los países en los que la flexibilidad temporal es inexistente y sólo se puede encontrar algún tipo de flexibilidad en las materias.

El Estado español se caracteriza por tener un sistema educativo rígido, esto es, en el que no existe flexibilidad temporal [posibilidad de decidir localmente la distribución del tiempo, ni entre cursos ni dentro de un curso] y la flexibilidad de materia es muy reducida, lo que reduce la capacidad de adaptar las cargas lectivas a las características del alumnado.

\title{
Distribución por edad del tiempo obligatorio de enseñanza
}

Como se deduce del apartado anterior, la variabilidad en relación al número total de horas por ciclo debe matizarse dado que los países difieren también en la manera en la que distribuyen esas cargas lectivas dentro de cada ciclo. En los siguientes tres gráficos presentamos un grupo de países en función de la manera en la que distribuyen las diferentes cargas lectivas según la edad del alumnado. En general, y como se pone de manifiesto en la siguiente sección, varios países otorgan bastante libertad a los centros para distribuir las cargas lectivas entre cursos y entre asignaturas, por lo que los datos representados deben tomarse como una aproximación. 
En los países incluidos en el gráfico 7 se observa una tendencia creciente a medida que aumenta la edad del alumnado en la carga lectiva que se corresponde con ciclos cortos. La progresión se hace por tanto de manera escalonada incrementándose cada 3 o 4 años a medida que se incrementa el nivel madurativo y la capacidad del alumnado. Se muestran Estonia, Finlandia, Islandia y Polonia a modo de ejemplos, pero en este grupo podríamos incluir también a Noruega, los Países Bajos, Suecia, Suiza o Reino Unido por su alto grado de flexibilidad vertical. Por ejemplo, en el caso de Suecia como indica Eurydice ${ }^{5}$ : "Cada escuela decide la duración del día escolar y las horas de apertura y cierre de la escuela. Las horas normales son de 8 - 13.30 en los años inferiores de la escuela obligatoria [grundskolan]; La duración de la jornada escolar aumenta con la edad de los alumnos."

En el gráfico 8 hemos agrupado a aquellos países que presentan un incremento más progresivo y no tan escalonado. Se trata de Alemania [datos de 2015], Austria, Eslovaquia, Eslovenia y Letonia. En este caso, aunque la tendencia de incrementar las horas a medida que lo hace el nivel de maduración para ajustarse mejor a las capacidades del alumnado es similar al grupo anterior, se hace en un contexto de ausencia de flexibilidad vertical.

Por último, el gráfico 9 nos muestra un patrón más diferenciado, se trata de países en los que la estructura de carga lectiva dentro de cada gran ciclo (primaria y secundaria obligatoria 0 básica] es más rígida, se mantiene estable durante todo el ciclo, y parece por tanto adaptarse menos al desarrollo de las capacidades del alumnado. Hablamos aquí de Bélgica [flamenca y francófona], España, Francia, Italia o Portugal. En algunos, como Bélgica (flamenca y alemana] - Italia encontramos algún grado de flexibilidad horizontal, pero no vertical. En general la carga lectiva se mantiene de las más altas en ambos ciclos en relación a los otros modelos presentados, pero la diferencia entre ciclos dentro de un mismo sistema es más acentuada en el paso de primaria a secundaria como es el caso de España o Bélgica, en el que se produce un incremento muy notable. El caso español es sin duda el más radical en este aspecto, pasando a los 11 a los 12 años de edad de 790 horas que tienen en primaria a 1.042 horas en primero de la ESO, un incremento de 252 horas anuales que supone un 32\% en tan sólo un curso.

\section{Gráfico 7. Tiempo de enseñanza en la enseñanza general obligatoria (2016) por nivel de educación, en instituciones públicas (I). Fuente: Elaboración propia de OCDE, 2016.}

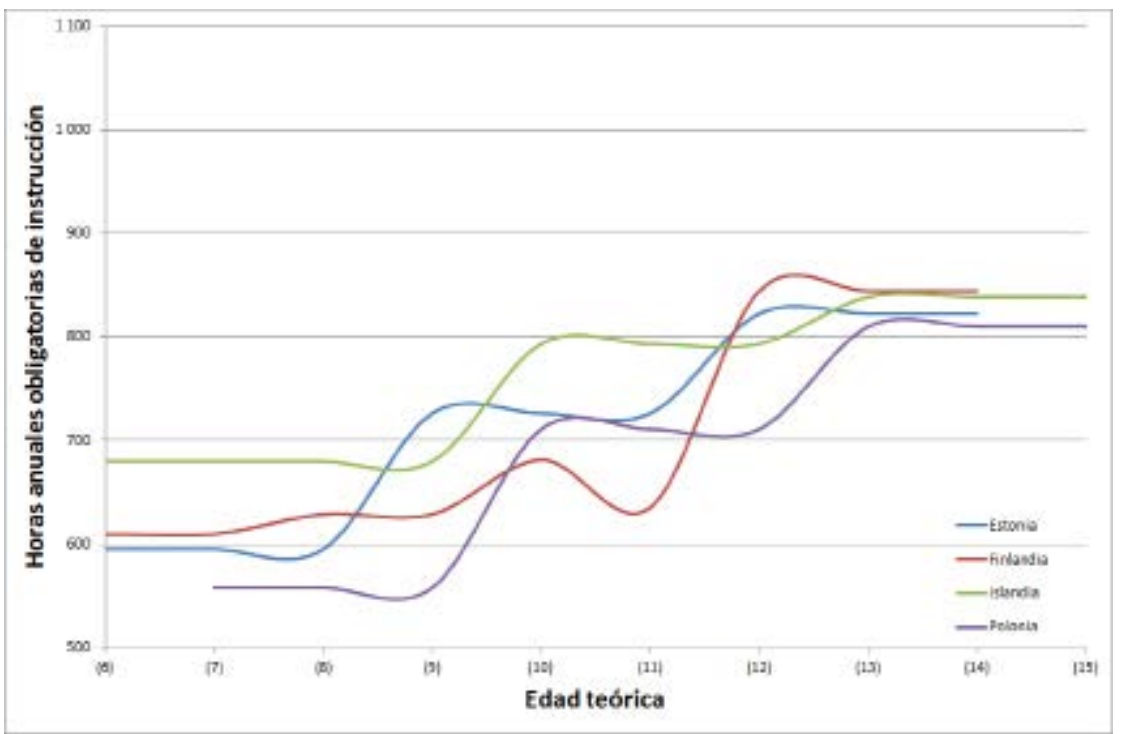

${ }^{5}$ https://webgate.ec.europa.eu/fpfis/mwikis/eurydice/index.php/Primary Education 
Gráfico 8. Tiempo de enseñanza en la enseñanza general obligatoria (2016) por nivel de educación, en instituciones públicas (II). Fuente: Elaboración propia de OCDE, 2016.

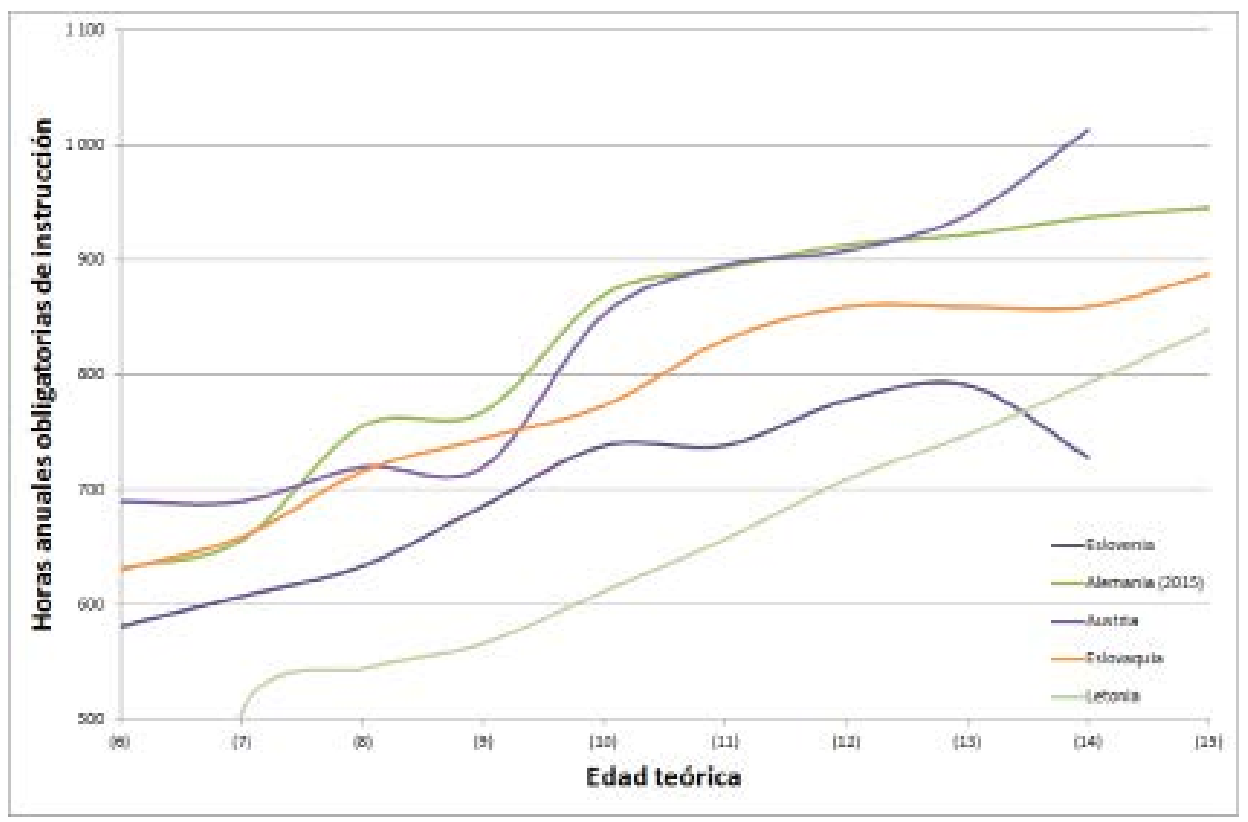

Gráfico 9. Tiempo de enseñanza en la enseñanza general obligatoria (2016) por nivel de educación, en instituciones públicas (III). Fuente: Elaboración propia de OCDE, 2016.

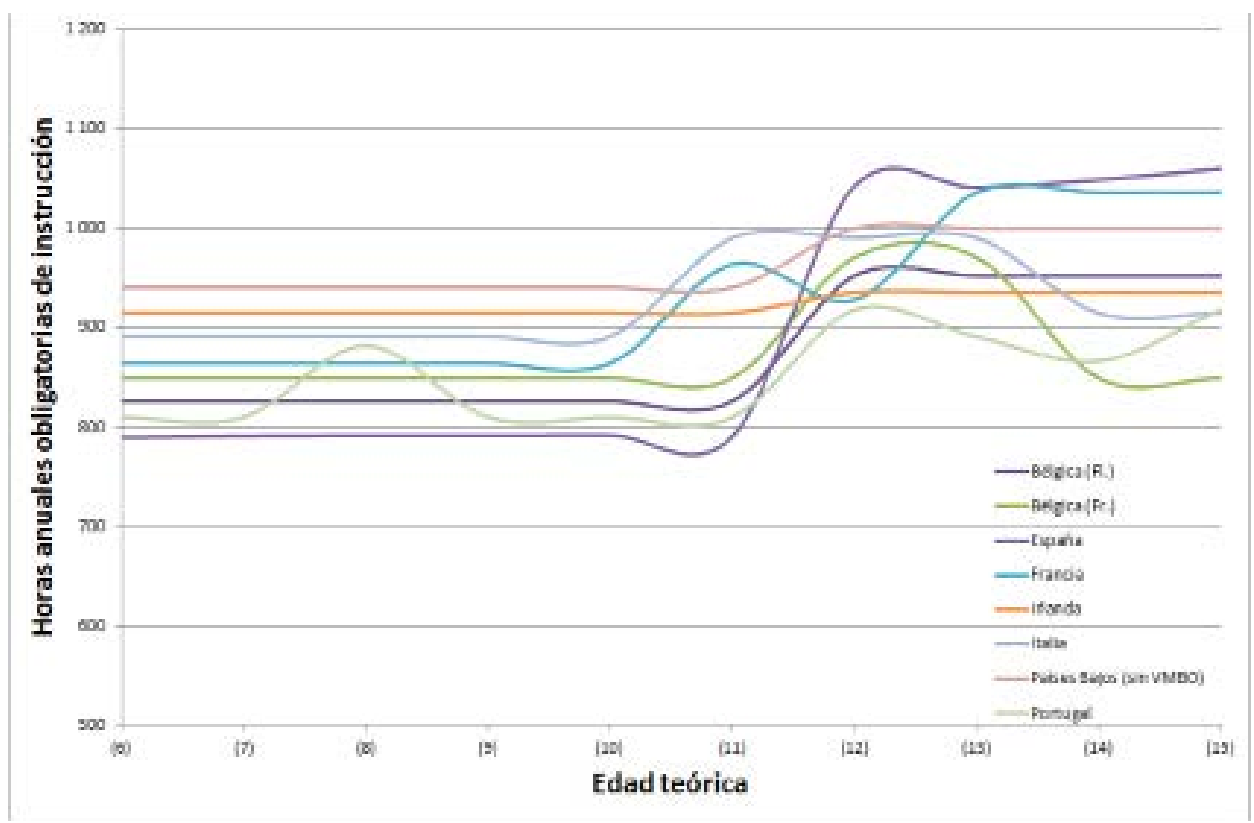


Frente a países que presentan una progresión de la carga lectiva acorde con

el incremento de la edad del alumnado -y por tanto de su teórico grado de

maduración-, España se caracteriza por un reparto de la carga lectiva plano,

esto es, sin progresividad. Existe únicamente un escalón [el más pronunciado

además a nivel comparativo] entre el último curso de educación primaria y el primero de ESO, educación secundaria.

\section{Estudios existentes sobre tiempo escolar y rendimiento}

La relación entre tiempo escolar y rendimiento se antoja compleja dado el variado número de factores que la afectan. Además no se nos escapa que el alumnado es muy diverso como diversas son sus circunstancias y sus contextos. No obstante lo anterior, o quizá a consecuencia de ello, la relación entre tiempo escolar y rendimiento académico ha atraído la atención de investigadores, generalmente del ámbito de la psicología y de la pedagogía. En esta sección tratamos de dar cuenta de sus hallazgos. Aunque queda mucho camino por recorrer:

"La relación entre el tiempo de aprendizaje y el logro escolar debe ser investigada sobre una base empírica más completa, para poder sacar conclusiones claras sobre su alcance, naturaleza y causas. Esto requiere el examen de los cambios en el rendimiento hora por hora durante el día, ya que se expresan por una amplia gama de edad en el estudio de una variedad de temas. Además, las diferencias individuales en el rendimiento a cada hora del día deben ser monitoreadas. Esta información puede ayudar a los planificadores de planes de estudios a desarrollar directrices más precisas para la determinación de la hora más conveniente para el aprendizaje de temas específicos. Esto podría ser especialmente útil para las escuelas pequeñas con presupuestos limitados que no pueden ofrecer los mismos cursos tanto en la mañana como en la tarde" [Klein, 2004:444] 


\title{
Efecto de la edad de inicio de la escolarización obligatoria en el rendimiento
}

Un primer ejemplo de la relevancia del cuándo y no sólo del cuánto lo muestra el siguiente gráfico 10, en el que se aprecia el efecto en las competencias medias en matemáticas según el mes de nacimiento. En éste se aprecia cómo el sistema español, en el que la escolarización se organiza por grupos en función del año de nacimiento de enero a diciembre ${ }^{6}$, favorece a aquellos alumnos de más edad.

\section{Según indica el propio Cebolla Boado [2016]:}

\begin{abstract}
"el mes de nacimiento suele verse como un accidente biográfico sin apenas consecuencias sobre nuestras oportunidades. Sin embargo, durante la etapa preescolar y la primaria, el momento en que nacen los niños da cierta forma a sus resultados escolares. En España, los niños nacidos cada mes de diciembre son irremediablemente los más jóvenes de sus clases, mientras que los de enero están en la situación opuesta. Nacer en la primera parte del año da más músculo tanto académico como no académico. Además de tener un mejor rendimiento medio, los primeros niños de cada año parecen sufrir menos bullying, son menos absentistas, más ambiciosos y seguros de sí mismos".
\end{abstract}

El gráfico 10 es por tanto otro claro ejemplo de la limitada flexibilidad del sistema educativo para adaptarse a la diversidad en términos madurativos del alumnado. Como indica Cebolla [2016] "La evidencia más fiable recomienda un modelo de enseñanza muy personalizado durante los primeros años de vida [...] a estrategias basadas en juegos guiados, la administración selectiva de estímulos y la solución de problemas en función de las necesidades de cada niño."

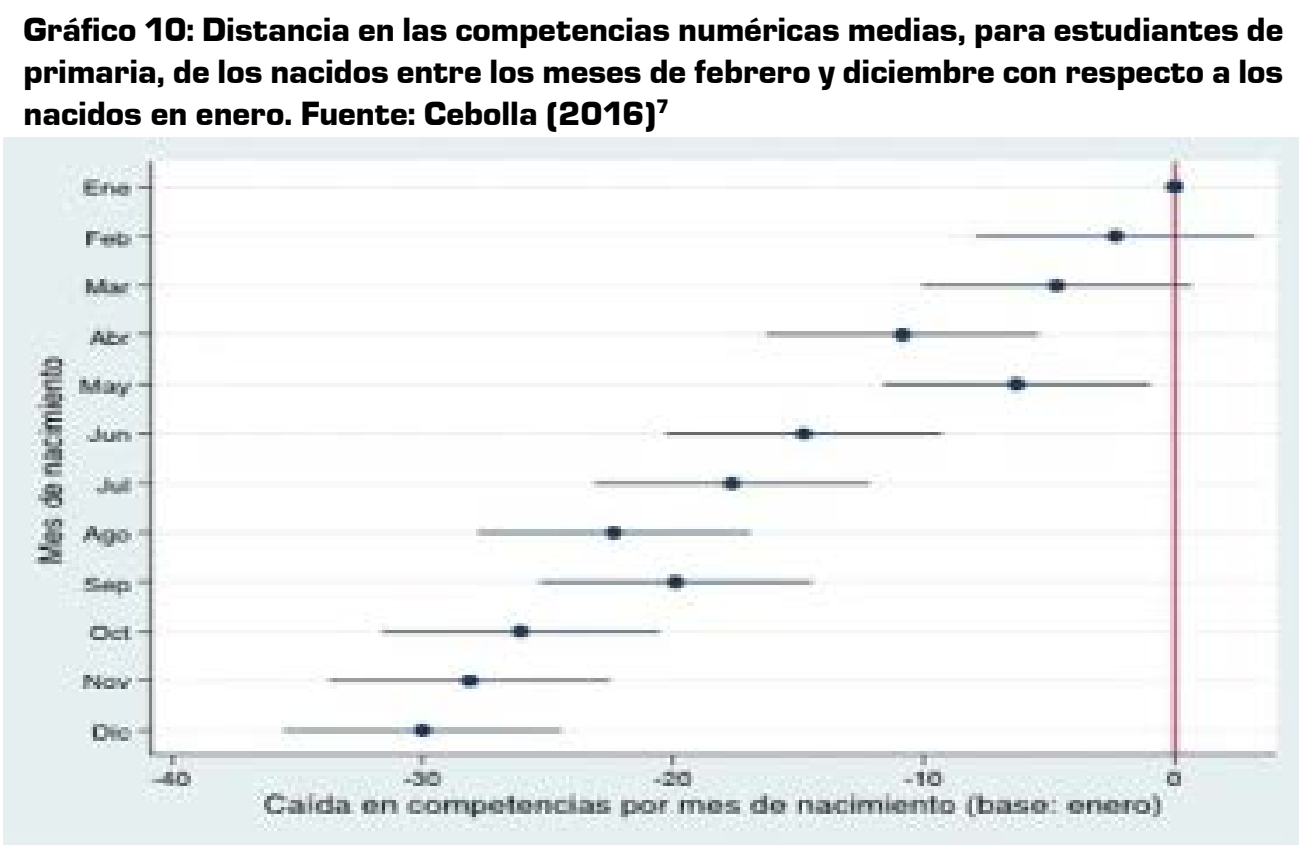

En algunos países, como el caso de Estonia, son las propias familias las que deciden si escolarizar en primaria a los 6 o a los 7 años de edad, lo que permite cierto grado de adaptabilidad en función del desarrollo del menor, pero también en función del contexto familiar.

\footnotetext{
${ }^{6}$ En otros países la edad de inicio de la escolarización toma como año el escolar, esto es de septiembre a agosto. Esto, per sí, no debiera suponer una diferencia en la composición de los grupos (los mayores y los pequeños pueden llevarse hasta casi un año de diferencia) pero sí puede afectar a que inicien la escolarización, por término medio, 9 meses más mayores que sus equivalentes españoles.

${ }^{7}$ http:/ / www.eldiario.es/piedrasdepapel/efecto-mes-nacimiento-preguntas-respuestas_6_568053207.html
} 
El rendimiento académico es muy sensible a la edad madurativa del alumnado, diferencias incluso de meses son detectables durante los primeros años de primaria. Que el año de referencia para la escolarización en España sea el año natural y no el año escolar adelanta la escolarización en nueve meses.

\section{El efecto de la falta de alimentación y descanso adecuados}

Según estudios recientes ${ }^{8}$, una de las situaciones del alumnado que claramente afecta negativamente al rendimiento es la falta de alimentación adecuada y la falta de descanso. Según PIRLS $^{9} 2011$ y TIMSS $^{10} 2011$ en promedio, a nivel internacional, entre el 27-29\% [11\% en el caso del Estado español] de los estudiantes de cuarto curso [10 años de edad] están en aulas donde la enseñanza se ve afectada "algo o mucho" porque los estudiantes carecen de una alimentación suficiente. Esto les perjudica frente a quienes no padecen esas carencia nutricionales tanto en sus logros de lectura qquienes carecen de una alimentación suficiente obtienen de media 495 frente a quienes no tienen esas carencias que obtienen de media 519 puntos en la pruebas de lectura] como de matemáticas [472 frente a 498) (Mullis et al. 2012a, p.22; Mullis et al. 2012b, p.380].

También se produce una brecha en la capacidad de lectura [507 vs 518] y en la de matemáticas [11 puntos de diferencia] debida a la privación de sueño. Pero la cantidad de estudiantes de cuarto curso [10 años de edad] que sufren privación de sueño, el 49\% [36\%-38\% en el caso del Estado español] representan una proporción mayor de todo el alumnado, [Mullis et al. 2012a, p.22), proporción que todavía se incrementa un 10\% en alumnos de octavo curso (14 años de edad].

Meijer [2008) apunta que la reducción crónica del sueño puede afectar negativamente al rendimiento escolar directa e indirectamente a través de la motivación y la atención.

El rendimiento académico es muy sensible al estado de salud, en especial a una nutrición inadecuada y a un descanso insuficiente. En el caso de España se estima que la primera afecta a uno de cada diez alumnos y el segundo a casi cuatro de cada diez.

\section{Evidencias acerca de los ciclos de alerta y fatiga}

Siguiendo a Gromada y Shewbridge [2016] podemos afirmar que las investigaciones sobre los ritmos de alerta y fatiga no son un área de interés novedosa, ya en los comienzos del siglo pasado Bade [1907, citado en Gromada y Shewbridge, 2016:13] identificó en un extenso estudio dos ciclos de alerta entre el alumnado de primaria: un primer ciclo de ascenso hasta las 12:00h. y descenso hasta las 14:00h. y un segundo ciclo de ascenso a partir de las 14:00h. Investigaciones posteriores [Rutenfranz y Hellbrügge, 1957, Fischer y Ulich, 1961 citados en Gromada y Shewbridge, 2016:13] encontraron que los participantes, en edad escolar, obtuvieron mejores resultados en cálculos matemáticos

\footnotetext{
${ }^{8}$ Nos referimos a las evaluaciones comparativas internacionales, que realiza la International Association for the Evaluation of Educational Achievement en más de 60 países, de los logros estudiantiles en matemáticas y ciencias [TIMSS] y en lectura [PIRLS]. ${ }^{9}$ PIRLS es el acrónimo de Progress in International Reading Literacy Study

${ }^{10}$ TIMSS es el acrónimo de Trends in International Mathematics and Science Study
} 
entre las 10:00h. y las 12:00h. y entre las 15:00h. y las 16:00h., mientras que se obtenían peores durante la primera hora del día escolar y alrededor de las 14:00h. [Gromada y Shewbridge, 2016:13]. Investigaciones más recientes también identificaron ciclos diarios similares de alerta de los estudiantes en el Reino Unido, Alemania, España, Israel y Estados Unidos [Gromada y Shewbridge, 2016:13].

Klein [2004] señala que entre las direcciones de las escuelas que consideran que el comienzo de la jornada escolar es el mejor para el éxito en el aprendizaje se hacen esfuerzos para programar las asignaturas principales a primera hora del día. Solía pasar con las asignaturas de lengua y de matemáticas que siempre ocupaban la primera franja horaria, en lo que se venía a denominar como horas nobles, posiblemente confundiendo por una audiencia atenta lo que en realidad era mayoritariamente una audiencia todavía medio dormida. Por otro lado, cuando las escuelas no relacionan la hora del día con la eficacia del aprendizaje, "la programación de clases se delega en el personal administrativo cuyos principios rectores son puramente técnicos y los factores psicoeducativos son irrelevantes" Klein [2004:441].

La investigación psicológica y bio-psicológica lleva un siglo estudiado la interacción entre la hora del día en la que se realizan las tareas y la eficiencia del rendimiento. De hecho, hasta la fecha, se ha demostrado que más de 100 funciones humanas varían de acuerdo con el ciclo circadiano ${ }^{11}$ (Mayo Clinic, 1995, citado en Klein, 2004). Los estudios indican que:

\begin{abstract}
"Los efectos de los biorritmos son evidentes en un declive funcional durante las primeras horas de la tarde. Este fenómeno, con su concomitante sensación de fatiga y menor producción de trabajo, se atribuyó por primera vez a la lentitud derivada de la digestión tras la comida. Sin embargo, estudios posteriores demostraron que la disminución temporal del rendimiento se produce incluso cuando las personas no comen una comida del mediodía [Blake, 1971 y Javierre et al., 1996). Hoy esa desaceleración se atribuye a los biorritmos" [Klein, 2004:442).
\end{abstract}

Andrade y Menna-Barreto [1996] en su estudio sobre chicas adolescentes [16 años] mostraron una tendencia general a obtener peores puntuaciones en diferentes pruebas por la mañana y valores más altos en la tarde, en congruencia con otros estudios realizados. Según sus propias palabras:

\begin{abstract}
"La disminución del nivel de somnolencia a medida que avanzaba el día mostraba un patrón circadiano en lugar de un efecto acumulativo debido a las actividades escolares. La demostración de un menor rendimiento y un mayor nivel de somnolencia en la mañana debe tenerse en cuenta a la hora de diseñar los horarios de las actividades escolares para los adolescentes, grupo de edad en el que la somnolencia diurna es particularmente alta". (Andrade y Menna-Barreto, 1996:341-342]
\end{abstract}

Klein en su revisión encontró evidencias similares:

“Dunn [1985] indicó que, para los adolescentes, las horas de la tarde son más efectivas para el aprendizaje. Monte et al. [2000] coincidió. Encontraron que los tiempos de aprendizaje más efectivos para los cursos 10-12 eran las horas de la tarde [...] Una conexión positiva entre la temperatura corporal y capacidad se informó también en estudios anteriores [Altabet, 1995] [...] Debido a los cambios diurnos, los adolescentes suelen estar alertas a altas horas de la noche y por lo tanto se acuestan tarde [Gail, 2001]. Para estar en la escuela a las 8:00, deben levantarse temprano, incurriendo así en un alto déficit de sueño. Los resultados son deterioro del potencial de memoria, menores niveles de atención [Dingers \& Kribbs, 1991] y mayor fatiga mental.

\footnotetext{
${ }^{11}$ Según la RAE circadiano es un adjetivo relativo a un período de aproximadamente 24 horas. Se aplica especialmente a ciertos fenómenos biológicos que ocurren rítmicamente alrededor de la misma hora, como la sucesión de vigilia y sueño.
} 
Les resulta difícil lidiar con tareas complejas y sus logros académicos disminuyen [Wolfson \& Carskadon, 1998]. Dahl [1999] encontró que los estudiantes son especialmente propensos a la fatiga cuando la fuente de la motivación proviene de tareas que implican conceptos abstractos." [Klein, 2004:443].

El propio Klein [2004) realiza un estudio con 850 alumnos de curso 7 a 9 [de 13 a 15 años] en un centro de jornada continua que impartía clases de 8:00h. a 14:30h., en los que diferentes grupos de alumnos tiene una determinada asignatura siempre a la misma franja horaria durante todo el experimento, franja que es diferente en cada grupo. Sus resultados, como indica el Gráfico 11, muestran que en la tendencia general a incrementar la atención hay dos momentos de caída. Un primer declive en las sesiones que empezaban a partir de las 10:00h., por efecto del recreo y de la actividad deportiva que parte del alumnado realiza entonces, y un declive más prominente en el logro en las clases que comienzan entre las 12:00 y las 13:00 horas.

Por su parte, el Gráfico 12 muestra que la dispersión, esto es la diferencia entre quienes sacan mejores y peores notas dentro de un mismo grupo, se incrementaba a medida que avanzaba la hora de impartición de la materia, y por lo tanto se incrementaba la fatiga. Como indica Klein [2004:447]:

\begin{abstract}
"Como resultado, la varianza en el logro aumentó con el tiempo. Incluso cuando los logros académicos medios disminuyeron en la lección después de la larga pausa de 10:00 y en las lecciones que comienzan entre las 12:00 y las 13:00 la brecha se amplió entre estudiantes de bajo y alto rendimiento. Esto refuerza la afirmación de que estos últimos son más capaces de hacer frente a las distracciones"
\end{abstract}

La disminución funcional durante las 12:00 y las 13:00 horas ha sido documentada además en la industria y otros entornos de trabajo no relacionados con la educación [Klein, 2004:447)

\footnotetext{
Gráco 11: Rendimiento escolar promedio según la hora en que comenzó la lección. Fuente: Klein (2004).
}

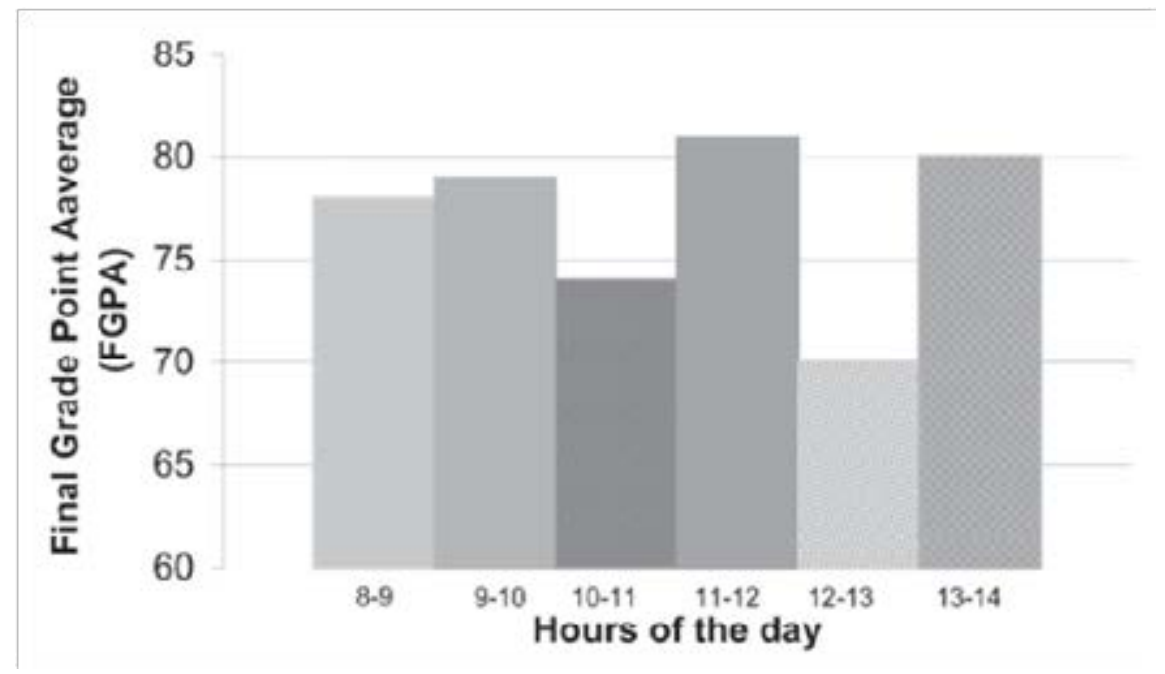




\section{Gráfico 12: Distribución de las desviaciones estándar del rendimiento académico según la hora en que comenzó la lección. Fuente: Klein (2004).}

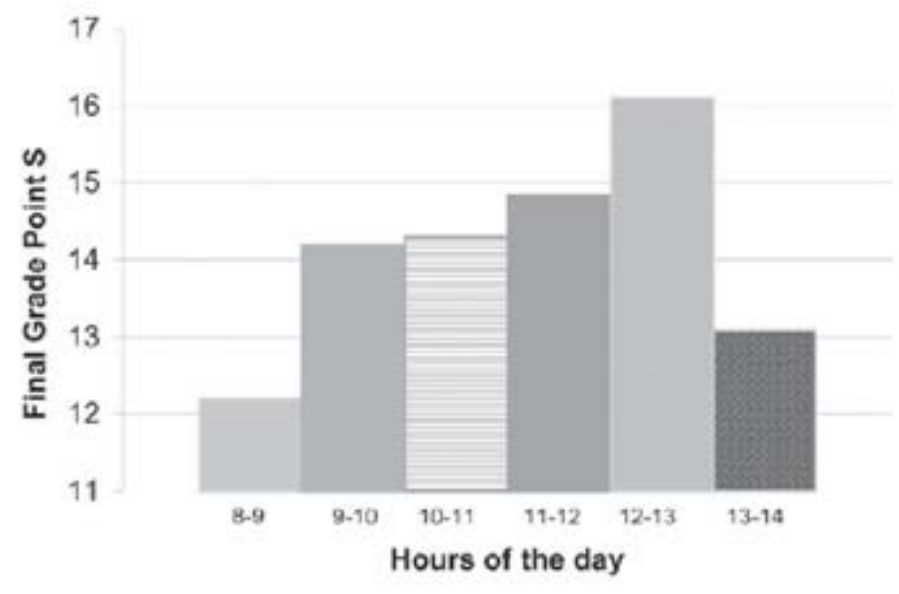

Por su parte Testu [1994a, 1994b, 2008 citados en Gromada y Shewbridge, 2016:13] encontró que los niños de 10 a 11 años tienen un bajo nivel inicial de alerta entre las 8:00h. y las 9:00h., alerta que se eleva a un pico de atención alrededor del final de las clases matinales 111:00h. a 12:00h.] [ver Gráfico 13]. Hay un segundo nivel bajo de alerta inmediatamente después de la pausa para de la comida, pero el estado de alerta vuelve a aumentar a un pico de atención por la tarde alrededor de las 16:00 horas [Gromada y Shewbridge, 2016:13].

Es importante destacar que los ciclos observados de alerta cambian significativamente a medida que las personas crecen, así, tanto la longitud como la amplitud de los ciclos de alerta cambian con la edad [Gromada y Shewbridge, 2016]. Más concretamente:

"los estudiantes de edades comprendidas entre los 13 y los 14 años tienen sus picos de atención más tarde que los de 9 a 10 años [Fischer y Ulich, 1961]. Además, los niños más pequeños [de 5 a 9 años] tienden a tener un pico mucho más débil o incluso insignificante de alerta en la tarde y, en consecuencia, muestran un rendimiento mucho más débil por la tarde que los estudiantes mayores. Fisher [1978] encontró estimaciones más altas del tiempo real de aprendizaje de los niños en los cursos superiores, lo que refleja que los niños mayores se pueden concentrar por periodos más largos de tiempo 111 minutos de matemáticas y 19 Minutos de lectura en $2^{a}{ }^{a}$ curso, 15 minutos y 35 minutos respectivamente en 5a curso]" [Gromada y Shewbridge, 2016:13).

Más aún:

"Carskadon [1999] examinó el impacto del comienzo más temprano de la escuela en los estudiantes a medida que pasaron a la escuela secundaria superior y encontró que los estudiantes tenían niveles patológicos de somnolencia a las 8.30 de la mañana afectando su capacidad de aprender en las primeras horas escolares. Un distrito escolar de Minnesota experimentó al cambiar el inicio de la escuela de 7:15 a 8.40 a.m. y una encuesta a 7000 estudiantes de secundaria reveló una mayor cantidad de descanso durante la semana, un rendimiento escolar ligeramente mejor y menos casos de sentimientos depresivos [Carpenter, 2001]" [Gromada y Shewbridge, 2016:15] 
Gráfico 13: Variaciones diarias en el rendimiento de los alumnos de 10-11 años después de 3 eventos. Fuente: Testu (1994), INSERM, 2001, p. 54, citado en Suchaut, B. (2009, May).

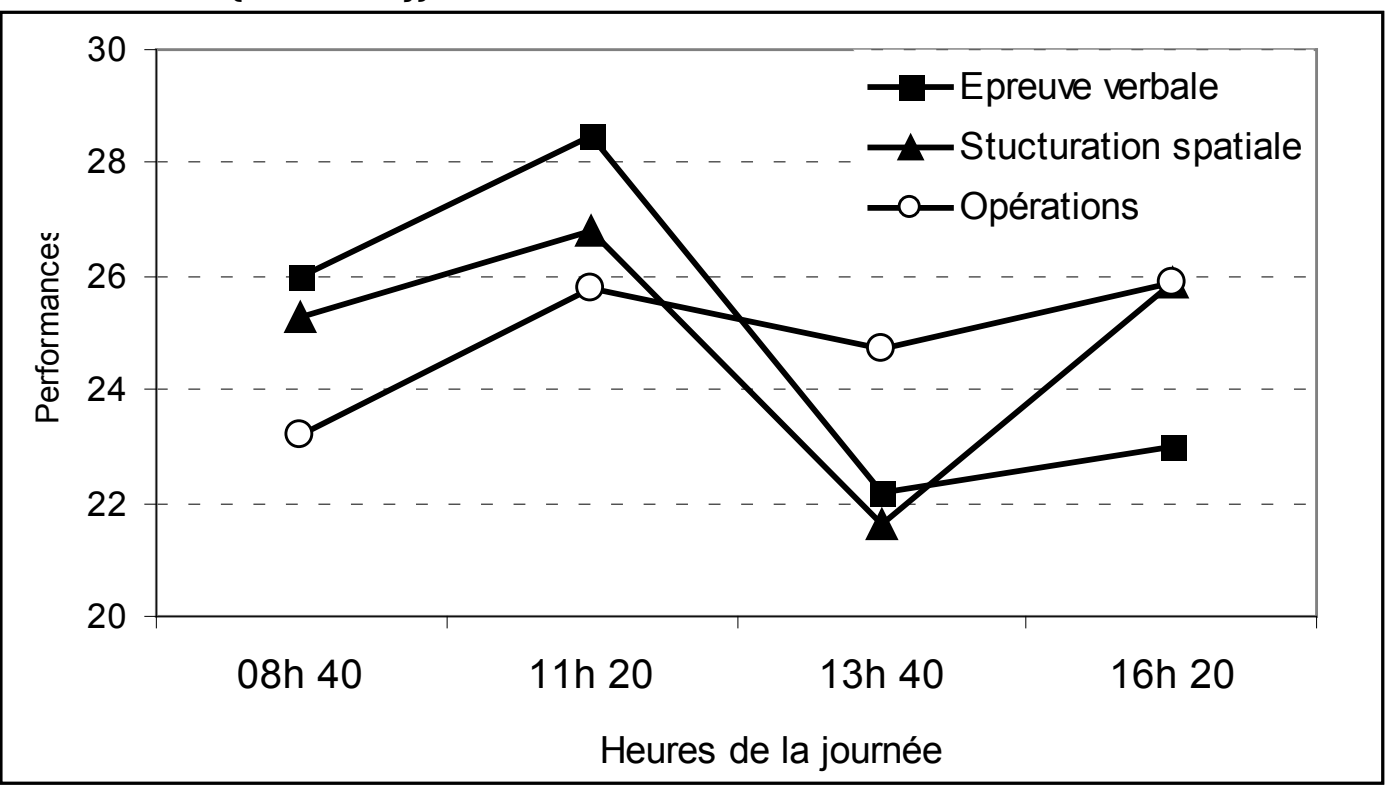

En esta línea el estudio de Carskadon [1999] muestra gráficamente estas variaciones en los ciclos circadianos [gráficos 14 y 15] que son consecuencia tanto de factores sociales como biológicos. En la primera la línea superior [denominada Tanner 1-2] muestra que los niños y las niñas pre-pubescentes con una oportunidad de sueño de 10 horas no tienen sueño, mientras que la línea inferior [denominada Tanner 3-5] muestra que los más maduros físicamente están más somnolientos, aunque tengan la misma oportunidad de dormir. En la segunda figura se muestra las variaciones en la secreción de melatonina, que está controlada por el sistema circadiano, y es una excelente medida para determinar el tiempo del reloj interno [Carskadon, 1999].

Gráfico 14. Cambio en el desarrollo durante la vigilia diurna en condiciones de sueño óptimo. Fuente: Carskadon (1999)

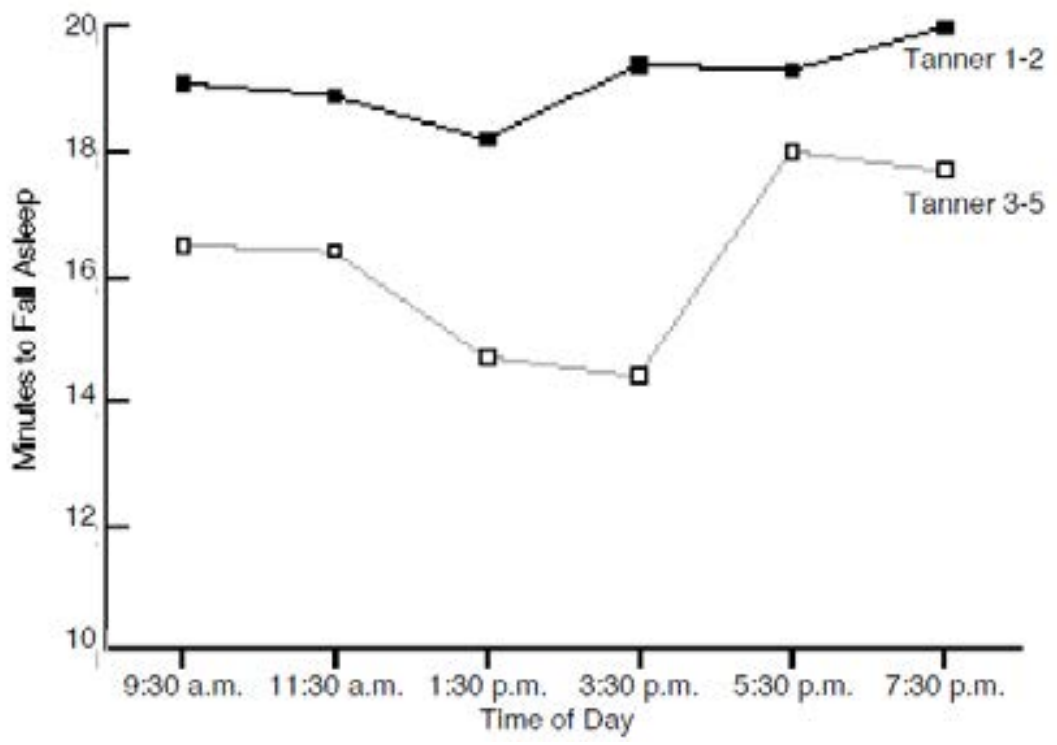




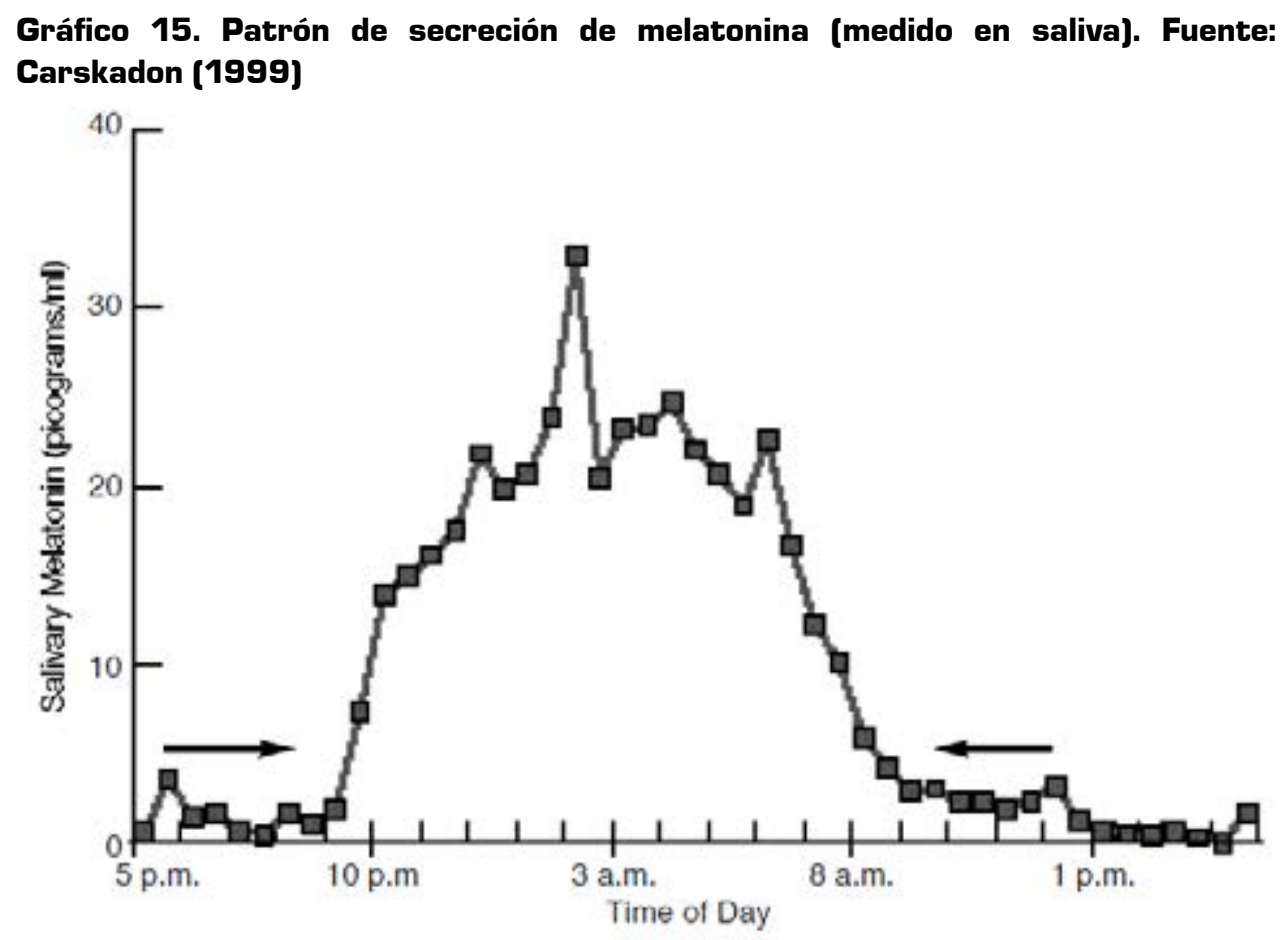

Wolfson y Carskadon [1998] estudiaron 3.120 estudiantes de Rhode Island de 13 a 19 años y encontraron que los estudiantes que recibian peores calificaciones [ $C, D$ y $E$ en el sistema norteamericano] se acostaban en promedio 40 minutos más tarde y dormían un promedio de 25 minutos menos cada noche que los estudiantes que obtenían las mejores notas [ $A$ o B] [Gromada y Shewbridge, 2016:15].

Además algunas investigaciones indican que se da más absentismo en el alumnado que muestra preferencia por el aprendizaje en horas más avanzadas del día (mediodía y tarde] [Gromada y Shewbridge, 2016:48].

Existe contrastada evidencia de que la atención del alumnado no es plana a lo largo del día sino que presenta picos de atención entorno a las $11 \mathrm{~h}$.-12h. y entorno a las $16 \mathrm{~h}$. . Y que además en la pre-adolescencia y adolescencia, debido variaciones en los biorritmos, se produce un efecto retardo en esas curvas de atención.

\section{Efecto de los cambios en los tiempos de enseñanza}

Según indican Gromada y Shewbridge [2016] en su revisión de la literatura, se ha documentado un efecto del descanso estival sobre el aprendizaje del alumnado, que depende tanto de las materias como del nivel socioeconómico de las familias. Así, por un lado se documenta un efecto "olvido" equivalente a un mes de clases en la asignatura de matemáticas [Alexander y col. 2007, citado en Gromada y Shewbridge, 2016:20] que se reparte bastante igualitariamente entre niveles socioeconómicos. Mientras que en asignaturas como lengua, se observa un efecto "ventaja" que favorece a aquél alumnado de nivel socioeconómico más elevado. 
En esta línea numerosos estudios apuntan al efecto beneficioso y compensador para el alumnado en desventaja de los programas estivales ya sean de recuperación o de enriquecimiento. Especialmente positivos [hablamos de una mejora del $40-50 \%$ en los test estandarizados al cabo de tres años de participación] son los programas que ofrecen atención individualizada o grupos reducidos [NationalAcademy of Education, 2009, citado en Gromada y Shewbridge, 2016:21] a cargo del profesorado del centro escolar y alineado con el currículum [Cooper y col., 2000, citado en Gromada y Shewbridge, 2016:21].

Por otra parte, se ha discutido ampliamente sobre los beneficios de la extensión del tiempo de enseñanza:

\begin{abstract}
Los profesores pueden cubrir el plan de estudios con más profundidad y amplitud ly no sólo centrarse en las materias evaluadas en evaluaciones o exámenes de alto nivel] que puedan corresponder mejor a los intereses de los estudiantes y presentar materiales con una variedad más contextual aumentando la comprensión de los estudiantes [...]. Más tiempo puede permitir una mayor interacción y relaciones más positivas entre maestros y estudiantes, lo que también puede beneficiar a los resultados académicos (Farbman and Kaplan, 2005, citado en Gromada y Shewbridge, 2016:28].
\end{abstract}

Sobre este asunto se reconoce que un incremento del tiempo por sí mismo no redunda necesariamente en una mejora del rendimiento (Aronson y col., 1998; Levin, Glass y Meister, 1984; Karweit, 1985, citados en Gromada y Shewbridge, 2016:28] y que es necesario tener en cuenta el incremento potencial de la fatiga y el aburrimiento [Duffett y col., 2004, citado en Gromada y Shewbridge, 2016:28]. Lo que de nuevo nos lleva a la cuestión de la importancia de adaptar los tiempos de enseñanza a las necesidades y características del alumnado. Dicho en otras palabras, el tiempo de enseñanza que no se sincroniza adecuadamente a las necesidades y características del alumnado es, en buena medida, tiempo perdido además de una pérdida de tiempo ${ }^{12}$. De hecho los análisis de PISA 2009 muestran que la mayor asociación entre tiempos de enseñanza y rendimiento se da con tiempos de enseñanza moderados [Gromada y Shewbridge, 2016:30). Además, la aparente falta de relación entre tiempo de enseñanza y rendimiento [excepto para Grecia, Corea, Japón y Polonia en la que explica entorno a un 10\%] puede deberse a que "una educación de calidad elevada puede compensar, en cierta medida, la escasez de horas"[Scheerens, 2013, citado en Gromada y Shewbridge, 2016:30].

También es importante enfatizar que no es sólo que los alumnos peor preparados requieran mayor tiempo para alcanzar el nivel de los avanzados [ver gráfico 16] sino que además la concentración horaria perjudica cognitivamente más a aquellos alumnos peor preparados, incrementando las distancias entre ambos:

\footnotetext{
"Drory [1982] encontró que el deterioro en la calidad del desempeño de las tareas prolongadas aparece principalmente entre las personas que son menos capaces. La mayoría de los trabajadores con alto potencial manifiestan una mayor facilidad para hacer frente a la fatiga mental. Este hallazgo ayuda a explicar la creciente disparidad en el logro entre los alumnos de una clase. Los estudiantes competentes lograron aprovechar sus recursos personales para hacer frente a las dificultades de atención encontradas durante el largo día escolar. Los estudiantes más débiles, carentes de las herramientas con las cuales lidiar con estos problemas, eran incapaces de mantener la concentración y mantener un alto nivel de rendimiento durante todo el día." (Klein, 2004:447)
}

\footnotetext{
12 Una comparativa de los resultados en matemáticas de PISA 2003 y PISA 2012 evidencian que en Noruega, España, Bélgica, Grecia, México, los Países Bajos y la República Checa, a pesar de haberse aumentado el tiempo de enseñanza en matemáticas, la relación entre el tiempo y el rendimiento en matemáticas se ha vuelto más negativo en 2012 [Gromada y Shewbridge, 2016:31].
} 


\section{Gráfico 16. Efectos diferenciados en la progresión del aprendizaje. Fuente: Suchaut, 1996.}

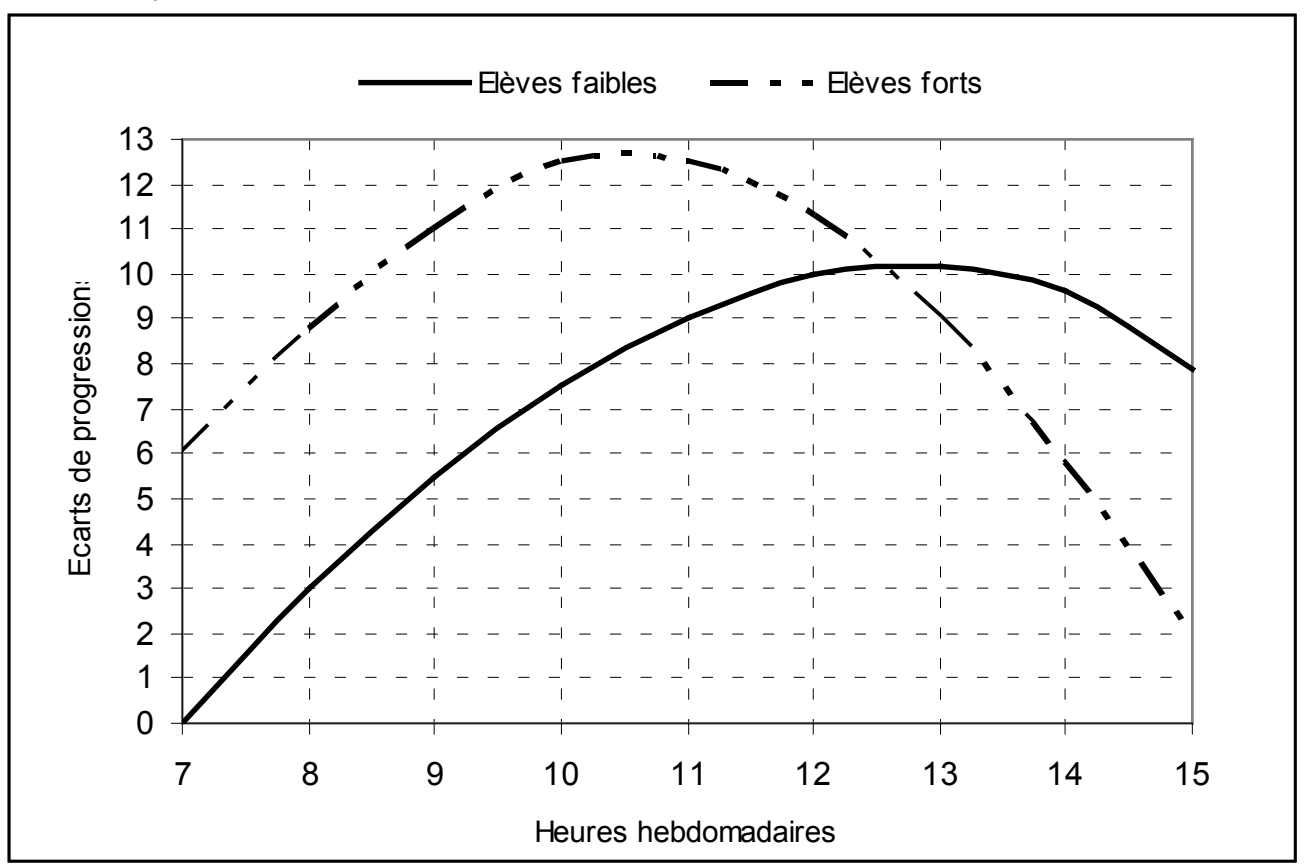

Es por ello que el alumnado en desventaja es, una vez más, el que más puede beneficiarse de mejoras educativas [programas de recuperación para alumnos más lentos o aumento del tiempo de enseñanza en escuelas con una alta proporción de estudiantes desfavorecidos], tanto es así que se ha estimado que el alumnado de contextos socioeconómicos desfavorecidos se beneficia hasta un tercio más de este tipo de incrementos en el tiempo de enseñanza [Lavy, 2010, citado en Gromada y Shewbridge, 2016:33):

"Este argumento se relaciona con los hallazgos de que los cambios en la asignación del tiempo de enseñanza tienden a tener un efecto más fuerte en dos subgrupos principales de estudiantes: 1] los estudiantes más lentos y los estudiantes de bajo rendimiento (Patall et al., 2010; Brown y Saks, 1986], así como 2] los estudiantes desfavorecidos debido a su bajo nivel socioeconómico o de origen inmigrante [Mazzarella, 1984; Silva, 2007; Llach, Adrogué y Gigaglia, 2009; Grissmer et al., 2000). Estos resultados sugieren la consideración de intervenciones específicas, tales como programas de recuperación para alumnos más lentos o aumento del tiempo de enseñanza en escuelas con una alta proporción de estudiantes desfavorecidos [OCDE, 2012a]" [Gromada y Shewbridge, 2016:31].

Pero por esa misma razón son esos estudiantes los más vulnerables cuando las medidas adoptadas van en perjuicio de la calidad de la enseñanza:

"Scheerens et al. [2013] encuentran que suficiente tiempo es especialmente importante para los estudiantes más vulnerables. Se han demostrado que incrementos adicionales de tiempo de enseñanza para los alumnos más lentos aumenta su rendimiento [Cotton, 1989; Brown y Saks, 1986] y reduce su ansiedad relacionada con la tarea [Guida, Ludlow y Wilson, 1985]. Bloom [1976] cree que el 10\% más lento de los estudiantes necesita hasta 5 a 6 veces más tiempo que el 10\% más rápido, un tiempo que normalmente no se le da. Las estimaciones de Suchaut [1996, 2009] son menos extremas [ver gráfico 16]. Demuestra que más tiempo afecta el progreso de los niños en lectura pero con un efecto de techo que varía en función del nivel inicial de aptitud de los estudiantes [...]. Para Suchaut, este techo se fija en 10.5 horas a la semana para los estudiantes más rápidos y 13 horas a la semana para los estudiantes más lentos." [Gromada y Shewbridge, 2016:32]. 
No está de más recordar aquí que el origen socioeconómico determina en buena medida el grado de desventaja que pueda tener el alumnado, en palabra de Hart y Risey: "Lo que los niños escuchan de pequeños en casa explica la mayoría de las variaciones en su proceso de lectura posterior" [1995, citado en Gromada y Shewbridge, 2016:32] , efecto que se prolonga a lo largo de su vida: "el origen socioeconómico de los individuos [...] tiene un persistente efecto en sus competencias, logros, expectativas y oportunidades educativas, desde la infancia hasta la edad de la jubilación" [Cebolla-Boado y col., 2014].

En definitiva, cabe señalar que:

\begin{abstract}
"algunos estudiantes son más lentos que otros y se benefician de más tiempo de aprendizaje, al igual que los estudiantes con antecedentes de inmigrantes y estudiantes en escuelas con mayores concentraciones de estudiantes de contextos socioeconómicos menos favorecidos. Se espera que el aumento del tiempo de enseñanza asignado para estos grupos particulares de estudiantes tenga un mayor impacto en su desempeño" [Gromada y Shewbridge, 2016:37].
\end{abstract}

Se ha documentado el efecto beneficioso para el alumnado en desventaja de los programas estivales de recuperación o de enriquecimiento, en particular de los programas que ofrecen atención individualizada o grupos reducidos a cargo del profesorado del centro escolar. Además, la concentración horaria perjudica más a quién más dificultades tiene porque se fatiga antes.

\title{
Uso eficaz del tiempo de enseñanza
}

Decíamos al inicio que el tiempo de enseñanza teórico podía entenderse como el número de horas anuales que los estudiantes deben dedicar, en las aulas formales, al aprendizaje de las partes obligatorias y no obligatorias del currículo según la legislación educativa[OCDE, 2011, citado en Gromada y Shewbridge, 2016]. No obstante, como ya venimos insistiendo, los estudios realizados van consolidando la apreciación de que no sólo es relevante el tiempo total destinado a formarse como el uso que se le da ese tiempo y, en especial, el momento en el que se da ese aprendizaje.

Como indican en su extensa revisión Gromada y Shewbridge "importa tener suficiente tiempo de enseñanza como un recurso educativo clave, pero la conclusión clave [de la revisión] es que lo que más importa es la forma en que se utiliza ese tiempo asignado"[Gromada y Shewbridge, 2016:3]. Así, el número de horas que se dedican a la enseñanza sólo en parte influye en el rendimiento en la escuela; ya que, como venimos defendiendo, la calidad del tiempo de aprendizaje es tan, si no más, importante que la cantidad:

\footnotetext{
"Cotton y Savard [1981] revisaron treinta y cinco estudios que midieron la relación entre el tiempo y el aprendizaje y concluyeron que la relación se hace más fuerte a medida que se utilizan medidas de tiempo más precisas. Se encontró una pequeña relación positiva entre el tiempo de enseñanza y el rendimiento académico, la relación se hizo más fuerte entre el tiempo de atención y el rendimiento académico, mientras que el tiempo real de aprendizaje emergió como el predictor más fuerte de logro entre todas las medidas del tiempo de aprendizaje de los estudiantes." [Gromada y Shewbridge, 2016:40]
} 


\section{Gráfico 17. Modelo para comprender el uso eficaz del tiempo de enseñanza asignado. Fuente: Education at Glance 2016, pp.380.}

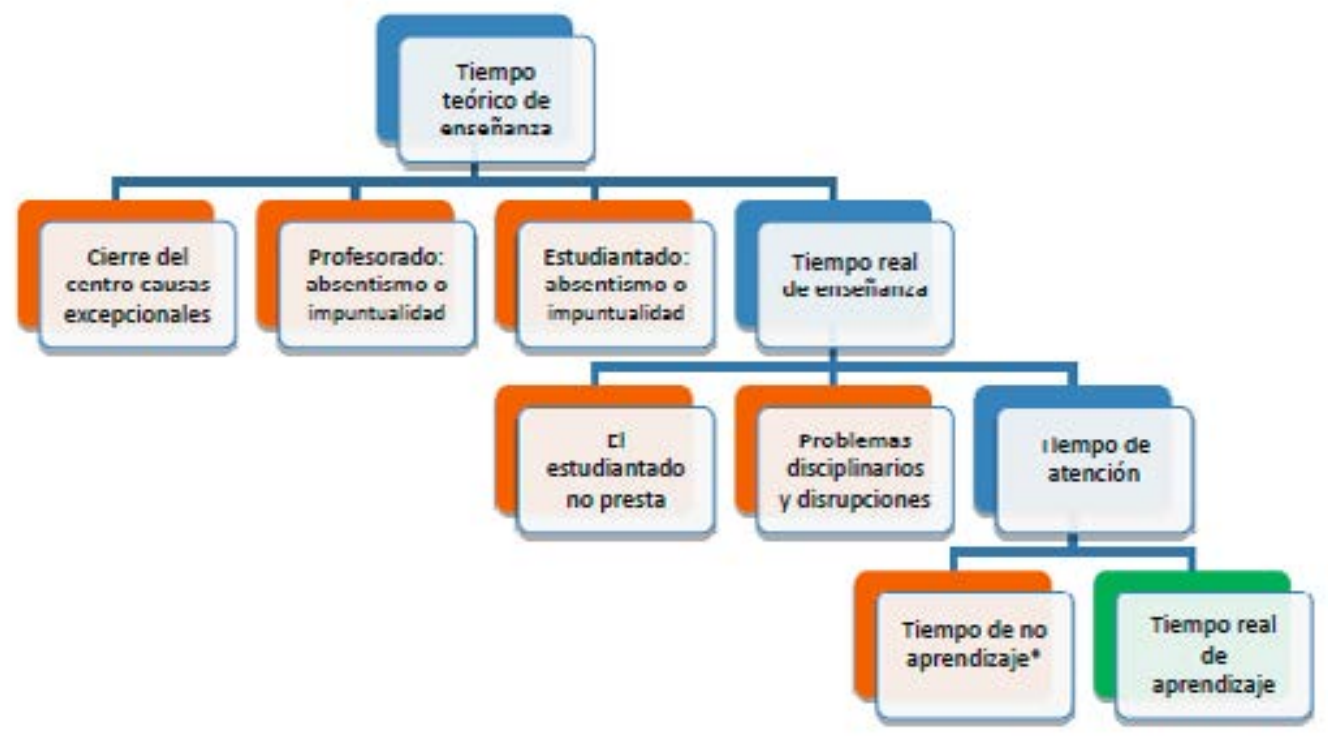

*El material académico no supone suficiente dificultad y/o interés, no está alineado con el currículum.

Como decíamos al inicio del estudio, el tiempo real de enseñanza es el tiempo enseñanza resultante una vez descontados los posibles cierres del centro educativo (por causas extraordinarias] así como las faltas de asistencia o de puntualidad, bien del profesorado ${ }^{13}$ [bajas por enfermedad, tiempo de formación, etc.] bien del alumnado [enfermedad, absentismo] [ver gráfico 17]. Según datos de PISA 2012, que muestra la opinión de las direcciones de los centros, la falta de puntualidad del profesorado no supone un problema para la enseñanza. Si lo supone en cambio el absentismo del profesorado ${ }^{1}$, aunque siendo menos relevante en el Estado español [13\%] que en la media de la OCDE [20\%] [OCDE, 2013: Tabla IV.5.19].

Algo similar ocurre con el absentismo escolar del estudiantado, incluyendo llegar tarde a la escuela [16\% en España, 31\% de media en la OCDE] y faltar a la escuela [25\% en España, 31\% de media en la OCDE] [OCDE, 2013: Tabla IV.5.9]. Los estudiantes pueden perder oportunidades de aprendizaje por faltar a la escuela o a las clases, o por falta de puntualidad (ver gráfico 17). El absentismo escolar estudiantil no sólo perjudica al estudiante individual, sino que, cuando es un fenómeno generalizado, contribuye a un ambiente de aprendizaje disruptivo y perjudica a toda la clase [Gromada y Shewbridge, 2016].

"El tiempo real de aprendizaje ha demostrado tener una influencia positiva tanto en el rendimiento académico como en las actitudes de los estudiantes hacia el aprendizaje [Cotton y Savard, 1981; Karweit, 1985; Mazzarella, 1984). El aumento en el tiempo real de aprendizaje parece ser tanto eficaz como eficiente, ya que tiende a aumentar el rendimiento de los estudiantes al tiempo que ahorra un escaso recurso de tiempo de enseñanza [Walberg, 1988]." [Gromada y Shewbridge, 2016:40]

\footnotetext{
${ }^{13}$ El absentismo puede en parte ser debido al retraso en la sustitución de profesorado de baja laboral.
} 
Según PISA 2012, y ahora bajo la propia perspectiva del alumnado participante, España está a la cabeza, tras Italia, de los países europeos de la OCDE en el porcentaje de estudiantes que indicaron haber faltado un día de clases en las dos semanas anteriores a la prueba PISA [el 24,2\% faltó 1 o 2 veces, el 2,6\% faltó 3 o 4 veces, y el 1,2\% faltó 5 o más veces], y la tercera, tras Grecia e Italia, en el porcentaje de estudiantes que informaron haber faltado a algunas clases en las dos semanas anteriores a la prueba PISA [el 25,5\% faltó 1 o 2 veces, el 3,9\% faltó 3 o 4 veces, y el 2,9\% faltó 5 o más veces] [OCDE, 2013: Tabla IV.5.3].

Como también indicamos al inicio, el tiempo de atención puede definirse como la parte del tiempo real de enseñanza en el que el alumnado presta efectivamente atención [Berliner, 1990, citado en Gromada y Shewbridge, 2016]. Por tanto se habrá de descontar aquel tiempo en el que el estudiantado no presta atención y aquel tiempo destinado a resolver problemas disciplinarios y otras disrupciones (ver gráfico 17). En este sentido PISA 2012 señala que los principales elementos de distracción que restan tiempo de atención para el alumnado español son: que las y los estudiantes no escuchan lo que dice la o el docente [34\%], que la o el docente tiene que esperar mucho tiempo para que las y los estudiantes se calmen [33\%], que hay ruido y desorden [32\%], que las y los estudiantes no comienzan a rendir durante mucho tiempo después de que comience la lección [30\%], o que las y los estudiantes no puede trabajar bien [23\%] [OCDE, 2013: Figura IV.5.4).

Entendíamos también que el tiempo de aprendizaje es la parte del tiempo de atención en el que se produce un aprendizaje efectivo o real, y que requiere que el material académico suponga suficiente dificultad e interés, y esté alineado con el currículum [Cotton, 1989, citado en Gromada y Shewbridge, 2016] [ver gráfico 17). El tiempo de aprendizaje es claramente el tiempo que mejor predice el éxito académico (Fraser y col., 1987, citado en Gromada y Shewbridge, 2016).

Según datos de TALIS 2013 [OCDE, 2014] en el Estado español el 7,4\% del tiempo en clase se dedica a tareas administrativas, el 14,7\% a mantener el orden en el aula, y el 77,2\% a la enseñanza y el aprendizaje. De todos modos, como matizan diversos estudios realizados en los EEUU:

\begin{abstract}
"Prácticamente todos los estudios sugieren que existe amplio margen de mejora en la utilización del tiempo de enseñanza ya asignado [Levin, 1986] e indican un fenómeno general de la escasez de tiempo efectivo. Si tan sólo la mitad del tiempo asignado puede ser dedicado a la enseñanza real [Gettinger y Seibert, 2002], el aumento de la eficacia del tiempo actual aparece como una de las prioridades educativas relacionadas con el tiempo. Hossler et al. [1988] cree incluso que hasta el $70 \%$ de las maestras y maestros necesitan mejorar sus habilidades de gestión de la clase" [Gromada y Shewbridge, 2016:45]
\end{abstract}

Dado que la motivación y autoconfianza de las y los estudiantes afectan a la calidad del aprendizaje, el grado y la continuidad del compromiso y la profundidad del entendimiento alcanzado. Es sólo cuando el estudiantado está físicamente presente, y están mentalmente preparado y dispuesto a aprender, que puedan aprovechar al máximo las oportunidades que ofrecen las escuelas y seguir aprendiendo más allá de la educación formal [Gromada y Shewbridge, 2016].

En definitiva, y aunque existe una amplia variabilidad en las estimaciones que diferentes estudios en los EEUU hacen del tiempo perdido con fines no educativos, podemos retener que entorno a la mitad del tiempo de enseñanza es efectivamente tiempo de atención, destinándose la otra 
mitad a cuestiones relativas a procedimiento y disciplinarias, las transiciones entre clases, otras actividades no académicas, socialización y muchos otros (Cotton, 1989, citado en Gromada y Shewbridge, 2016:45]. Pero es que, se estima que sólo la mitad de ese tiempo de atención resultante puede considerarse como tiempo de aprendizaje [Fisher, 1978; Caldwell y col., 1982 citado en Gromada y Shewbridge, 2016:45).

A esto hay que añadirle que diferentes grupos de alumnos muestran diferentes niveles de aprovechamiento del tiempo de aprendizaje, así:

\begin{abstract}
"Werner y Simpson [1974] durante un período de 30 días midieron la capacidad de atención de niñas y niños al inicio de la escuela primaria con tres grupos de alumnado diferentes, identificado por los profesores. El grupo del alumnado mal adaptado pudo centrar su atención el 66\% del tiempo dedicado a las tareas, el grupo del alumnado moderadamente adaptado el $81 \%$ y el del alumnado bien adaptados el 88\%. La proporción de trabajo realizado correctamente por cada grupo de alumnos se relaciona estrechamente, 69\%, 82\% y 88\%, respectivamente." [Gromada y Shewbridge, 2016:45]
\end{abstract}

Se entiende así que sea prioritaria la optimización tiempo de aprendizaje. Por ello la falta de adecuación del tiempo de enseñanza a las horas preferidas por el alumnado es señalado también como un factor clave que reduce su tiempo de aprendizaje además de fomentar la falta de asistencia a clase:

\begin{abstract}
"La investigación sobre las preferencias individuales de los estudiantes sobre cuando se sienten más alerta y listos para el aprendizaje ha revelado que pueden estar relacionados con el absentismo e indican qué puede ser de especial importancia para los estudiantes en riesgo hacer que el tiempo de enseñanza coincida con sus tiempos preferidos de aprendizaje. El análisis multinivel de PISA 2012 muestra que los sistemas escolares que conceder una mayor discreción a las escuelas para determinar los planes de estudio y de evaluación tienden a ser aquellos con un menor número de estudiantes que faltan a la escuela" (Gromada y Shewbridge, 2016:40).
\end{abstract}

Pero también el tipo de tareas que se realizan tiene un efecto en el rendimiento, y éstas pueden también verse afectadas [favorecidas o dificultadas] por la manera en la que se usa el tiempo en la escuela. En un estudio de Levin [y col., 1984, 1987, citado en Gromada y Shewbridge, 2016:35] se señala que mucho más efectivo que el incremento de horas o la reducción del número de alumnas y alumnos era el establecimiento de tutorías sistemáticas con pares de mayor edad que la alumna o alumno en cuestión o con personas adultas.

\footnotetext{
"Hay argumentos para proporcionar días de enseñanza más largos y / o aumentar el número de semanas de enseñanza para ayudar a abordar los cambios sociales y económicos, principalmente para satisfacer las necesidades de niñas y niños con padres que trabajan, en familias monoparentales y en familias menos favorecidas desde el punto de vista socioeconómico. [Gromada y Shewbridge, 2016:37]
}

En consecuencia, dese diferentes investigaciones se aboga por diferentes cantidades de tiempo de enseñanza para los niños de diferentes edades. Touitou y Bégué consideran que un sistema que respete los ritmos biológicos debe abarcar, dependiendo de la edad, de 4 a 6 horas de tiempo de enseñanza al día, de 4 días y medio hasta 5 días escolares por semana y de 180 a 200 horas al año. A su vez, La ligue de l'enseignement aboga por un tiempo de enseñanza diaria de cinco horas para niñas y niños de la escuela primaria debido a su alcance de atención más limitado. Suchaut argumenta que la organización del tiempo debe tener en cuenta la evidencia de la investigación y limitar la semana escolar a alrededor de 20 horas hasta el tercer curso [9-10 años de edad] e introducir un tiempo de enseñanza diaria más corto distribuido a través de un 
mayor número de días. Esto no debe ser más de seis horas de enseñanza por día en la escuela secundaria inferior y no más de siete horas en la escuela secundaria superior. Testu [2008] sugiere que los aumentos del número semanal de horas deben ocurrir en función de la edad de la o el estudiante, con 21 horas para niñas y niños de 6 a 9 años, 25,5 horas para niñas y niños de 9 a 13 años, 28 horas para el estudiantado de 13 a 15 años y 31 horas para el de 16 a 19 años. Para todos los grupos de edad, Testu aboga por las clases que comienzan no antes de las 8.30 am y un descanso largo de mediodía [12 a $2.30 \mathrm{pm}$ ] que ayudaría a manejar la caída del mediodía en los niveles de alerta [Gromada y Shewbridge, 2016:14].

En conclusión,

"[...] debe haber expectativas realistas sobre cómo efectivamente el estudiantado puede aprender durante el día y el año escolar [...] la enseñanza podría organizarse para optimizar mejor los tiempos en que los estudiantes están mejor capacitados para concentrarse" [Gromada y Shewbridge, 2016:3]

El tiempo real de aprendizaje es sólo una fracción del tiempo teórico de enseñanza debido a cuestiones relativas a absentismo, falta de puntualidad, tareas administrativas, problemas disciplinarios y disrupciones, la falta de adecuación de las tareas al nivel e interés del alumnado, y la falta de sincronización con sus horarios preferidos para el aprendizaje.

\section{Modelos actuales de jornada escolar:}

Como hemos pretendido mostrar en el capítulo tercero, la variabilidad entre los sistemas educativos en Europa en lo que respecta al tiempo escolar es compleja ya sea en términos de cargas lectivas por etapa, ciclo o curso, ya sea por su distribución en el calendario escolar, ya sea por el grado de flexibilidad temporal con la que cuentan los diferentes sistemas. En consecuencia, la distribución de la carga lectiva a lo largo de la semana (la jornada lectiva del alumnado) y más aún la jornada escolar, son de una variabilidad extraordinaria. Dado no obstante el amplio interés que se ha suscitado en los últimos tiempos respecto del uso y organización del tiempo escolar, en esta sección tratamos de dar cuenta de los modelos existentes en nuestro entorno estatal y europeo.

Antes de adentrarnos en la cuestión particular de los horarios escolares en las diferentes Comunidades Autónomas [CCAA], tiene sentido perfilar, de manera breve, los principales problemas del sistema educativo español en lo que a uso del tiempo se refiere.

En el gráfico 18 se muestra el porcentaje de alumnado repetidor en Educación Primaria y Educación Secundaria Obligatoria por titularidad del centro. Como se puede observar con claridad, el recurso a la repetición de curso está mucho más extendido en los centros públicos que en los privados [y concertados]. 
Gráfico 18. Porcentaje de alumnado repetidor en Educación Primaria y Educación Secundaria Obligatoria por titularidad del centro. Curso 2013-14. Fuente: Sistema Estatal de Indicadores de la Educación. Edición 2016

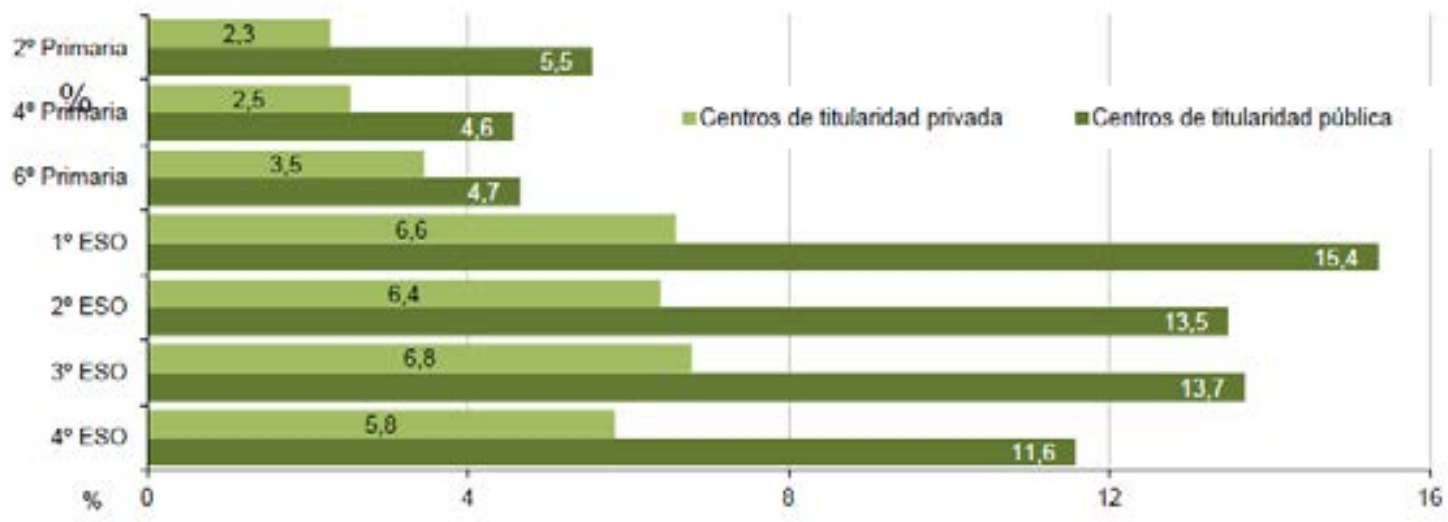

En cuanto al recurso a la repetición, en el Estado español dónde un tercio del alumnado ha repetido alguna vez, se sitúa en el grupo de países en los que más alumnado repite [ver gráfico 19], sólo por detrás de Bélgica y Portugal.

Gráfico 19. Relación entre repetición y equidad. Fuente: OECD, 2013

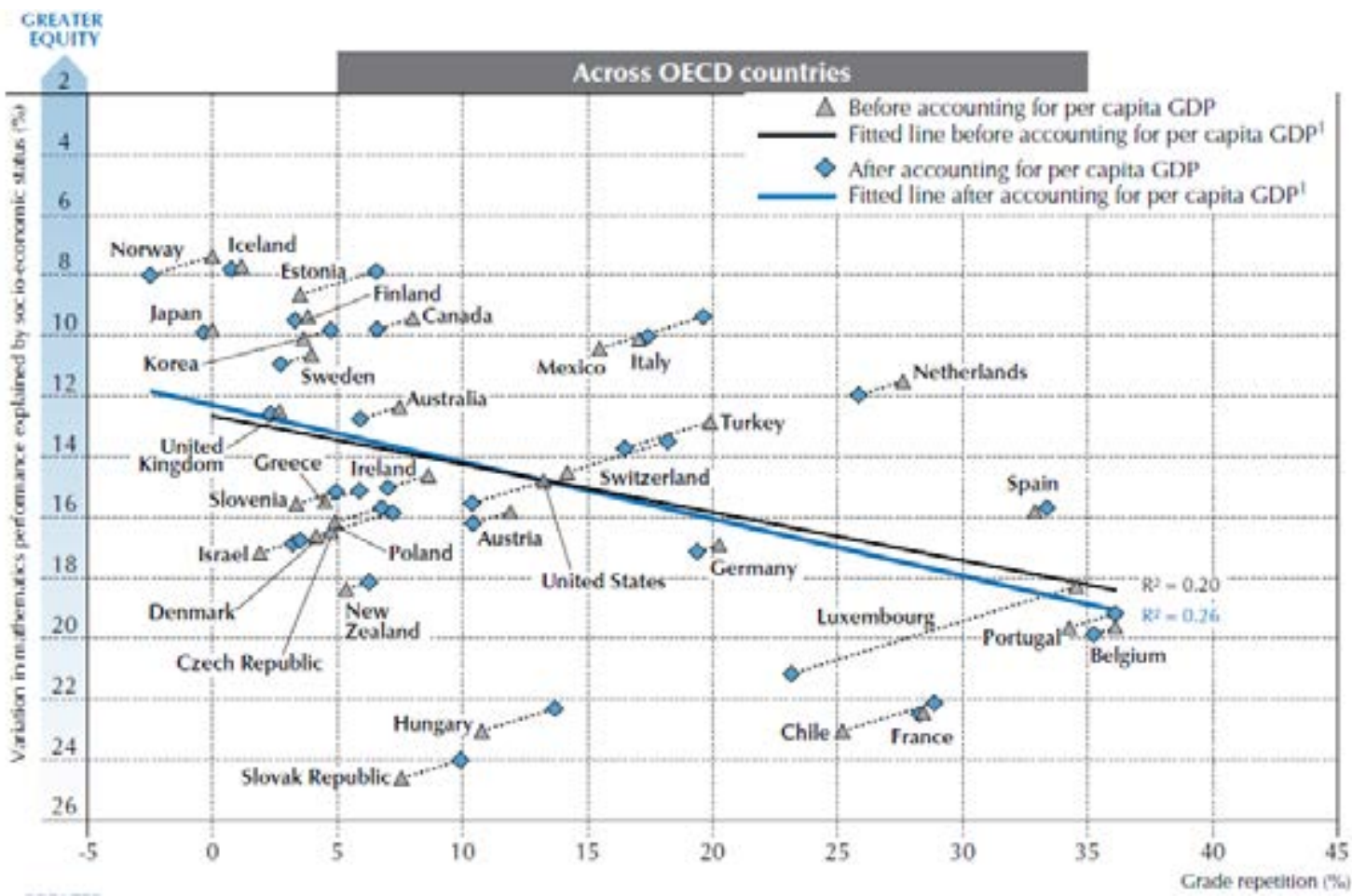


La repetición tiene un efecto directo en las tasas de idoneidad (ver gráfico 20), tasas que nos indican el porcentaje del alumnado que está en el curso que le corresponde por la edad, esto es, porcentaje del alumnado que no ha repetido nunca. La repetición supone un incremento de recursos [económicos y temporales] de dudosa rentabilidad dado que su efectividad y su valor pedagógico son muy cuestionados. Además, los países que recurren a menudo la repetición de curso se correlacionan negativamente con la equidad (ver gráfico 13), esto es, a más repeticiones mayor diferencia de rendimiento entre el alumnado de estatus socioeconómico alto y el de estatus socioeconómico bajo, perjudicando a estos últimos.

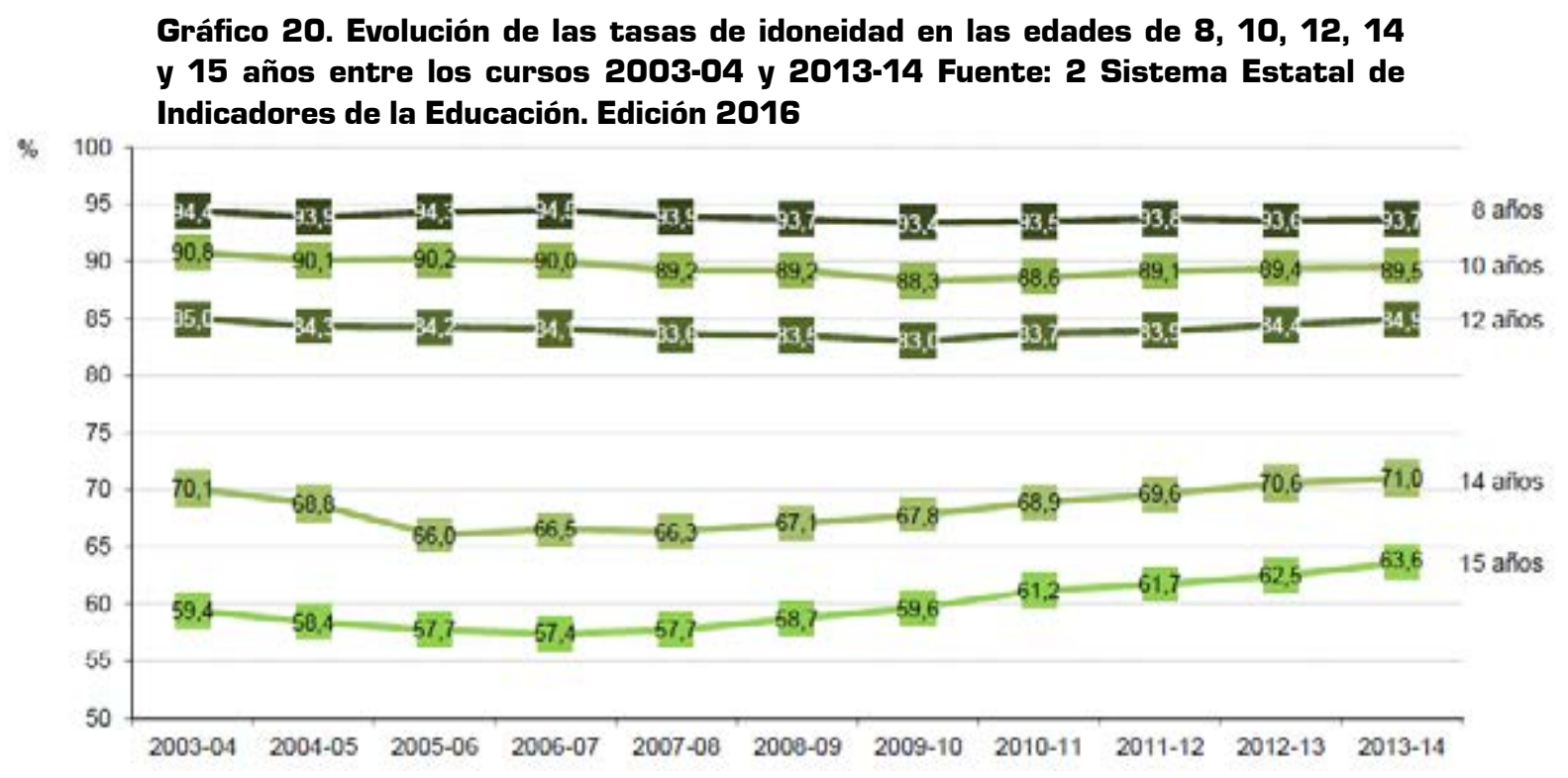

Como decíamos, existe cierto consenso en que el recurso a la repetición de curso es un mecanismo ineficiente tanto en términos del efecto sobre el rendimiento como en términos de los costes económicos que implica:

\footnotetext{
"Algunas investigaciones sugieren que la repetición de curso no beneficia el aprendizaje [Hauser, 2004; Alexander, Entwisle y Dauber, 2003; Jacob y Lefgren, 2009; Manacorda, 2012], y hay un entendimiento general sobre que la repetición de curso es gravosa para el sistema [West, 2012; OCDE, 2011a], la repetición de curso no obstante se sigue utilizando en muchos países [Goos y col., 2013]. A veces la posibilidad de repetición de curso, en sí, es vista como una fuente de motivación hacia un mayor compromiso con la escuela, y se acompaña de otras intervenciones para ayudar a un o a una estudiante a tener éxito.
}

PISA examina la cuestión de la repetición de curso no a nivel individual de la o del estudiante, pero si a nivel del sistema con el fin de evitar el sesgo de selección (Heckman y Li, 2003). La repetición de curso tiende a mostrar una relación negativa con la equidad, y esto es especialmente evidente cuando la relación se examina en el conjunto de los países de la OCDE [...] para los que el 26\% de la variación del impacto del estatus socioeconómico de la o del estudiantes sobre su rendimiento en matemáticas puede explicarse 'por las diferencias en la proporción de estudiantes que repiten un curso', incluso teniendo en cuenta el PIB per cápita“ [OCDE, 2013: 34]. 
España encabeza también el grupo de países en abandono escolar [ver tabla 3], más elevado en el caso de los hombres que en de las mujeres. Además, como veremos más adelante en esta guía, hay que señalar que el absentismo estudiantil es precursor del abandono.

Tabla 3. Población de 18 a 24 años que no ha completado la Ed. Secundaria $2^{a}$ etapa y no sigue ningún tipo de estudio-formación, 2014. Fuente: MECD Las cifras de la educación en España. Estadísticas e indicadores, 2016.

\begin{tabular}{|c|c|c|c|}
\hline$\%$ & Total & Hombres & Mujeres \\
\hline España & 21,9 & 25,6 & 18,1 \\
\hline Malta & 20,3 & 22,2 & 4,6 \\
\hline Islandia & 19,0 & 24,3 & 13,5 \\
\hline Rumanía & 18,1 & 19,5 & 14,1 \\
\hline Portugal & 17,4 & 20,7 & 3,3 \\
\hline Italia & 15,0 & 17,7 & 7,9 \\
\hline Bulgaria & 12,9 & 12,8 & 6,5 \\
\hline Reino Unido & 11,8 & 12,8 & 6,0 \\
\hline Noruega & 11,7 & 12,9 & 10,4 \\
\hline Estonia & 11,4 & 15,3 & 2,9 \\
\hline Hungría & 11,4 & 12,5 & 5,1 \\
\hline Unión Europea (28 países) & 11,2 & 12,8 & 9,6 \\
\hline Bélgica & 9,8 & 11,8 & 8,9 \\
\hline Alemania & 9,5 & 10,0 & 2,3 \\
\hline Finlandia & 9,5 & 11,9 & 10,7 \\
\hline Francia & 9,0 & 10,2 & 7,5 \\
\hline Grecia & 9,0 & 11,5 & 2,7 \\
\hline Países Bajos & 8,7 & 10,6 & 3,7 \\
\hline Letonia & 8,5 & 11,7 & 10,3 \\
\hline Dinamarca & 7,8 & 9,5 & 12,9 \\
\hline Austria & 7,0 & 7,6 & 18,3 \\
\hline Irlanda & 6,9 & 8,0 & 6,1 \\
\hline Chipre & 6,8 & 11,2 & 6,6 \\
\hline R. Eslovaca & 6,7 & 6,9 & 6,6 \\
\hline Suecia & 6,7 & 7,3 & 16,7 \\
\hline Luxemburgo & 6,1 & 8,3 & 12,2 \\
\hline Lituania & 5,9 & 7,0 & 5,7 \\
\hline R. Checa & 5,5 & 5,8 & 7,7 \\
\hline Polonia & 5,4 & 7,3 & 6,8 \\
\hline Suiza & 5,4 & 5,5 & 5,4 \\
\hline Eslovenia & 4,4 & 6,0 & 5,2 \\
\hline Croacia & 2,7 & 3,1 & 7,2 \\
\hline
\end{tabular}

Una característica más del sistema educativo español es el relativo alto grado de asistencia a clases de repaso o apoyo (ver tablas 4 y 5 y gráfico 21). En la tabla 4 y el y gráfico 21, que se refiere a datos de PISA [alumnado de 15 años de edad] podemos observar como el caso español, de 28 países que se comparan, ocupa posiciones altas en todas las comparaciones: es tercera en estudio con un tutor personal, quinta en asistencia a academias de repaso y séptima en deberes escolares. Sólo en estudio con algún familiar baja a posiciones más intermedias, y aun así siempre por encima de la media de la OCDE. 
Tabla 4: Ranking de países según el recurso de su estudiantado a diferentes formas de aprendizaje de materias curriculares fuera de la escuela, PISA - 2012. Fuente: elaboración propia de OECD, 2013.

\begin{tabular}{|c|c|c|c|c|c|c|c|}
\hline \multicolumn{2}{|l|}{ Deberes escolares } & \multicolumn{2}{|c|}{ Estudio con un tutor personal } & \multicolumn{2}{|c|}{ Clases de refuerzo $^{1}$} & \multicolumn{2}{|c|}{ Estudio con familiar ${ }^{2}$} \\
\hline Italia & 1 & Albania & 1 & Grecia & 1 & Albania & 1 \\
\hline Irlanda & 2 & Grecia & 2 & Albania & 2 & Hungría & 2 \\
\hline Rumania & 3 & España & 3 & Letonia & 3 & Polonia & 3 \\
\hline Estonia & 4 & Polonia & 4 & Bulgaria & 4 & Suecia & 4 \\
\hline Lituania & 5 & Portugal & 5 & España & 5 & Italia & 5 \\
\hline Polonia & 6 & Bulgaria & 6 & Estonia & 6 & Letonia & 6 \\
\hline España & 7 & Italia & 7 & Polonia & 7 & Bulgaria & 7 \\
\hline Hungría & 8 & Hungría & 8 & Lituania & 8 & Lituania & 8 \\
\hline Letonia & 9 & Rumania & 9 & OECD media & 9 & Rumania & 9 \\
\hline Países Bajos & 10 & Letonia & 10 & Alemania & 10 & Austria & 10 \\
\hline Bulgaria & 11 & OECD media & 11 & Rumania & 11 & Noruega & 11 \\
\hline Bélgica & 12 & Eslovenia & 12 & Eslovenia & 12 & Luxemburgo & 12 \\
\hline Grecia & 13 & Lituania & 13 & Italia & 13 & Alemania & 13 \\
\hline Albania & 14 & Estonia & 14 & Eslovaquia & 14 & Países Bajos & 14 \\
\hline Francia & 15 & Eslovaquia & 15 & Luxemburgo & 15 & España & 15 \\
\hline OECD media & 16 & Alemania & 16 & República Checa & 16 & OECD media & 16 \\
\hline Reino Unido & 17 & Luxemburgo & 17 & Portugal & 17 & Suiza & 17 \\
\hline Noruega & 18 & Países Bajos & 18 & Países Bajos & 18 & Eslovenia & 18 \\
\hline Alemania & 19 & Francia & 19 & Hungría & 19 & Dinamarca & 19 \\
\hline Luxemburgo & 20 & Irlanda & 20 & Reino Unido & 20 & Estonia & 20 \\
\hline Austria & 21 & Austria & 21 & Suiza & 21 & Reino Unido & 21 \\
\hline Dinamarca & 22 & República Checa & 22 & Irlanda & 22 & República Checa & 22 \\
\hline Suiza & 23 & Reino Unido & 23 & Francia & 23 & Grecia & 23 \\
\hline Portugal & 24 & Suiza & 24 & Austria & 24 & Francia & 24 \\
\hline Eslovenia & 25 & Bélgica & 25 & Bélgica & 25 & Eslovaquia & 25 \\
\hline Suecia & 26 & Noruega & 26 & Suecia & 26 & Portugal & 26 \\
\hline Eslovaquia & 27 & Suecia & 27 & Noruega & 27 & Irlanda & 27 \\
\hline República Checa & 28 & Dinamarca & 28 & Dinamarca & 28 & Bélgica & 28 \\
\hline Finlandia & 29 & Finlandia & 29 & Finlandia & 29 & Finlandia & 29 \\
\hline
\end{tabular}

Notas: 1] Clases de refuerzo organizadas por una empresa privada y costeada por los progenitores. 2] Estudio con algún progenitor u otro miembro de la familia

La tabla 5 por su parte nos muestra, para las CCAA participantes en PISA 2012 con muestra suficiente, que la materia que más apoyo extraescolar requiere son las matemáticas seguidas de las ciencias naturales y la lengua [excepto para Catalunya en la que estas dos últimas invierten el orden]. El apoyo en otras materias tampoco presenta valores desdeñables situándose en valores por lo general por debajo de las matemáticas excepto en el caso del País Vasco, Catalunya, Navarra y Madrid en las que supera al apoyo recibido en matemáticas.

Este amplio recurso a los deberes, las tutorizaciones y las clases de repaso significa que el alumnado requiere una mayor carga de trabajo de la establecida como tiempo de enseñanza teórica, que como hemos señalado anteriormente es en el caso español una de las más altas. Además, en el caso español, el acceso a estos recursos educativos extraordinarios depende del nivel socioeconómico de las familias y no de las necesidades objetivas del alumnado, lo que reduce aún más la equidad del sistema. 
Gráfico 21: Tiempo de aprendizaje de las y losestudiantes en la escuela y después de la escuela. Fuente: OECD (2013)

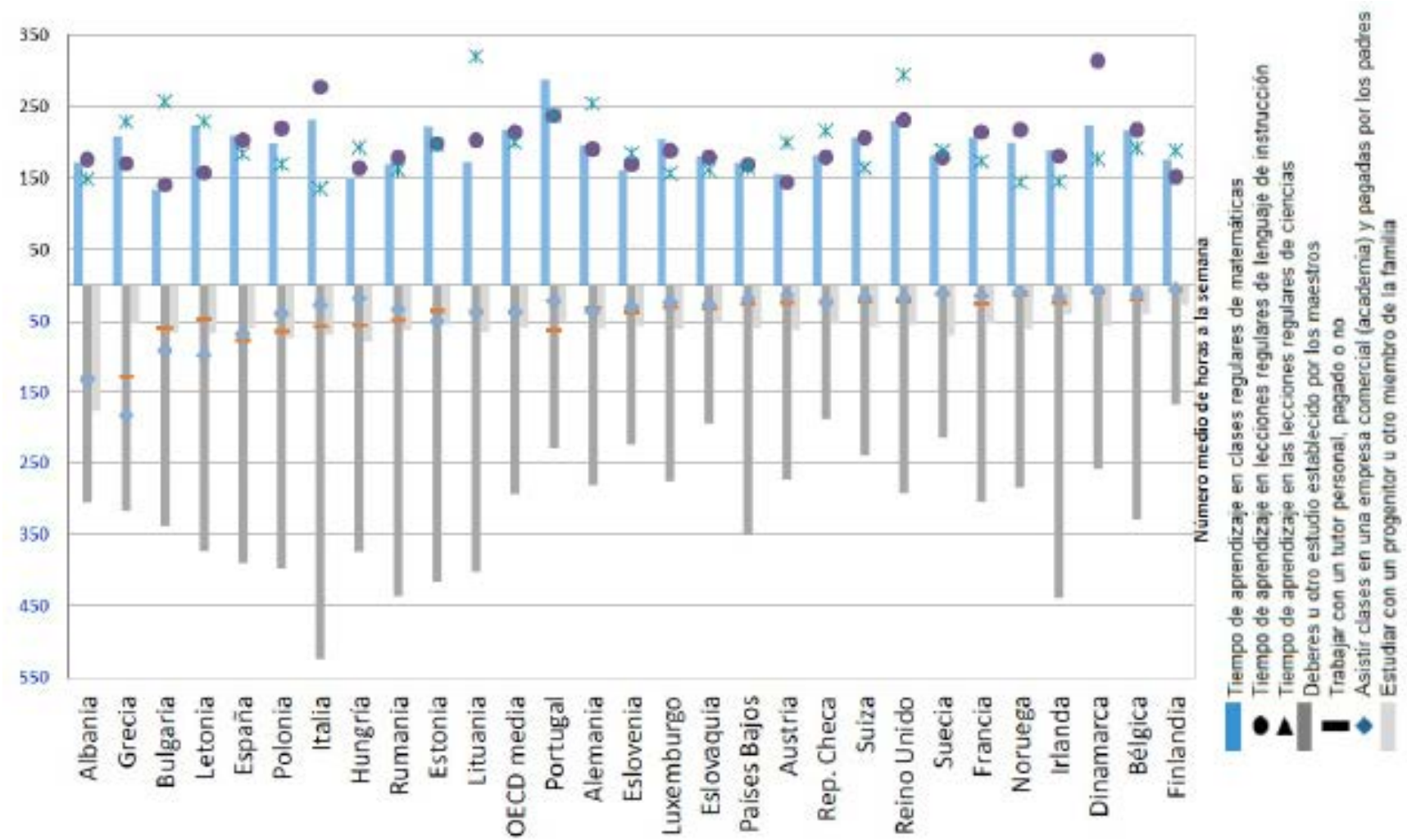

Tabla 5: Porcentaje de estudiantes que asisten a clases después de la escuela por CCAA, 2012. Fuente: elaboración propia a partir de OECD (2013)

\begin{tabular}{l|r|r|r|r|r} 
& Matemáticas & Lengua & Ciencias & $\begin{array}{r}\text { Otras } \\
\text { materias }\end{array}$ & Media \\
\hline Cantabria & 52,7 & 26,8 & 32,8 & 48,0 & 40,1 \\
\hline Asturias & 55,4 & 23,1 & 35,6 & 44,9 & 39,8 \\
\hline País Vasco & 41,8 & 22,5 & 30,2 & 59,9 & 38,6 \\
\hline Galicia & 49,9 & 19,6 & 32,4 & 38,0 & 35,0 \\
\hline La Rioja & 47,1 & 16,6 & 26,6 & 43,1 & 33,3 \\
\hline Illes Balears & 44,8 & 21,7 & 26,4 & 39,8 & 33,2 \\
\hline Extremadura & 42,1 & 22,0 & 28,6 & 34,6 & 31,8 \\
\hline Navarra & 40,5 & 18,2 & 22,5 & 44,3 & 31,4 \\
\hline Castilla León & 45,6 & 19,2 & 22,6 & 37,8 & 31,3 \\
\hline Murcia & 41,8 & 22,0 & 24,8 & 32,1 & 30,2 \\
\hline Aragón & 38,9 & 16,6 & 25,4 & 39,6 & 30,1 \\
\hline Andalucía & 38,6 & 20,5 & 23,6 & 33,1 & 29,0 \\
\hline Madrid & 34,3 & 15,5 & 20,6 & 37,1 & 26,9 \\
\hline Cataluña & 29,9 & 17,8 & 14,9 & 44,2 & 26,7
\end{tabular}


El sistema educativo español se caracteriza por un alto grado de repetición a pesar de ser un elemento cuyo utilidad está ampliamente discutida. La repetición además se vincula con la falta de equidad. El abandono escolar temprano es otra de las características del sistema español junto al amplio recurso a los deberes, las tutorizaciones y las clases de repaso, lo que denota el uso ineficiente del tiempo escolar.

\subsection{Comparativa a nivel de CCAA}

En el contexto de las reformas educativas de los años 90 en el Estado español (LOGSE de 1990 y LOPEGCE de 1995] se comienza en algunas CCAA a replantear la organización horaria de la jornada lectiva a fin de compactarla en horario matinal. Este proceso de compactación horaria que anteriormente se había dado excepcionalmente por cuestiones de fuerza mayor (falta de instalaciones que obligaban a doble turno, escuelas rurales alejadas de los domicilios de los alumnos, etc.] comienza entonces a implantarse. Es importante retener que la compactación surge como una demanda laboral del profesorado y no como una innovación de mejora docente. Otros autores han descrito ya detalladamente los intereses, las estrategias, las tensiones y los procedimientos que se han seguido para la progresiva implantación de la jornada continua en el Estado español [Fernández Enguita, 2001] por lo que remitimos a dichos trabajos a quien desee ampliar información. Nosotros en esta guía nos centramos en la descripción de los datos disponibles que permiten ahondar en la mejor comprensión de la relación entre organización del tiempo escolar y el rendimiento del alumnado. Su extensión se produce primero en los centros de educación Secundaria de titularidad pública, en los que a día de hoy es el modelo imperante, y algo después de manera regionalizada por CCAA pasa a los centros, de Educación Primaria e incluso de Infantil también de titularidad pública [ver gráfico 22].

Como se muestra en el gráfico $22^{14}$, y según datos de ANPE [Sindicado Independiente de Docentes], la extensión de este modelo a las etapas de Primaria e Infantil se inicia en las Islas Canarias [1992] y en Galicia [1993] siguiéndole algunos años después Andalucía [1999], CastillaLa Mancha y Castilla León [ambas en 2001], les Illes Balears [2002], Asturias, Extremadura y Murcia [las tres en 2004], Madrid [2005], La Rioja [2006], Navarra [2007]. Más recientemente, en 2016 se ha regulado tanto en el País Valencià como en Aragón. Quedan por tanto tres CCAA, Cantabria, Catalunya y el País Vasco que no la han regulado, y que por tanto de darse algún centro se debe bien a las condiciones de excepcionalidad antes descritas, o a una suerte de "proyecto piloto" o "experimental" que se ha dado ocasionalmente en otras CCAA antes de su regulación15

\footnotetext{
14. La plantilla base del gráfico se ha extraído de http://analisisydecision.es/trucos-excel-mapa-de-espana-por-comunidadesautonomas/

${ }^{15}$ Los datos aquí presentados se han obtenido del documento de ANPE titulado "LA JORNADA ESCOLAR EN LA ESCUELA PÚBLICA" de 2010 recuperado de http://www.anpe.es/Html/pdf/r530/20 21\%20INFORMACION\%20PROFESIONAL.pdf

A fin de actualizar los datos se realizaron consultas a todas las consejerías de educación de las diferentes CCAA el 7 de octubre de 2016, habiendo obtenido datos, hasta la fecha, de Aragón, de les llles Balears, del Gobierno Vasco y de la Comunidad Valenciana. A todas ellas agradecemos su colaboración.
} 
Gráfico 22. Grado de implantación de la jornada continua escolar en los centros públicos. Fuente: elaboración propia a partir de ANPE y consejerías de educación 12, 13, 14

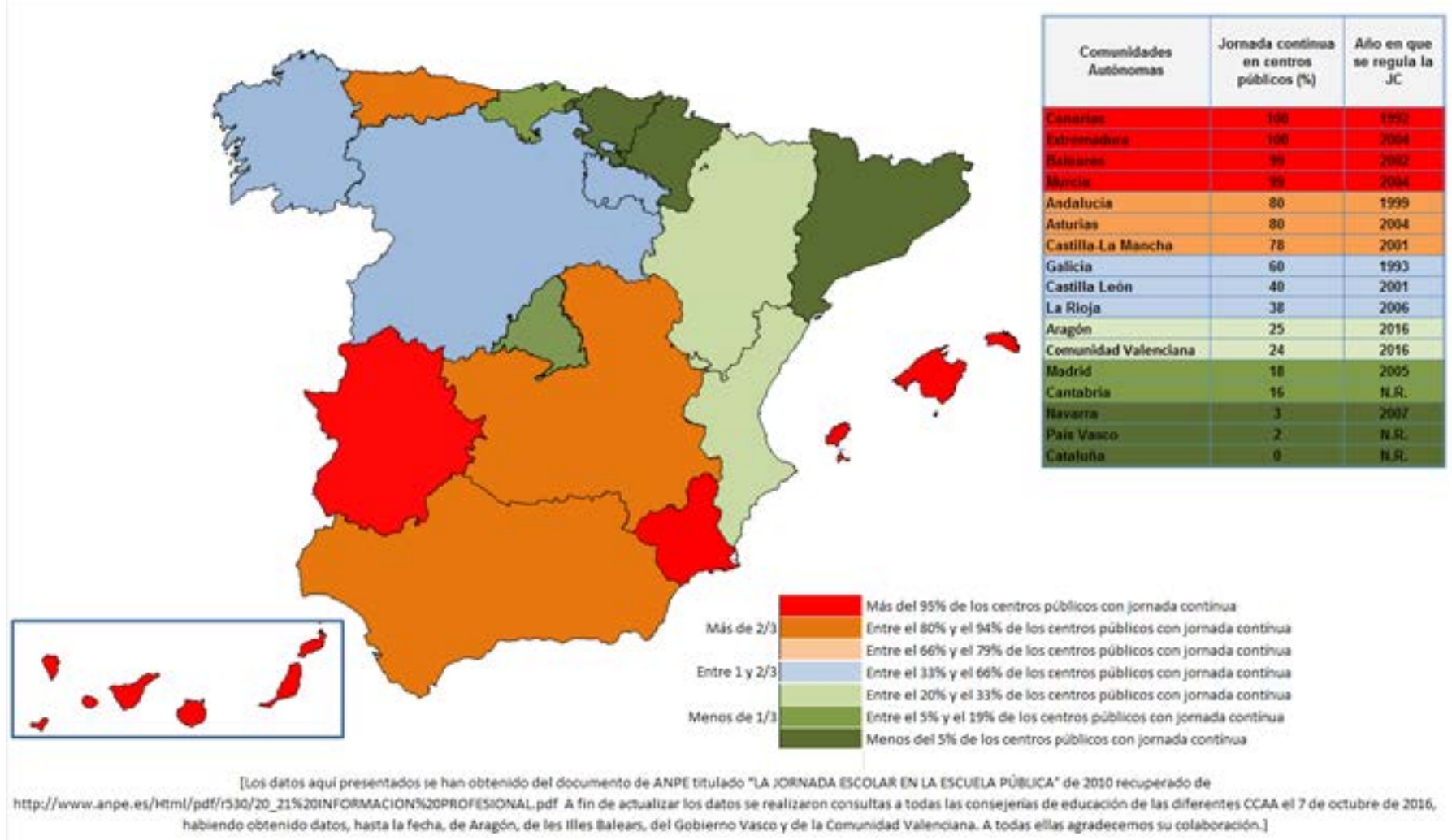

Como decíamos, la motivación de este cambio en la organización de la jornada lectiva es de tipo laboral, lo que explica su relativo éxito en el conjunto de la escuela pública y su escasa presencia en la privada y concertada ${ }^{16}$. El grado de implantación de la misma, aunque altamente correlacionado con los años en vigor de la normativa [ $R=0$ '72] es variable como se muestra en el gráfico 22, siendo su implantación en la enseñanza pública prácticamente universal en Balears, Canarias, Extremadura y Murcia [99-100\%], muy elevada en Andalucía, Asturias y Castilla La Mancha [entorno al 80\%] algo más moderada en Galicia [60\%], Castilla León [40\%] y La Rioja [38\%], y con una implantación menor en Aragón [25\%] y País Valencià [24\%] aunque notable dada la todavía reciente normativa en estas dos CCAA, y menor aún en la Comunidad de Madrid [18\%] y Cantabria [16\% aun no estando regulada]. Siendo prácticamente inexistente en Navarra [3\%, aun estando regulada], en el País Vasco [2\%] y Catalunya [inexistente].

\footnotetext{
${ }^{16}$ Se han realizado sendas consultas a la Confederación Española de Centros de Enseñanza y a CICAE - Asociación de colegios privados e independientes el 9 de noviembre de 2016, de momento sin respuesta.
} 
Como ya indicábamos al inicio de esta guía, la falta de estudios oficiales más precisos sobre la relación entre el tipo de jornada y rendimiento académico, tras más de dos décadas de su implantación, es un síntoma, ciertamente lamentable, de lo poco que importa rendir cuentas de lo que se hace en educación, situándonos en las antípodas de las reformas educativas basadas en la evidencia (evidence-basededucationalpolicy). Esta falta de datos nos obliga a aproximarnos a esta cuestión de una manera mucho menos precisa de lo que hubiéramos deseado. En la tabla 6 se presenta un resumen de los datos de los que disponemos para, a modo exploratorio, indagar en la relación entre la implantación de la jornada continua y el rendimiento académico. En ella aparecen tan sólo las CCAA que participaron en PISA 2012 con un tamaño muestral suficiente como para realizar inferencias de los resultados de su alumnado.

En la tabla 6 se aprecia así mismo que en todas las áreas y en todas las CCAA la enseñanza pública puntúa en PISA-2012 por detrás de la enseñanza concertada, y esto es más evidente tanto en aquellas CCAA en las que la implantación de la jornada continua tiene mayor alcance [Balears, Extremadura o Murcia] como en aquellas CCAA en las que existe menos cuota de enseñanza pública [País Vasco, Madrid, Navarra y Catalunya).

Tabla 6. Implantación de la jornada continua escolar en los centros públicos y diferencial pública - privada en pruebas PISA 2012. Fuente: elaboración propia a partir de ANPE (2010) y OECD [2013)

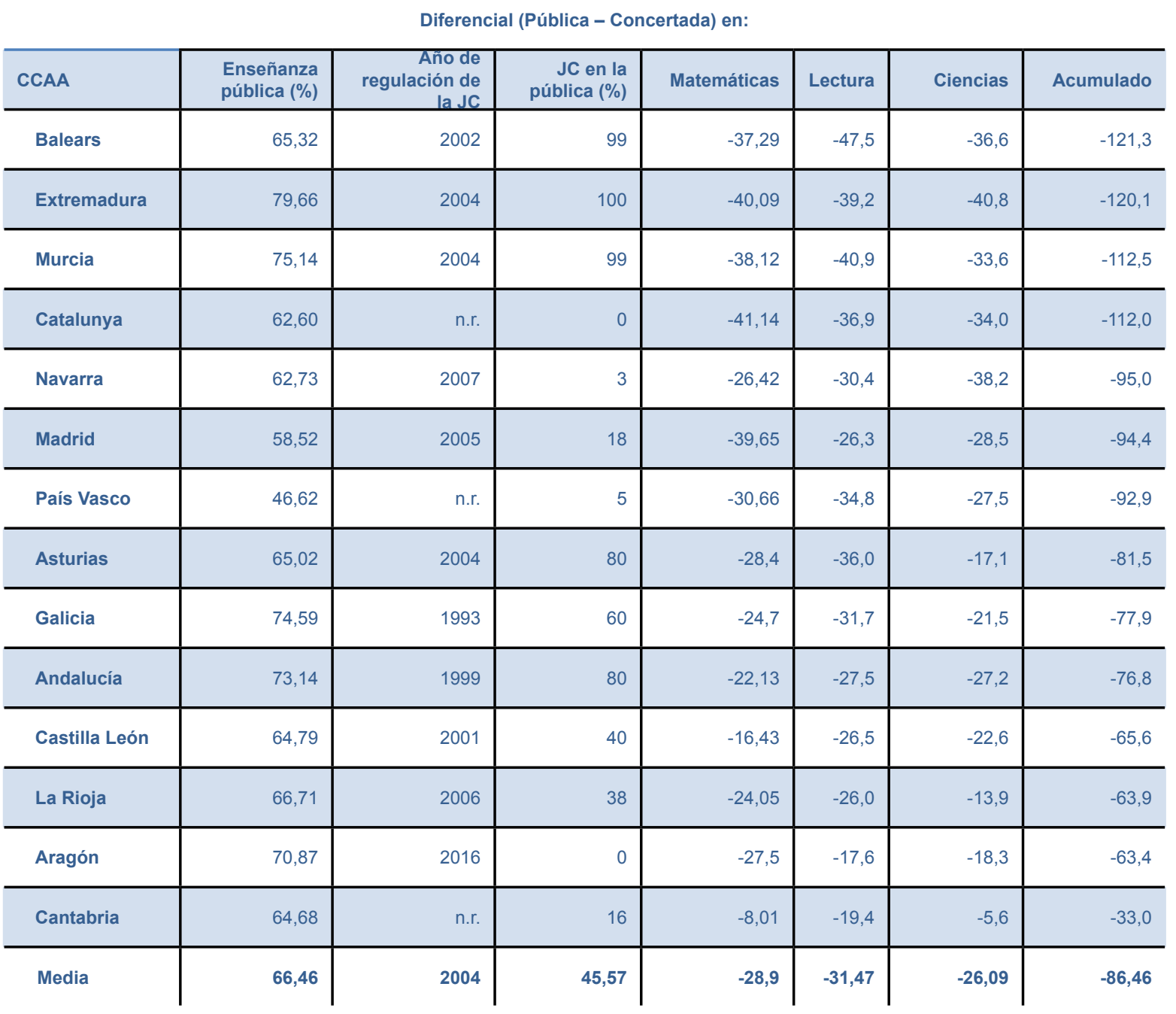




\section{Gráfico 23. Implantación de la jornada continua escolar en los centros públicos y diferencial pública - privada/concertada en pruebas PISA 2012. Fuente: elaboración propia a partir de ANPE (2010) y OECD (2013)}

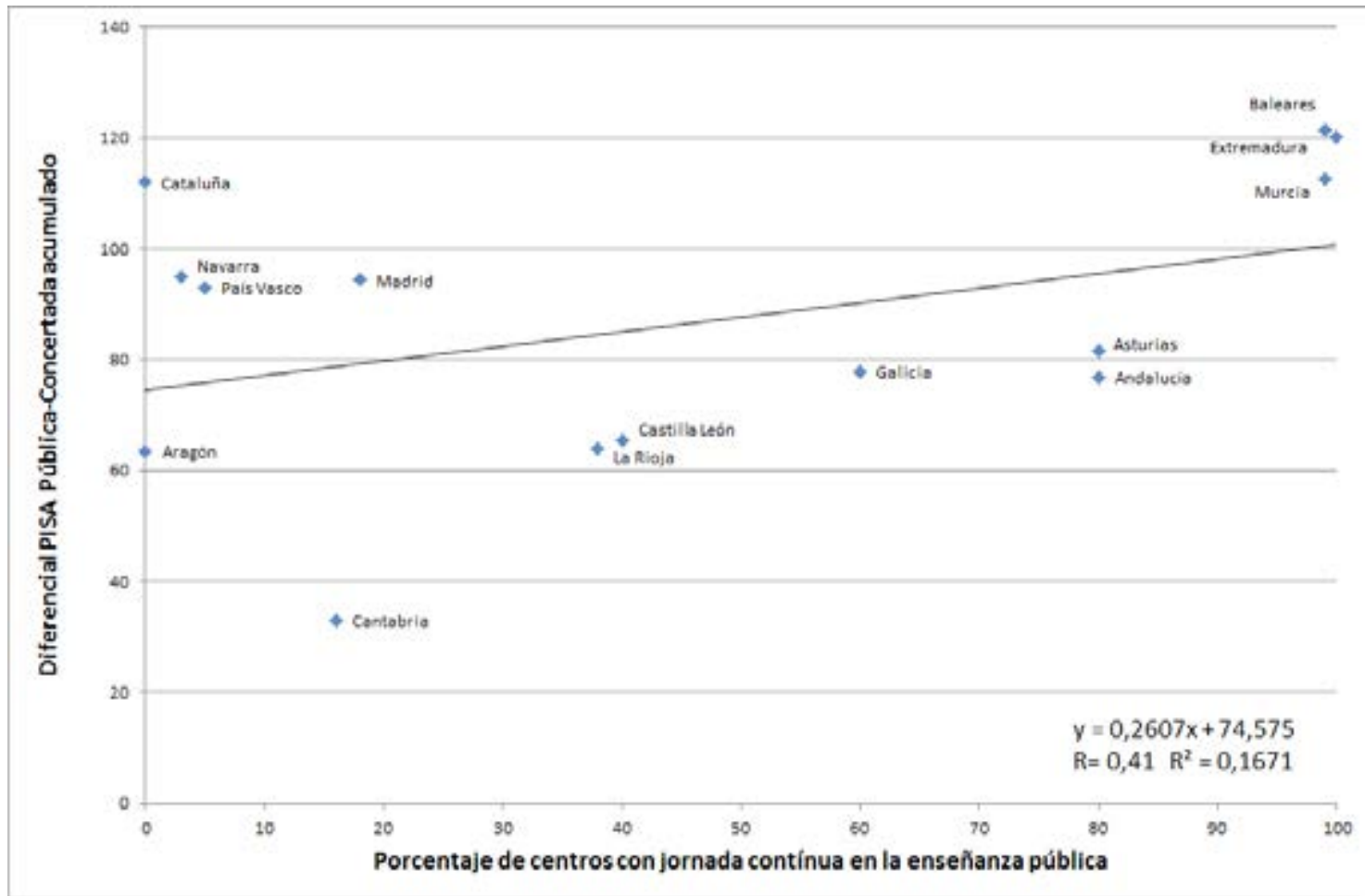

Asumiendo que en la mayoría de las CCAA los centros que optan por la jornada continua son de titularidad pública, y a falta de mejores datos, en el gráfico 23 correlacionamos el porcentaje de centros con jornada continua en la enseñanza pública con el diferencial pública - privada/ concertada en la prueba PISA-2012.

La regresión del gráfico 23 sugiere una correlación positiva ${ }^{17}$ elevada [0'41] entre tener una mayor implantación de la jornada continua en la enseñanza pública y que el diferencial público privada sea mayor. Se trata de un ejercicio de exploración, dado que la correlación no prueba la causalidad de una relación ni tampoco despeja otras posibles variables que pudieran influir en la relación. En nuestro caso, sin poder descartar la influencia de otras variables, podemos indicar a priori que 1] bien aquellas CCAA que tienen mayor implantación de la jornada continua obtienen resultados en PISA peores en términos relativos en la enseñanza pública a los que se obtienen en esas mismas CCAA en la enseñanza concertada; o 2] que aquellas CCAA en las que los resultados son peores en la enseñanza pública en términos relativos, han implantado en mayor medida la jornada continua.

\footnotetext{
${ }^{17}$ Como hemos visto en la tabla 6 la diferencia siempre es a favor de la privada/concertada, en el gráfico 23 esta diferencia se muestra en valores absolutos para facilitar su lectura. Está ampliamente documentado que las diferencias entre los rendimientos de la pública y la privada/concertada se deben a diferencias en la composición social de ambos grupos. La diferente distancia entre ellos por comunidades autónomas podría no obstante guardar relación con el diferente grado de extensión de la jornada continua. Este último extremo ha de tomarse con cautela porque los datos disponibles no permiten verificarlo ni cuantificarlo.
} 
Gráfico 24. Implantación de la jornada continua escolar en los centros públicos y repetidores. Fuente: elaboración propia a partir de ANPE (2010) y OECD (2013)

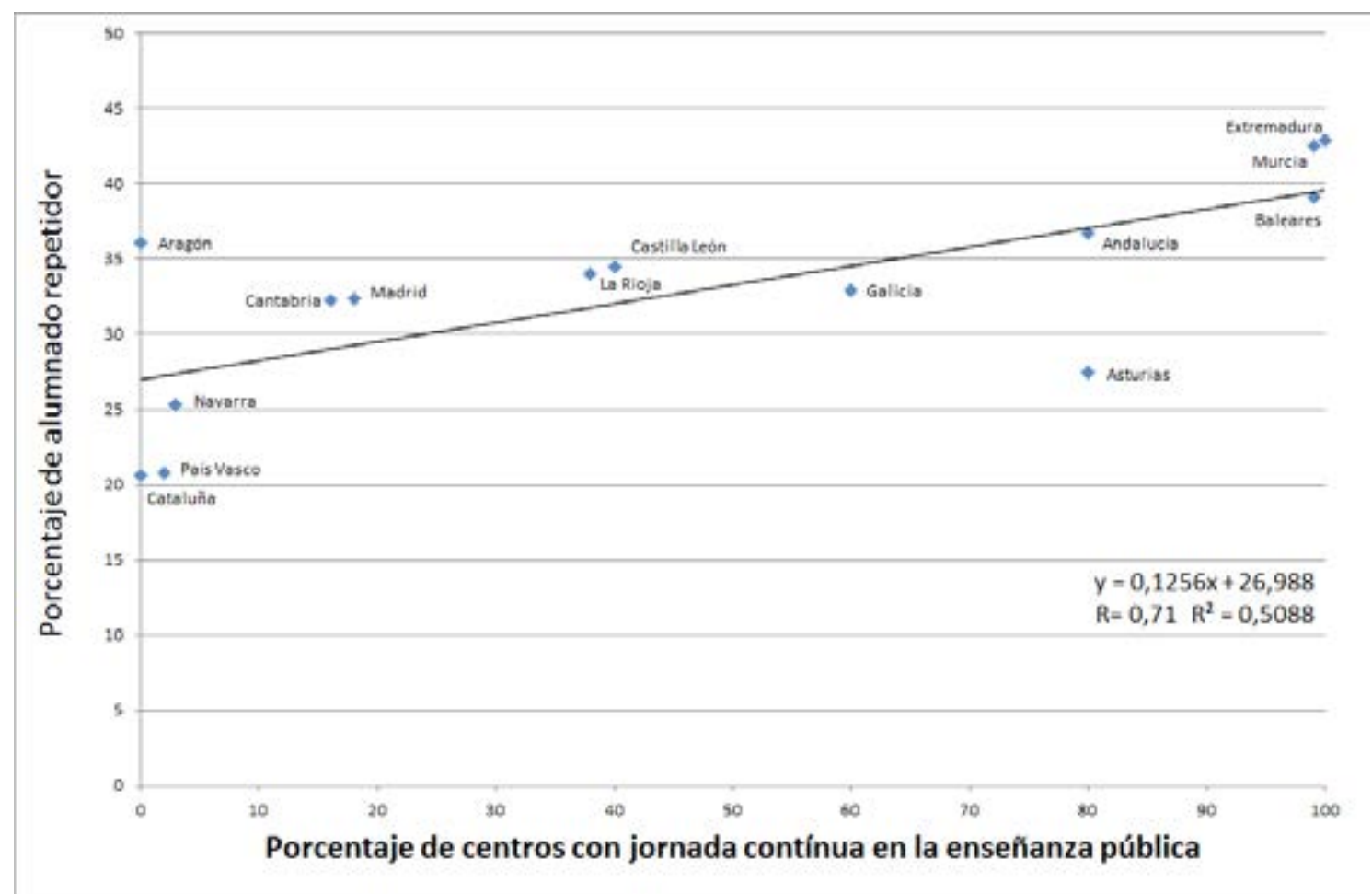

En el gráfico 24 relacionamos el porcentaje de centros con jornada continua en la enseñanza pública [según datos de ANPE 2010) con el porcentaje acumulado de repetidores en cada CCAA ofrecidos por PISA 2012 [OECD, 2013]. De nuevo la regresión indica una correlación positiva muy elevada [ $R=0$ '71] entre tener una mayor implantación de la jornada continua en la enseñanza pública y contar con un número mayor de repetidores. De nuevo también, dado que la correlación no prueba la causalidad de una relación ni tampoco despeja otras posibles variables que pudieran influir en esta correlación. En nuestro caso, sin poder descartar la influencia de otras variables, podemos indicar a priori que o bien aquellas CCAA que tienen mayor implantación de la jornada continua generan más repetidores; o bien que aquellas CCAA con más repetidores implantan en mayor medida la jornada continua.

De cualquier modo, y aunque los resultados aquí presentados deben tomarse con muchas cautelas $^{18}$, podemos señalar que existen indicios que apunta a una posible relación entre tipo de jornada escolar y rendimiento académico.

Para el caso valenciano contamos con el informe que realizó la propia Comisión de Seguimiento del Programa Experimental de la Jornada Continua en 2015, que publico la revista Magisterio ${ }^{19}$, y en el que alertaban de que ocho de los nueve centros piloto que aplicaron la jornada continua el curso anterior habían descendido la puntuación de su alumnado en las pruebas diagnósticas.

\footnotetext{
${ }_{18}$ Hemos requerido la información tuvieran disponible sobre este asunto a la OCDE, en particular hemos escrito al coordinador del Review of Policies to ImprovetheEffectiveness of Resource Use in Schools (SchoolResourcesReview) de momento sin respuesta.

${ }^{19}$ El artículo completo se encuentra en la página 14 de la edición Comunidad Valenciana de la revista Magisterio de fecha 08/04/2015 disponible en: https://issuu.com/gruposiena/docs/12055valencia?e=8701546/12227836
} 


\section{Figura 1: Extractola revista Magisterioedición Comunidad Valenciana de la revista Magisterio de fecha 08/04/2015 \\ Evaluación centros con continua}

Resultados de los nueve centros que la implantaron en 2013-14

\begin{tabular}{lccc} 
Tipo de conducta & Eval. 2014 & Eval. 2013 & Dif. \\
\hline Centro público A & 485,37 & 453,96 & 31,41 \\
\hline Centro público B & 392,13 & 402,44 & $-10,31$ \\
\hline Centro público C & 359,41 & 373,19 & $-13,78$ \\
\hline Centro público D & 361,86 & 376,31 & $-14,45$ \\
\hline Centro público E & 543,16 & 570,64 & $-27,48$ \\
\hline Centro público F & 386,59 & 416,56 & $-29,97$ \\
\hline Centro público G & 423,39 & 465,1 & $-41,71$ \\
\hline Centro público H & 441,6 & 545,03 & $-103,43$ \\
\hline Centro público I & 482,82 & 606,33 & $-123,51$ \\
\hline
\end{tabular}

Fuente: Comisión de Seguimiento del Programa Experimental de la Jornada Continua.

En consecuencia, la mencionada comisión, en fecha 16 de marzo de 2014 recomendaba la no extensión del programa.

Más aún, la evaluación del programa realizada en el curso 2015/2016 muestra que, a pesar de que las notas del profesorado de los centros en los que se implementa la continua son más elevadas, las de las pruebas diagnósticas son más ligeramente más bajas 14'64 puntos de media, lo que podría ser indicativo de un efecto placebo [esto es, que el rendimiento baja objetivamente pero el profesorado subjetivamente entiende que sube]. Por otro lado la tabla también indica que si bien la matricula no se resiente, al menos de momento, los usuarios del servicio de comedor se desploma un 30\% en los centros tras la implantación de la jornada continua.

La jornada escolar continua lleva extendiéndose de manera muy irregular por el territorio español desde hace un cuarto de siglo, especialmente en centros de titularidad pública. Una mayor tasa de adopción de este tipo de jornada se vincula con regiones en las que hay un peor resultado académico y mayor repetición de curso. 
Figura 2: Evaluación del programa experimental de jornada continua 20152016. Extracto la revista Magisterio edición Comunidad Valenciana de fecha 21/02/2017

\begin{tabular}{|c|c|c|c|c|c|c|c|c|c|c|}
\hline \multirow[b]{2}{*}{ Colegjo Públlco } & \multirow[b]{2}{*}{ Localldad } & \multicolumn{3}{|c|}{ Evaluación Dlagnóstica } & \multicolumn{3}{|c|}{ Solicitudes Matricula } & \multicolumn{3}{|c|}{ Usuarios comedor/mes } \\
\hline & & 2014 & 2013 & Difer. & 2015-16 & Curso Jp & Dif. \% & 2015-16 & Curso Jp & Dif. \% \\
\hline NdSra. de la Paz & Alicante & 386,39 & 416,56 & $-29,9 /$ & 246 & 203 & 20,00 & 41,10 & 49,88 & $-1 /, 60$ \\
\hline Acurín & Caural & 482,82 & 606,33 & $-123,51$ & 927 & 922 & 0,54 & 179,77 & 231,00 & $-22,18$ \\
\hline Antonio Machado & Clda & 543,16 & 570,64 & $-27,48$ & 470 & 411 & 14,36 & - & - & - \\
\hline Rajoletes & San Juan & 123,39 & 165,10 & $-11,71$ & 503 & 183 & 1,11 & 225,01 & 290,88 & $-22,63$ \\
\hline Dean Martí & Oropesa & 441,60 & 545.03 & -103.43 & 380 & 371 & 2,43 & 61,07 & 104.38 & -41.49 \\
\hline La Mediterrània & Oropesa & 361,86 & 376,31 & $-14,45$ & 360 & 315 & 14,29 & 135,06 & 125,50 & 7,62 \\
\hline Cofrentes & Cofrentes & 485,37 & 453,96 & 31,41 & 50 & 45 & 11,11 & - & - & - \\
\hline Miguel de Cervantes & Paterna & 359,41 & 373,19 & $-13,78$ & 212 & 262 & $-19,08$ & 129,85 & 224,88 & $-42,26$ \\
\hline LopedeVega & Torrent & 392,13 & 402,44 & $-10,31$ & 334 & 387 & $-13,70$ & 149,35 & 106,25 & 40,56 \\
\hline Iotal 2013-14 & & 430,10 & $46 /, 13$ & $-3 /, 03$ & 3.482 & 3.401 & 2,38 & 921,24 & $1.132, / 1$ & $-18,6 /$ \\
\hline Virgerı del Rernedio & Alicante & 350,30 & 337,61 & 12,69 & 195 & 194 & 0,52 & 146,66 & 172,50 & $-14,98$ \\
\hline L'Albufereta & Alicante & 577,76 & 515,80 & 61,80 & 499 & 511 & $-2,35$ & 249,29 & 382,00 & $-34,74$ \\
\hline LaAlmadraba & Alicante & - & - & & 308 & 209 & 17,37 & 175,31 & 151,00 & 13,81 \\
\hline RafaelAlitamira & Alicante & 511,14 & 443,25 & 67,89 & 405 & 378 & 7.14 & 137.98 & 20,63 & -37.74 \\
\hline San Nicolás de Bari & Alicante & 505,33 & 459.00 & 46.33 & 232 & 235 & -1.28 & 71.09 & 131.88 & -46.09 \\
\hline Aitana & Benidorm & 466,50 & 602,24 & $-135,74$ & 181 & 162 & 11,73 & 45,66 & 78,25 & $-41,65$ \\
\hline Leonor Canalejas & Benidorm & & 443,76 & $-48,72$ & 461 & & 6,71 & 155,40 & 227,63 & $-31,73$ \\
\hline José Marfa Paternina & Daya Nueva & 520,71 & 411,86 & 108,85 & 162 & 173 & $-6,36$ & - & - & - \\
\hline Pintor Sorolla & Elda & 408,02 & 502,67 & $-94,65$ & 471 & 536 & $-12,13$ & 133,81 & 209,63 & $-36,17$ \\
\hline Juan CarlosI & form. del Seg. & 433,09 & 480,60 & $-4 /, 31$ & 286 & 293 & -3, US & - & - & - \\
\hline MartínArtigot & Pilar de la H. & 470,78 & 486,78 & $-16,00$ & 461 & 412 & 11,89 & - & - & - \\
\hline Sant $R \propto c$ & Polop & 458,52 & 445,57 & 12,95 & 383 & 341 & 12,32 & 195,94 & 210,38 & 6,86 \\
\hline Dina. Vicenta Ruso & Santa Pola & - & - & - & 846 & 714 & 18,49 & 385,68 & 501,50 & $-23,09$ \\
\hline Cristo de la Paz & San Juan & 533,85 & 471,71 & 62,14 & 463 & 458 & 1.09 & 201,07 & 283.25 & -29.01 \\
\hline Lo Romero & Sanjuan & 439,98 & 459,95 & $-19,97$ & 423 & 424 & $-0,24$ & 160,92 & 380,00 & $-57,65$ \\
\hline Cuba & Torrevieja & 498,27 & 579,75 & $-81,48$ & 463 & 462 & 0,22 & 177,23 & 238,38 & $-25,65$ \\
\hline Ruperto Chapi & Villena & 457,40 & 536,48 & $-79,08$ & 588 & 576 & 2,08 & 111,93 & 162,00 & $-30,91$ \\
\hline Graüll & Javea & 587,52 & 623,99 & $-36,47$ & 380 & 405 & $-6,17$ & 71,39 & 164,88 & $-56,70$ \\
\hline Vicentelena & Javea & 421,33 & 304,02 & $-82,49$ & $3 / 0$ & $3 / 1$ & $-0,21$ & 11,28 & $1 / /, 88$ & $-36,5 b$ \\
\hline Verge dels Desemparals & Olivd & 616,97 & 611,55 & 5,42 & 248 & 249 & $-0,40$ & 59,17 & 87,75 & $-32,57$ \\
\hline Antonio Ferrandis & Paterna & 283,01 & 329,09 & $-46,08$ & 107 & 123 & $-13,01$ & 82,34 & 93,50 & $-11,94$ \\
\hline CiudadArtista Fallero & Valencia & 185,96 & 169,83 & 16,13 & 285 & 296 & $-3,72$ & 113,68 & 118,75 & $-3,11$ \\
\hline Total 2014-15 & & 471,08 & 485,78 & $-14,69$ & 8.217 & 7.956 & 3.28 & 2.781 .33 & 4.007 .79 & -30.60 \\
\hline
\end{tabular}

Fuente: Informe Sobre Jornada Escolar. Curso 2015-16. Conselleria de Educaci6n de la Generalitat Valenciana.

NUIA: En negrita, datos retendos a arsos en los quela jornaca continuaya estaba implantada.

- CURSO P. Serefiereal dato del último arrso en la que el centro tuvo jornada partida: 2012-13 para los primeros 9 centros; curso 2013-14 para el resto decentros. 


\title{
5.2. Comparativa a nivel europeo
}

Según la OCDE [2016] en base a las horas anuales de enseñanza y el número de días de enseñanza por año, los estudiantes de primaria tienen menos de cuatro horas de enseñanza obligatoria por día escolar en un tercio de los países, pero más de cinco en otros países (en el caso de Europa se trata de Dinamarca, Francia y Luxemburgo]. En el nivel de secundaria inferior [ESO] el número de horas de enseñanza obligatoria por día suele ser más elevado, con un tercio de los países a menos de cinco horas al día, y Dinamarca, Francia y España con seis horas o más por día.

En cuanto a la organización de los descansos la OCDE indica que:

"El aprendizaje en el aula exige que el estudiantado se centren y se concentren durante largos períodos de tiempo. De acuerdo con la OCDE [2016] pasar algún tiempo fuera del aula durante el día escolar en actividades que no sean de enseñanza puede ayudar a mejorar el rendimiento del estudiantado en el aula. En la educación primaria, las pausas en la enseñanza permiten al alumnado jugar, descansar e interactuar libremente con sus compañeras y compañeros para desarrollar habilidades cognitivas, emocionales y sociales. Las investigaciones sugieren que el estudiantado pueden aplicar esas habilidades en el aula, mejorando así su aprendizaje [Pellegrini y Bohn, 2005, Pellegrini et al., 2002]" [OCDE, 2016:385].

También indica que los países de la OCDE consideran cada vez más los recesos y las rupturas como componentes importantes de la jornada escolar:

\begin{abstract}
"En la mayoría de los países, la jornada escolar se divide en lecciones que duran de 45 a 50 minutos, permitiendo breves descansos entre ellos que completan una hora entera. En los países de la OCDE, las pausas de 10 a 15 minutos son generalmente lo suficientemente largas como para permitir a los estudiantes cambiar de aula y visitar el baño. Estas breves pausas son diferentes en longitud y propósito de las pausas más largas también observadas en la mayoría de los países. Durante las pausas más largas, los estudiantes pueden tomar el almuerzo o la comida y son comúnmente supervisados por una o un docente o grupo de docentes" [OCDE, 2016:385].
\end{abstract}

En la educación primaria, las pausas largas son comunes y, en algunos casos, son incluso obligatorias (como en el Estado español, donde el recreo en la escuela primaria se considera parte del tiempo obligatorio de enseñanza]. En varios países además existe "una pausa para la comida que se establece como parte del proceso de aprendizaje, donde los estudiantes aprenden sobre higiene, hábitos alimenticios saludables y/o reciclaje de residuos"'[OCDE, 2016:385].

\begin{abstract}
"En varios países, se pueden encontrar largas pausas en todos los niveles educativos [...] En Suiza, por ejemplo, las escuelas suelen organizar dos descansos de unos 20 minutos cada uno y una larga pausa para el almuerzo de unos 60 a 90 minutos [...] Las escuelas pueden usar el recreo y los descansos para diferentes propósitos. [...] En Dinamarca, los municipios a menudo utilizan las pausas y los recreos como parte integrante del ejercicio diario y actividades físicas para los estudiantes de todos los cursos. Este es también el caso en Eslovenia, donde las escuelas a veces organizan una larga pausa destinada a los estudiantes a practicar deportes en el gimnasio y en los campos de juego de la escuela" [OCDE, 2016:386].
\end{abstract}

Para realizar el gráfico 25, hemos recurrido a las descripciones recogidas en Eurydice ${ }^{20}$. Como a diferentes edades el alumnado puede tener horarios diferentes, en negro se representan las horas en las que todo el alumnado se encuentra en clase, en gris oscuro las horas en las que el alumnado más mayor sigue en clase pero las y los más jóvenes ya han salido. En gris claro representamos las horas que están cubiertas con otras actividades y en verde las horas de comida.

${ }^{20}$ https://webgate.ec.europa.eu/fpfis/mwikis/eurydice/index.php/Primary Education 


\section{Gráfico 25. Organización de la jornada escolar de educación primaria en Europa (2016). Fuente: Elaboración propia a partir de Eurydice 2016.}
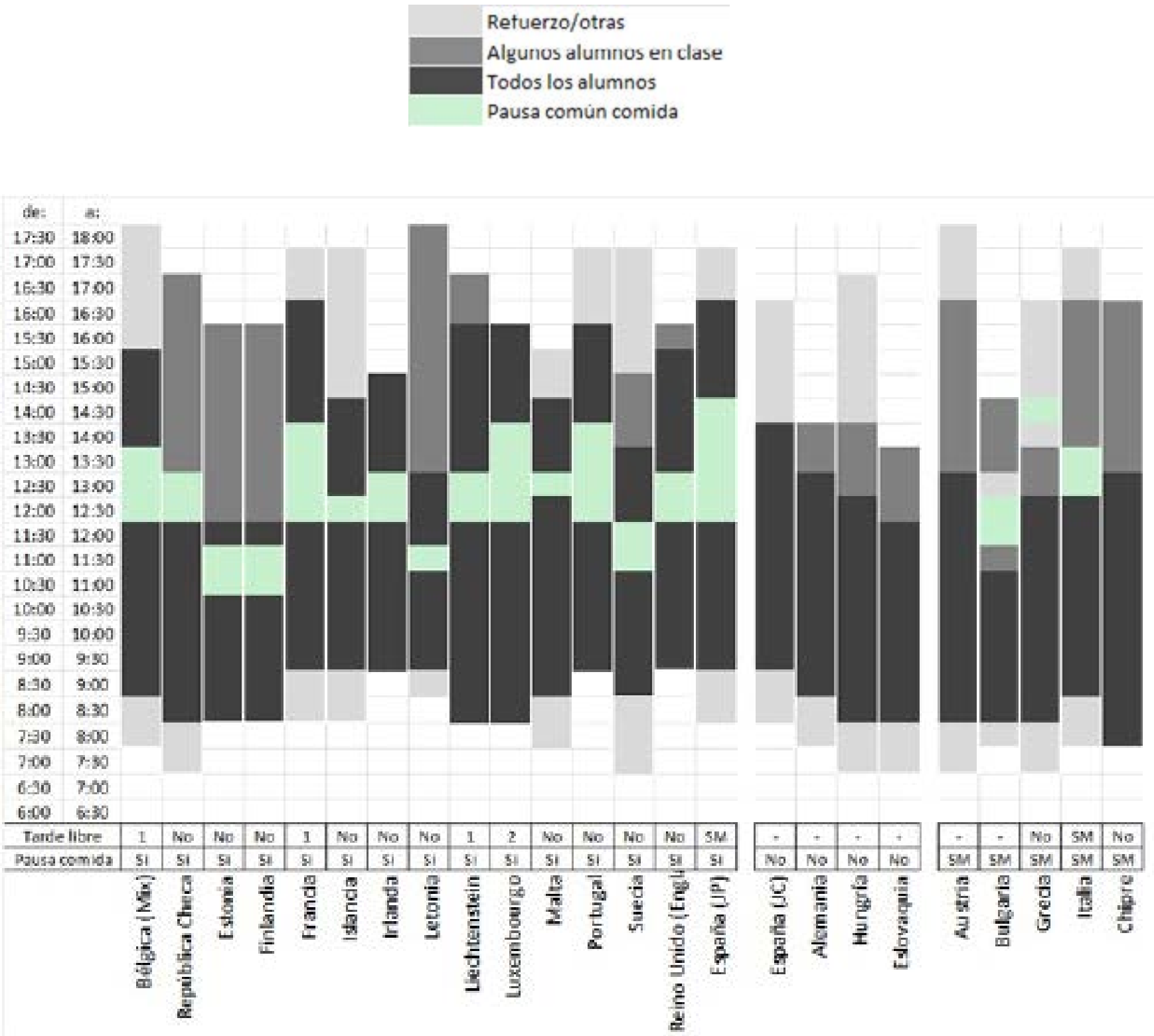

En el gráfico 25 se recoge explícitamente los países en los que existe una pausa para la comida en medio de un horario de tipo partido, mayoritario en nuestro contexto. Y se recoge también el número de tardes sin clase cuando se da esta situación.

En el gráfico 25 por tanto podemos observar que, independientemente de que a diferentes niveles de edad se asigne una carga lectiva diferente, en 14 de los países señalados [Bélgica, Republica Checa, Estonia, Finlandia, Francia, Islandia, Irlanda, Letonia, Liechtenstein, Luxemburgo, Malta, Portugal, Suecia o Inglaterra] la jornada es de tipo partida, con una pausa para comer de duración variable. En tres casos [Alemania, Hungría y Eslovaquia] la jornada es de tipo continua. Por último, en otros cinco países [Austria, Bulgaria, Grecia, Italia y Chipre] coexisten modelos mixtos al que podríamos sumar el caso español, no obstante, y a diferencia de España, en varios de estos países la tendencia es hacia la consolidación de la jornada partida (es al menos el caso de Austria, Bulgaria]. 
Figura 3: Grado de implantación de la jornada continua escolar en Europa (2016). Fuente: Elaboración propia a partir de Eurydice 2016.
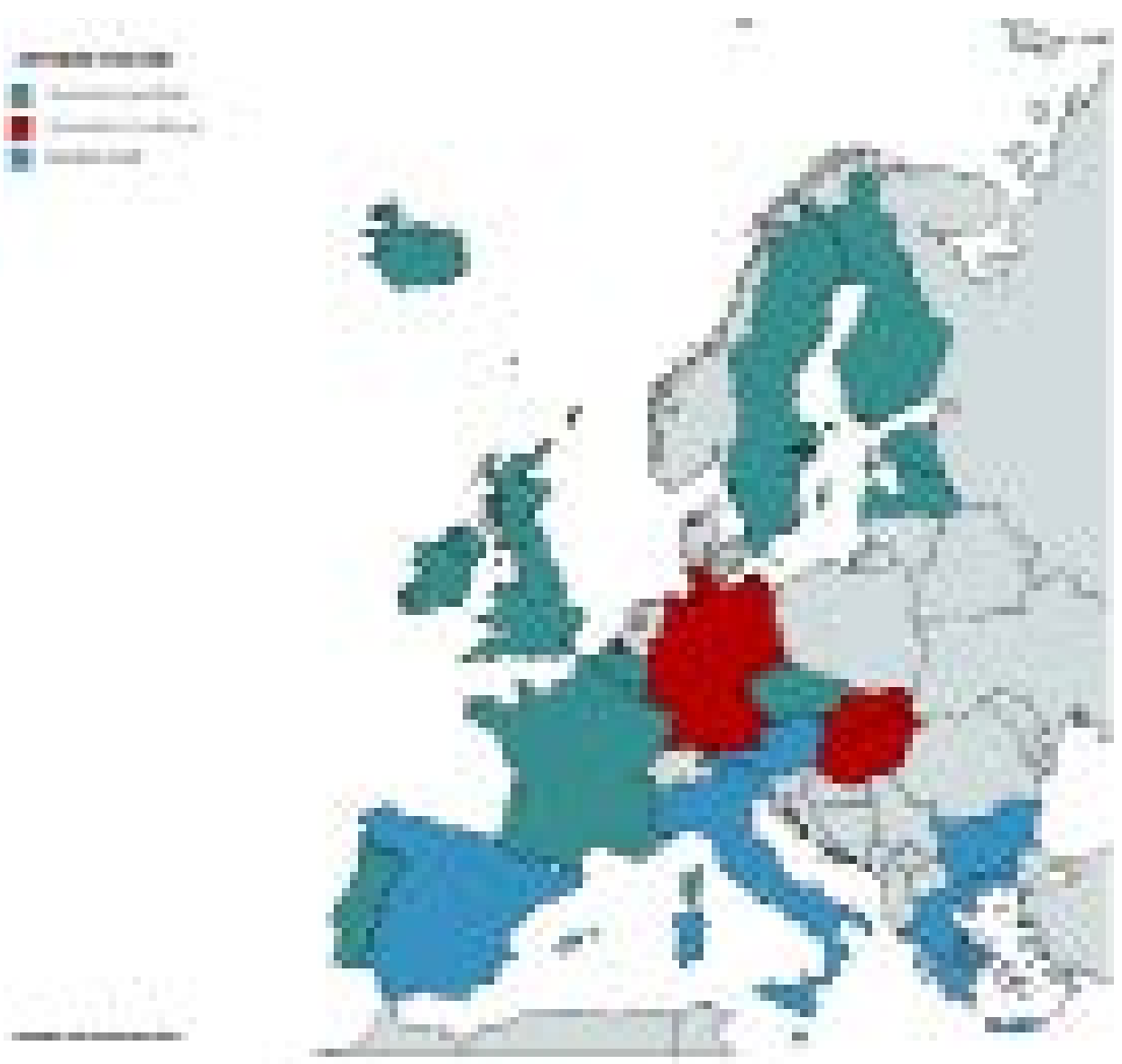

La jornada escolar continua es la excepción en Europa, donde predomina la jornada partida. Además la tendencia actual es a implementar la jornada partida. En Europa existe un amplio recurso a los descansos y a la utilización de la pausa de la comida como parte del proceso de aprendizaje [en cuestiones como la higiene, hábitos alimenticios saludables, reciclaje] de la mano de los docentes. 


\section{Las otras jornadas}

Como decíamos al inicio de este estudio, la distribución de los tiempos escolares guarda una estrecha relación con la organización del resto de tiempos sociales. De hecho una de las funciones de la escuela es la de guardia y custodia, en particular durante la minoría de edad y muy especialmente en las edades tempranas. Con la presencia cada vez más acentuada y prolongada en el tiempo de las mujeres en el mercado de trabajo, la contabilización de los diferentes tiempos -especialmente el del trabajo remunerado- es un asunto clave que no puede obviarse en la configuración de la jornada escolar del alumnado. Otras autoras han descrito ya detalladamente el impacto social y educativo de la jornada escolar continua en el Estado español [Sintes, 2012; Gimeno, 2008] por lo que remitimos a dichos trabajos a quien desee ampliar información. En esta sección tratamos únicamente de perfilar una respuesta a la siguiente pregunta: ¿Cuáles son los patrones de trabajo y husos horarios de la población española en general y de las familias con hijos en edad escolar en particular?

Según la OCDE ${ }^{8}$, en 2014 en el Estado español el 30,38\% de los hogares estaba compuesto por parejas con hijas y/o hijos y el 5,92\% por hogares monoparentales (en el $4,56 \%$ conviven con la madre y el 1,36\% restante con el padre]. En cuanto al número de niñas/os por hogar, el $17,64 \%$ de los hogares cuentan con una/o, el 13,63\% cuenta con dos, y el 2,84\% cuenta con tres o más. Además el 12,71\% del total de los hogares cuentan con alguna niña/o menor de seis años de edad.

Gráfico 26: Distribución de las horas de trabajo semanales habituales para hombres y mujeres empleados en España, de hogares de parejas con al menos un hijo de $\mathrm{O}$ a 14 años. Fuente: elaboración propia a partir de OCDE ${ }^{21}$

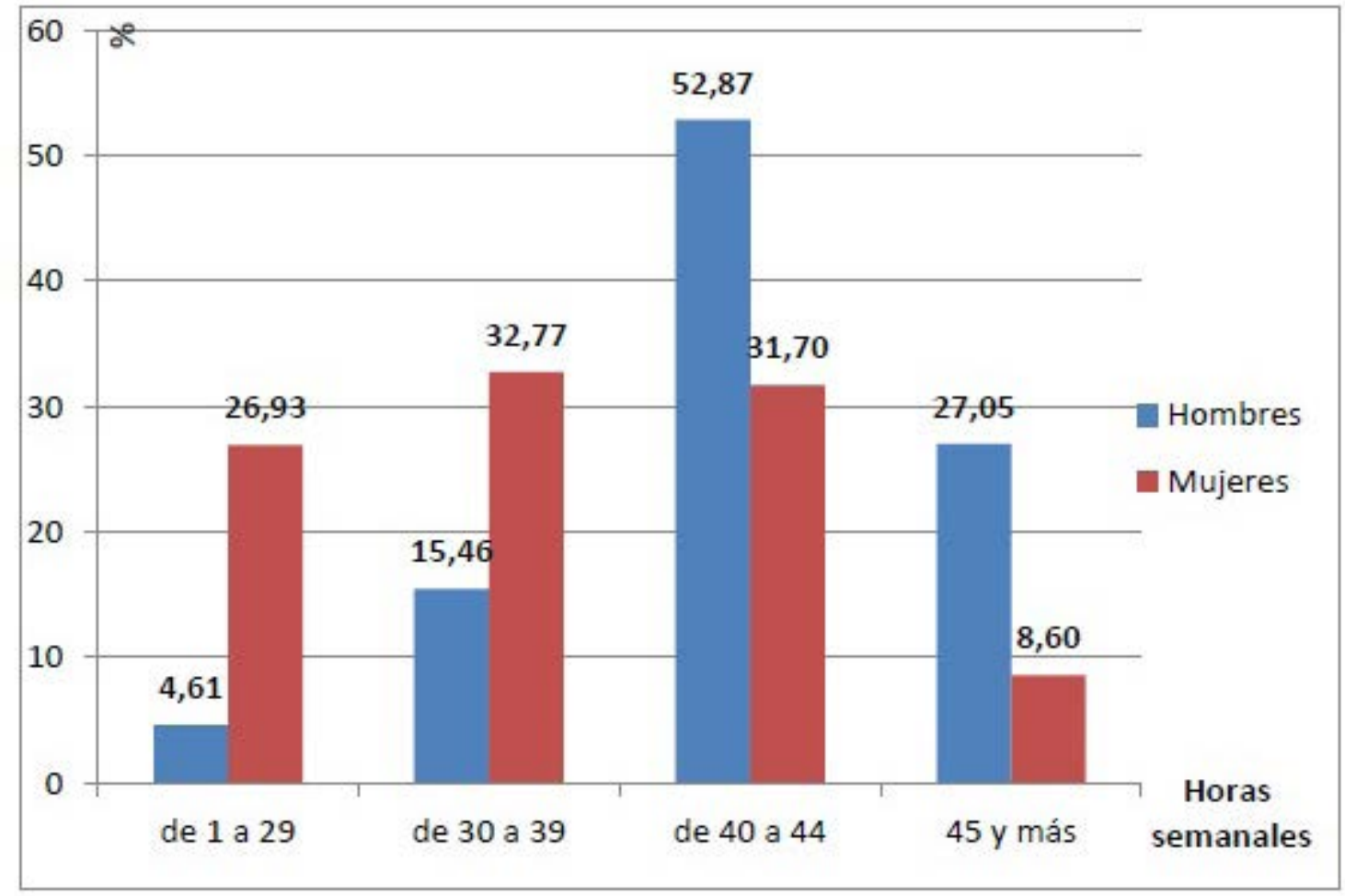

${ }^{21}$ http://www.oecd.org/social/family/database.htm 
Sin nos centramos en los hogares españoles con niñas y/o niños, el 32,59\% se compone de dos trabajadoras/es a tiempo completo, el $14,88 \%$ se compone de un trabajador o una trabajadora a tiempo completo y otra u otro a tiempo parcial, el 35,15 se compone de un solo o una sola trabajadora y un 10 '9\% de paradas/os.

Como se observa en el gráfico 26 ocho de cada diez hombres y cuatro de cada diez mujeres empleados que viven en hogares de parejas con al menos un hijo de 0 a 14 años trabajan 40 horas o más en España.

Gráfico 27: Distribución (\%) de niñas y niños (de 0 a 14 años) en hogares de una pareja por la situación laboral de as personas adultas en el hogar. Fuente: ídem. anterior.

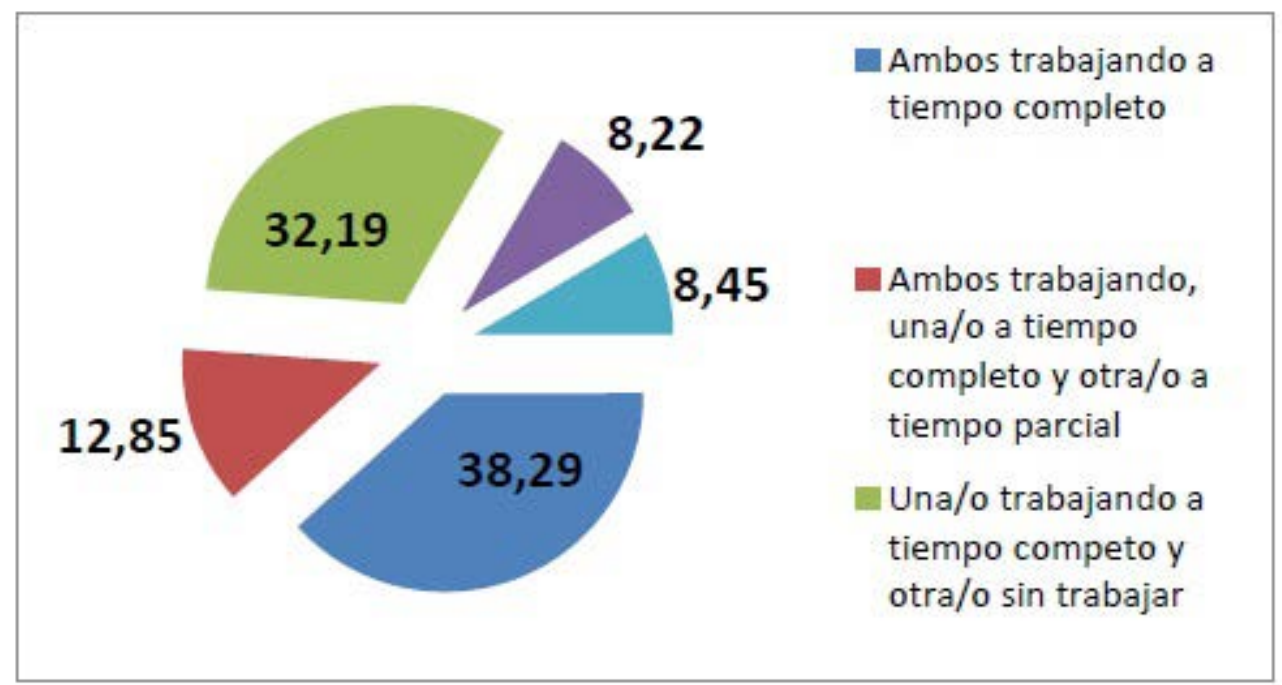

Gráfico 28: Distribución (\%) de niñas y niños (de 0 a 14 años) en hogares monoparentales por la situación laboral de las personas adultas en el hogar. Fuente: ídem. anterior.

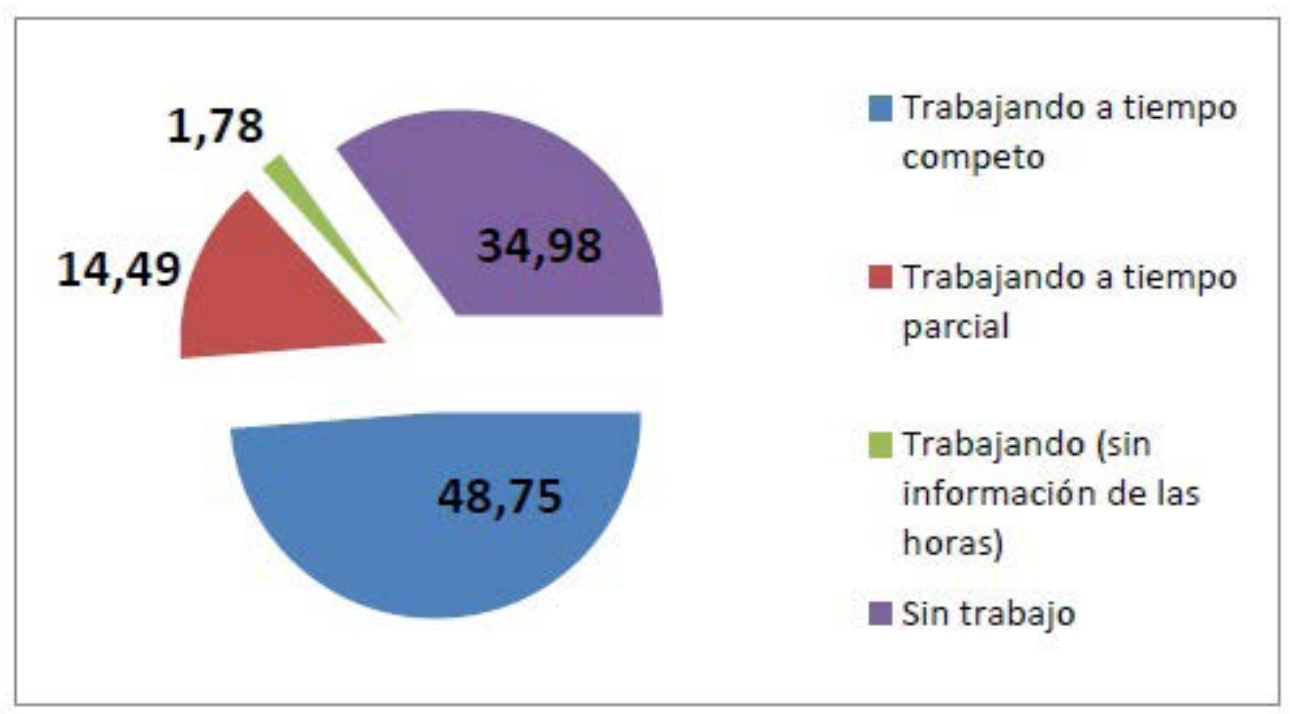


Si a nos centramos en la situación laboral de las y los adultos en los hogares familiares los gráficos 27 y 28 nos muestran que casi en el 40\% de las familias biparentales trabajan ambos progenitores a tiempo completo. Ese porcentaje se incrementa a casi el 50\% en el caso de personas que encabezan familias monoparentales.

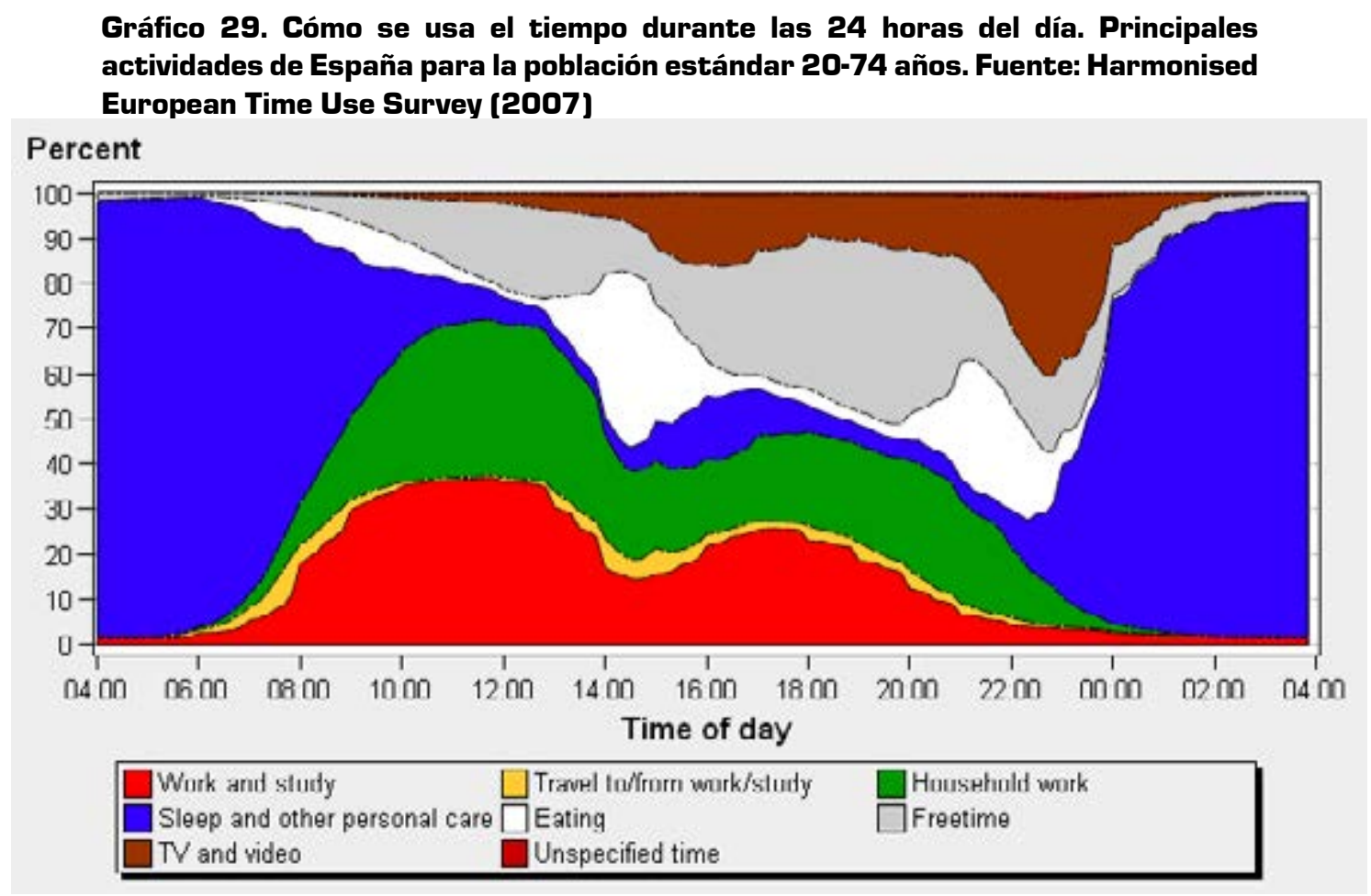

En cuanto al patrón de horas de trabajo, el siguiente gráfico 29 nos muestra, para el total de la población española de entre 20 y 74 años de edad, las principales actividades que realizan en fragmentos temporales de diez minutos. Como puede apreciarse, el patrón de trabajo mayoritario se organiza en dos periodos principales por la mañana y por la tarde con un descanso relativamente prolongado para la comida.

Herrero habla de la tendencia actual de rediseñar el modelo de jornada escolar, sin tener en cuenta los intereses del alumnado:

"Por lo tanto, la tendencia actual de rediseñar el modelo de jornada escolar, sin tener en cuenta los intereses de los alumnos, confirma la decisiva influencia social y docente, a través de los espacios participativos habilitados en este contexto. Esta dinámica es común a las realidades educativas de Francia, Italia, Portugal y España, que han desarrollado distintos debates sociales sobre el tiempo en la escuela, marcados por las raíces históricas y culturales que comparten.

Entender el tiempo que el niño pasa en la escuela como ajeno al del resto de su vida se convierte en un problema habitual. Es vital concebir como una unidad temporal aquella que incluye las horas que pasan en el centro, pero también las que transcurren con la familia, con los amigos o solos. Es el concepto que algunos autores han denominado como tiempo de cuidado (PEREYRA, 2003). Los ritmos de vida, y no los escolares, los sociales o los familiares, son los que deben guiar la gestión educativa. Por eso, es necesaria una visión global y no parcial de esta realidad.

Como hemos visto, no siempre se tienen en cuenta estos criterios y la influenciade la sociedad acaba desplazando, en muchos casos, las verdaderasnecesidades de los niños." Herrero [2012:213] 
La jornada escolar partida además se sincroniza mejor con las jornadas laborales, costumbres y husos horarios de la sociedad española en su conjunto, en particular con la ocupada. En España, la población ocupada y con hijos trabaja mayoritariamente 40 horas semanales o más.

\section{Una propuesta para el debate}

No queríamos acabar este estudio sin realizar una propuesta que de alguna manera condensara las recomendaciones y sugerencias que hemos ido desgranando a lo largo del estudio. Esta propuesta no es en absoluto una propuesta cerrada, un objetivo acotado, sino un punto de partida que trata de recoger algunas de las sugerencias que se derivan del análisis presentado y que pueden servir para el necesario debate sobre la organización del tiempo escolar en nuestro país.

\begin{tabular}{|c|c|c|c|c|c|c|c|c|c|c|c|c|c|c|}
\hline \multirow{2}{*}{$\begin{array}{c}\text { Desde } \\
17: 30\end{array}$} & \multirow{2}{*}{ A: } & & & & & & & & & & & \\
\hline & & & & & & & & & & & & & & \\
\hline $17: 00$ & $17: 30$ & & & & & & & & & & & & & \\
\hline $16: 30$ & $17: 00$ & & & & & & & & & & & & & \\
\hline $16: 00$ & $16: 30$ & & & & & & & & & & & & & \\
\hline $15: 30$ & $16: 00$ & & & & & & & & & & & & & \\
\hline $15: 00$ & $15: 30$ & & & & & & & & & & & & & \\
\hline $14: 30$ & $15: 00$ & & & & & & & & & & & & & \\
\hline $14: 00$ & $14: 30$ & & & & & & & & & & & & & \\
\hline $13: 30$ & $14: 00$ & & & & & & & & & & & & & \\
\hline $13: 00$ & $13: 30$ & & & & & & & & & & & & & \\
\hline $12: 30$ & $13: 00$ & & & & & & & & & & & & & \\
\hline $12: 00$ & $12: 30$ & & & & & & & & & & & & & \\
\hline $11: 30$ & $12: 00$ & & & & & & & & & & & & & \\
\hline $11: 00$ & $11: 30$ & & & & & & & & & & & & & \\
\hline $10: 30$ & $11: 00$ & & & & & & & & & & & & & \\
\hline $10: 00$ & $10: 30$ & & & & & & & & & & & & & \\
\hline $9: 30$ & $10: 00$ & & & & & & & & & & & & & \\
\hline $9: 00$ & $9: 30$ & & & & & & & & & & & & & \\
\hline $8: 30$ & 9:00 & & & & & & & & & & & & & \\
\hline $8: 00$ & $8: 30$ & & & & & & & & & & & & & \\
\hline \multicolumn{2}{|c|}{ Curso } & 1 & 2 & 3 & 1 & 2 & 3 & 4 & 5 & 6 & 1 & 2 & 3 & 4 \\
\hline \multicolumn{2}{|c|}{ Ciclo } & \multicolumn{3}{|c|}{ Infantil } & \multicolumn{6}{|c|}{ Primaria } & \multicolumn{4}{|c|}{ ESO } \\
\hline \multicolumn{2}{|c|}{ Edad } & 3 & 4 & 5 & 6 & 7 & 8 & 9 & 10 & 11 & 12 & 13 & 14 & 15 \\
\hline \multicolumn{2}{|c|}{ Acompañado } & 3,5 & 3,5 & 3,5 & 3 & 3 & 2 & 2 & 1 & 1 & 0 & 0 & 0 & 0 \\
\hline \multicolumn{2}{|c|}{ Refuerzo } & 2 & 2 & 2 & 1 & 1 & 1 & 1 & 1,5 & 1,5 & 2 & 2 & 2 & 2 \\
\hline \multicolumn{2}{|c|}{ Lectivo } & 0 & 0 & 0 & 2,5 & 2,5 & 3,5 & 3,5 & 4,5 & 4,5 & 5 & 5 & 5 & 5 \\
\hline \multicolumn{2}{|c|}{ Pausado } & 3,5 & 3,5 & 3,5 & 2,5 & 2,5 & 2,5 & 2,5 & 2 & 2 & 2 & 2 & 2 & 2 \\
\hline \multicolumn{2}{|c|}{ Máximo } & 9 & 9 & 9 & 9 & 9 & 9 & 9 & 9 & 9 & 9 & 9 & 9 & 9 \\
\hline
\end{tabular}


La propuesta que presentamosse caracteriza por:

- Se plantea desde la necesidad de la flexibilidad temporal y de materias.

- Se adecua a la capacidad del alumnado (el tiempo lectivose incrementa progresivamente acompañando el desarrollo madurativo del alumnado].

- Se ajusta alos bio-ritmos [seretrasa progresivamente la hora de inicio].

- Destina recursos temporales para adaptarse a la diversidad i reducir la desigualdad (tiempo de refuerzo].

- Plantea descansos suficientes [tempo pausado].

- Tiene en cuenta les necesidades de les familias [tiempoacompañado) elalumnado puedepermanecer menos tiempo en el centro que el marcado como máximo.

- El personal del centre dispone de más flexibilidad, la clave: la heterogeneidad.

\section{Conclusiones del estudio}

Como venimos indicando desde el inicio, la organización del tiempo escolar es un asunto complejo. A lo largo de esta guía hemos podido, por un lado, caracterizar el modelo educativo español en comparación a cómo se organiza en otros países de nuestro entorno y por ello hemos puesto de relieve la posición del sistema educativo español en el conjunto de los países de nuestro entorno [en ocasiones Europa, UE o OCDE] respecto de algunos indicadores. Así hemos visto, en una comparativa con 32 países europeos, que España se sitúa a la cabeza en términos de escolarización en la etapa de infantil de segundo ciclo pero en posiciones más retrasadas 0 intermedias en la post-obligatoria. En cuanto al número medio de años esperados en educación España se sitúa justo por encima de la media de los 21 países europeos de la OCDE y de los países de la OCDE en su conjunto. También el sistema español se caracteriza por estar, con nueve años, en la media en cuanto al tiempo de enseñanza obligatorio en la enseñanza general.

El español es, no obstante, uno de los sistemas analizados que mayor carga lectiva presenta, lo cual, junto a que cuenta con un número más limitado de días lectivos, hace que la intensidad de las jornadas lectivas tiende a ser más elevada comparada con la realidad en otros sistemas de nuestro entorno. También se caracteriza por tener un sistema educativo rígido, con muy poca flexibilidad de materias y nula flexibilidad temporal [ni horizontal ni vertical) a la hora de decidir cómo se distribuyen las cargas lectivas. Del mismo modo, el sistema educativo español se agrupa en el conjunto de sistemas que hace un planteamiento de cargas lectivas más elevadas y más rígidas en tanto que no se ajusta a una progresividad que acompañe a la también progresiva evolución de la capacidad del alumnado. Produciéndose además, de los modelos estudiados, el salto más notable de carga lectiva en el tránsito de la enseñanza primaria a la secundaria, incrementándola en un tercio. 
Hemos insistido en la importancia de adaptar los tiempos de enseñanza a las necesidades y características del alumnado. Dicho en otras palabras, el tiempo de enseñanza que no se sincroniza adecuadamente a las necesidades y características del alumnado es, en buena medida, tiempo perdido además de una pérdida de tiempo. El sistema educativo español de nuevo ignora esa máxima y se sitúa entre los países en el que más a menudo se recurre a la repetición y a las clases particulares, y en el que en consecuencia se produce un elevado abandono escolar. El amplio recurso a los deberes, las tutorizaciones y las clases de repaso significa que se requiere una mayor carga de trabajo por parte del alumnado de la establecida como tiempo de enseñanza teórico, que como hemos señalado anteriormente es de las más altas. Este esfuerzo extraordinario que alumnado y familias hacen por reforzar la formación recibida en la escuela choca con la mediocridad de los resultados del alumnado español en PISA, que este esfuerzo no consigue revertir. Así, si descartamos una menor inteligencia del alumnado español, los peores resultados observados podrían deberse a: 1] una mala gestión del tiempo escolar (por ciclo, curso, jornada); 2) a una mala organización de los contenidos curriculares (se exigen conocimientos que no se ajustan a la capacidad del alumnado o no se sincronizan convenientemente]; 3] a una mala praxis docente; 4] a una pobre motivación del alumnado; 5] a una combinación de varias de ellas.

Existen indicios razonables que apuntan a una posible relación entre tipo de jornada escolar continua y empeoramiento del rendimiento académico, de hecho así lo han apuntado también trabajos como el de Caride, 1993; Ridao y Gil, 2002; Cavet, 2011 [citados en Fernández Enguita, 2001 y Sintes, 2012), el informe de expertos de la Generalitat Valenciana ${ }^{22}$ de 2015, el pronunciamiento del Presidente del Colegio Oficial de Pedagogos y Psicopedagogos ${ }^{23}$, 0 incluso la propia Comisión Nacional para la Racionalización de los Horarios Españoles y de ARHOE desde la que se dice textualmente: "En general, no hay datos concluyentes en este aspecto, ni excesivo acuerdo. Normalmente la jornada continua es buena para los profesores pero no para los padres, y creemos que para los niños tampoco"24

Los estudios sobre el rendimiento subrayan la relevancia de la buena alimentación y un descanso suficiente para un rendimiento escolar óptimo. El retraso en las horas de comida que supone la compactación de la jornada ya ha sido denunciado por la Sociedad Valenciana de Pediatría ${ }^{25}$ por sus riesgos sobre la salud. Sobre el descanso ya se ha apuntado en esta revisión la existencia de numerosos estudios que recomiendan el retraso de la hora de inicio de la jornada escolar para pre-adolescentes y adolescentes cuando en nuestro país la práctica generalizada es a la inversa, adelantar la entrada una hora de las 9:00h. a las 8:00h. Otro asunto que tiende a pasarse por alto es la cuestión de la siesta en la etapa de segundo ciclo de infantil, que desafortunadamente es por lo general ignorada su pertinencia para el bienestar de los niños.

En la comparativa de países europeos podemos observar que, independientemente de que a diferentes niveles marcados por la edad del alumnado se asigne una carga lectiva diferente, en 14 de los países señalados la jornada es de tipo partida, con una pausa para comer de duración variable. En tres casos la jornada es de tipo continua, y en otros cinco países coexisten modelos mixtos, no obstante, en varios de estos países la tendencia es hacia la consolidación de la jornada partida. Así pues no es extraño en nuestro contexto europeo que las comidas se hagan en el centro y en compañía de la tutora o tutor, lo que, además de permitir una mejor supervisión y un

\footnotetext{
${ }^{22}$ http://www.lasprovincias.es/alicante/201503/18/educacion-descarta-jornada-continua-20150318014459-v.html

${ }^{23} \mathrm{http}: / /$ cadenaser.com/emisora/2016/09/13/radio valencia/1473752084 723933.html

${ }_{24} \mathrm{http://horariosenespana.com/images/Ciclo} \mathrm{III} \mathrm{ARHOE.pdfhttp://horariosenespana.com/images/Ciclo} \mathrm{III} \mathrm{ARHOE.pdfpág.} 64$

${ }^{25}$ http://www.levante-emv.com/comunitat-valenciana/2016/09/15/pediatras-alertan-jornada-continua-dana/1467059.html
} 
fortalecimiento de la relación profesorado-alumnado, permite además que se pueda vincular esta pausa para la comidacon contenidos y con actividades curriculares estableciéndose como parte del proceso de aprendizaje, donde los estudiantes aprenden sobre cuestiones como higiene, hábitos alimenticios saludables y/o reciclaje de residuos. No es cierto por tanto, como se ha venido aireando de manera interesada, que la jornada continua sea el modelo imperante en Europa. Ni siquiera el alumnado finlandés de primero de primaria que asiste a clase de 8h. a 12h .se va a casa sin comer, pues en esas escasas 4 horas dedican casi una a comer con su tutor una comida que, por cierto, está sufragada por la Administración Pública.

En nuestro caso, sin poder descartar la influencia de otras variables, podemos indicar a priori que 1) bien aquellas CCAA que tienen mayor implantación de la jornada continua obtienen resultados en PISA peores en términos relativos en la enseñanza pública a los que se obtienen en esas mismas CCAA en la enseñanza concertada y al alumnado se le hace repetir en mayor medida [podríamos denominarla hipótesis del empeoramiento de resultados]; o 2] que aquellas CCAA en las que los resultados son peores en la enseñanza pública en términos relativos, y en donde repite más el alumnado, se han implantado en mayor medida la jornada continua [hipótesis del apaga y vámonos].

En cuanto al debate de fondo sobre el cambio de jornada las piezas del complejo puzle indican que estamos ante una serie de paradojas:

1- Se proclama en nombre de la mejora pedagógica cuando las evidencias disponibles apuntan a que puede suponer un serio deterioro en el rendimiento [Caride, 1993; Ridao y Gil, 2002; Cavet, 2011], y en especial de aquel alumnado de procedencia más humilde y con menos recursos en el hogar [Caride, 1993; Fernández Enguita, 2001; Feito, 2007) dado que:

a) La compresión horaria fatiga más tanto a profesorado como alumnado [Sintes, 2012], en un sistema ya de por sí bastante poco motivador.

b) La compresión horaria en un sistema de mini-clases de 50 minutos como el actual hace que se pierdan horas efectivas de clase entre cambios de profesorado, salidas al patio, etc. La jornada compactada lo amplifica.

c) La compresión horaria, en parte debido a a] y b], hace que se incremente la cantidad [y la dependencia] de los apoyos fuera de la escuela. En consecuencia incrementa las desigualdades entre grupos sociales que tienen acceso a las clases particulares o de refuerzo. Con la paradoja de que cualquiera de las dos opciones puede suponer peor conciliación con el resto de tiempos sociales y/o un horario de actividades académicas aún más extenso para el alumnado que cuenta con ese apoyo, y sin lugar a dudas un peor rendimiento para el que carece de éste.

d) La compresión horaria se adapta peor a los ritmos cronobiológicos del alumnado [Sintes, 2012].

e] Todo lo anterior apunta a que este cambio no va a suponer una mejora, y probablemente sí un empeoramiento, de los 'grandes males' de nuestro sistema educativo, esto es un sistema poco motivador, poco compensador de las desigualdades, con una alta incidencia de la repetición y del abandono escolar temprano. 
2- Va en contra de la capacidad organizativa genuina en pro de la mejor educación del alumnado. En un momento en el que las tendencias de éxito lo son hacia la escuela a tiempo completo [Sintes, 2012] o tiempo esponjoso [Fernández Enguita, 2001]), adaptable a las necesidades del alumnado con proyectos inclusivos innovadores, esta modificación hacia la compactación se muestra anacrónica y contradictoria. $Y$ supone, de generalizarse, un lastre muy pesado y difícil de revertir.

3- Se proclama en nombre del derecho legítimo a compactar la jornada laboral del profesorado, pero la mejora laboral no puede hacerse a costa de la calidad del servicio y con perjuicio del alumnado. Como en cualquier otro servicio público no todo el personal tendría por qué hacer el mismo horario. Una racionalización de los horarios escolares en la línea de lo que se ha explicado en esta guía permitiría por un lado adaptarse mejor a las necesidades del alumnado y atender a las preferencias de las trabajadoras y los trabajadores [profesorado] [Feito, 2000).

4- Se proclama en nombre de la conciliación familiar cuando para la mayoría de las familias supondrá lo contrario [Sintes, 2012] en tanto que la mayoría de las y los trabajadores no disponen de jornada intensiva; sólo 1/4 de abuelas y abuelos pueden ayudar en las tareas de cuidado, y en los hogares dónde una de las personas adultas no trabaja puede suponer un impedimento para que lo haga; además de que el sistema de provisión de comedor y de actividades extraescolares queda, más aún, a merced de la voluntad política del momento, de los recursos económicos de las familias $\mathrm{y} / \mathrm{o}$ del municipio.

Para cerrar esta reflexión reproducimos aquí algunas de las recomendaciones extraídas del informe de Gromada y Shewbridge [2016] y de Suchaut [2012]:

\begin{abstract}
"dentro de una escuela reducir la cantidad de tiempo de enseñanza que imparten las y los docentes nuevos y aumentar la impartida por profesorado con experiencia mejoraría el uso eficaz del tiempo de enseñanza asignado [Jensen et al., 2012]. [...] La organización de tiempo de aprendizaje de manera diferente ha sido identificada como una forma potencial de mejorar el rendimiento escolar de niñas y niños desfavorecidos (OCDE, 2012a). El proyecto de la OCDE sobre entornos innovadores de aprendizaje ha identificado formas innovadoras de utilizar el tiempo en la escuela. La reprogramación de aprendizaje, el reagrupamiento de educadores, el reagrupamiento del alumnado, cambiar los enfoques pedagógicos y el uso de una combinación de enfoques pedagógicos [incluyendo la enseñanza directa), es una dimensión importante de la dinámica de las organizaciones para lograr una organización del aprendizaje más compleja y flexible [OCDE, 2013e]. Innovaciones para organizar el aprendizaje en un número menor, de clases más largas mejoran las oportunidades de aprendizaje más profundo, así como permitir una mayor flexibilidad."Gromada y Shewbridge [2016:50].
\end{abstract}

Suchaut [2012] indica que ante la reforma de la jornada escolar que se presenta inmediata, cree que se deben hacer algunas modificaciones en la misma teniendo en cuenta los ritmos de niñas y niños con el objetivo de mejorar la escuela primaria. Defiende que sólo teniendo en consideración los ritmos de niñas y niños se pueden hacer cambios profundos en la organización escolar para mejorar su calidad. Condiciones para ello: a) dar cierta libertad en el ámbito local para que hagan adaptaciones de la reforma estatal; b] coordinación de las acciones educativas locales; c] movilización de maestras y maestros para hacer un mejor uso del tiempo; d] toma de conciencia general de que es importante hacer un cambio significativo para mejorar el funcionamiento de la escuela pública. 


\section{Referencias bibliográficas}

Andrade, M. M., \&Menna-Barreto, L. [1996] Diurnal variation in oral temperature, sleepiness, and performance of high school girls. Biological Rhythm Research, 27[3], 336-342.

Carskadon, M. A. [1999]. When worlds collide: Adolescent need for sleep versus societal demands. Phi Delta Kappan, 80[5], 348.

Cebolla-Boado, H., Radl, J. y Salazar, L. [2014] Aprendizaje y ciclo vital. La desigualdad de oportunidades desde la educación preescolar hasta la edad adulta. Fundación La Caixa.

European Commission/EACEA/Eurydice, 2016a. The Organisation of School Time in Europe. Primary and General Secondary Education - 2016/17. Eurydice Facts and Figures. Luxembourg: Publications Office of the European Union.

European Commission/EACEA/Eurydice, 2016b. Compulsory Education in Europe - 2016/17. Eurydice Facts and Figures. Luxembourg: Publications Office of the European Union.

European Commission/EACEA/Eurydice, 2016c. Recommended Annual Instruction Time in Fulltime Compulsory Education in Europe 2015/16. Eurydice - Facts and Figures. Luxembourg: Publications Office of the European Union.

Feito Alonso, R. (2000). Sobre el debate de la jornada escolar. Cuenta y razón, [116], 45-51.

Feito Alonso, R. [2007]. Tiempos escolares. Cuadernos de pedagogía, ISSN 0210-0630, № 365, , págs. 74-79

Fernández Enguita, M. [2002] La jornada escolar: propuestas para el debate. Barcelona, Ariel.

Gimeno Sacristán, J. [2008]. El valor del tiempo en educación. EdicionesMorata.

Gromada, A. y Shewbridge, C. [2016], Student Learning Time: A Literature Review, OECD Education Working Papers, No. 127, OECD Publishing, Paris. DOl: http://dx.doi. org/10.1787/5jm409kqqkjh-en

Harmonised European Time Use Survey [online database version 2.0]. Created 2005-2007 by Statistics Finland and Statistics Sweden. [reference date 2007-10-01]. http://www.tus.scb.se

Herrero [2012] La perspectiva social de la jornada escolar en la Unión Europea estudio comparado en Italia, Francia, Portugal y España. Revista Española de Educación Comparada, 19 [2012], 193-218

Klein, J. [2004] Planning middle school schedules for improved attention and achievement, Scandinavian Journal of Educational Research, 48:4, 441-450, DOl: $10.1080 / 0031383042000245825$

Meijer, A. M. [2008]. Chronic sleep reduction, functioning at school and school achievement in preadolescents. Journal of Sleep Research, 17, 395-405 
Mullis, I. V., Martin, M. O., Foy, P., \& Drucker, K. T. [2012a]. PIRLS 2011 International Results in Reading. International Association for the Evaluation of Educational Achievement. Herengracht 487, Amsterdam, 1017 BT, The Netherlands.

Mullis, I. V., Martin, M. O., Foy, P., \& Arora, A. [2012b]. TIMSS 2011 international results in mathematics. International Association for the Evaluation of Educational Achievement. Herengracht 487, Amsterdam, 1017 BT, The Netherlands.

OECD[2013],PISA2012Results:WhatMakes Schools Successful[VolumeIV]: Resources, Policies and Practices, OECD Publishing, Paris. DOI: http://dx.doi.org/10.1787/9789264201156-en

OECD[2014], "Indicator D1: How much time do students spend in the classroom?", in Education ata Glance 2014: OECD Indicators, OECD Publishing. http://dx.doi.org/10.1787/888933119530

OECD [2016], Education at a Glance 2016: OECD Indicators, OECD Publishing, Paris. http:// dx.doi.org/10.187/eag-2016-en

Sintes, E. [2012] A les tres a casa? ímpacte social i educatiu de la jornada escolar contínua. Fundació Jaume Bofill.

Sistema Estatal de Indicadores de la Educación. Edición 2016

Suchaut, B. [2009] L'organisation et l'utilisation du temps scolaire à l'école primaire: enjeux et effets sur les élèves. In Conférence à l'initiative de la ville de Cran-Gevrier (Haute-Savoie).

Suchaut, B. [2012] Pour une nouvelle organisation du temps scolaire a l'ecole primaire. 12032. 